\title{
Verification and Expansion of Single-Degree-of-Freedom \\ Transformation Factors for Beams Using a Multi-Degree-of- Freedom Non-Linear Numerical Analysis Method
}

\author{
A Thesis \\ Presented to \\ the Faculty of California Polytechnic State University \\ San Luis Obispo, California \\ In partial fulfillment \\ of the Requirements for the Degree \\ Master of Science in Architecture with a Specialization in Architectural Engineering \\ by \\ Takayuki Yokoyama \\ November 2011
}


(C) 2011

Takayuki Yokoyama

ALL RIGHTS RESERVED 
COMMITTEE MEMBERSHIP

TITLE:

Verification and Expansion of Single-Degree-of-Freedom

Transformation Factors for Beams Using a Multi-Degree-

of-Freedom Non-Linear Numerical Analysis Method

AUTHOR: $\quad$ Takayuki Yokoyama

DATE SUBMITTED: November 2011

COMMITTEE CHAIR: $\quad$ Graham Archer, Ph.D., P.E.

COMMITTEE MEMBER: Ansgar Neuenhofer, Ph.D., P.E.

COMMITTEE MEMBER: Kevin Dong, M.S., S.E.

INDUSTRY ADVISOR: $\quad$ Shalva Marjanishvili, Ph.D., S.E. 


\begin{abstract}
Verification and Expansion of Single-Degree-of-Freedom Transformation Factors for Beams Using a Multi-Degree-of-Freedom Non-Linear Numerical Analysis Method Takayuki Yokoyama
\end{abstract}

The single-degree-of-freedom (SDOF) transformation factors as tabulated in John Biggs' textbook (Biggs 1964) are accepted as the equivalent factors for simplifying and analyzing a component's response to blast. The study validates the stiffness and mass transformation factors through multi-degree-of-freedom (MDOF) numerical methods. After validating the transformation factors, the MDOF numerical method is used to create new stiffness and mass transformation factors for loading cases not already included in Biggs' textbook.

The validated factors, as well as the newly developed factors are used in SDOF analyses. The deflections from the SDOF responses accurately predict the MDOF responses as long as the component behaves elastically; however, the deflections diverge when inelastic behavior is involved. The diverged deflections indicate that the SDOF inelastic response analysis method can be improved. 


\section{TABLE OF CONTENTS}

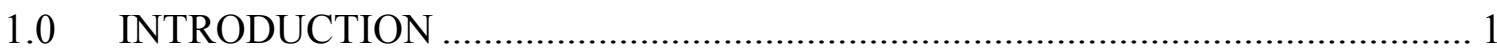

1.1 Literature Review and State of Practice.............................................................. 1

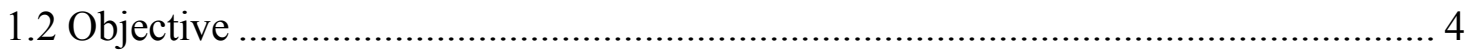

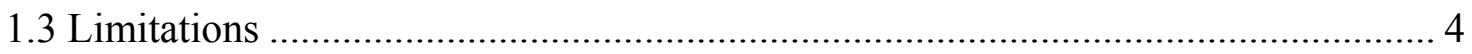

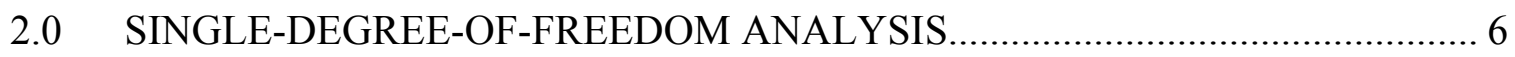

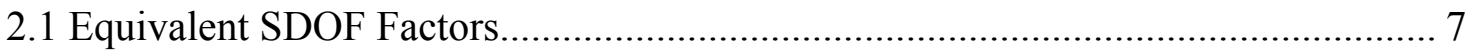

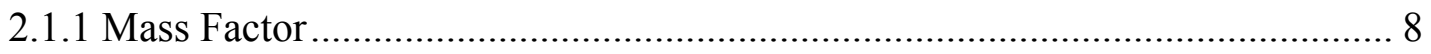

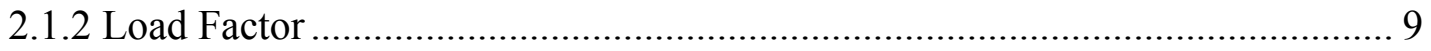

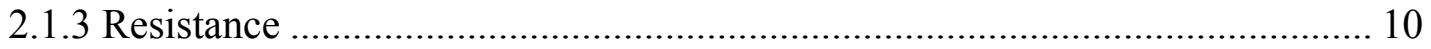

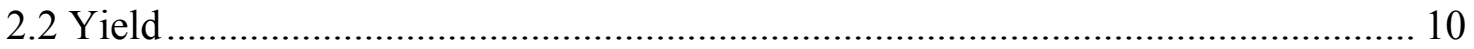

3.0 NUMERICAL ANALYSIS METHODS ……………………..................... 12

4.0 NEWMARK'S AVERAGE ACCELERATION SINGLE-DEGREE-OFFREEDOM ANALYSIS PROCEDURE ............................................................. 15

5.0 MULTI-DEGREE-OF-FREEDOM ANALYSIS .............................................. 17

5.1 Multi-Degree-of-Freedom Model ................................................................... 17

5.2 Newmark's Average Acceleration Method in MDOF ............................................ 21

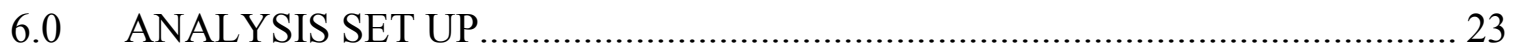

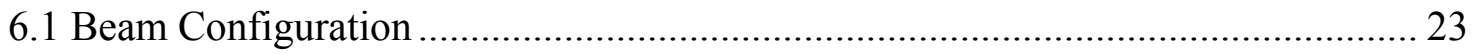

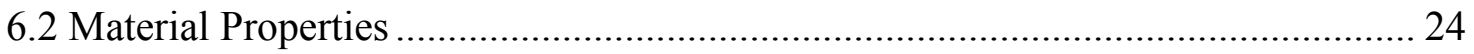

6.3 Definitions of Blast Load types.......................................................................... 26

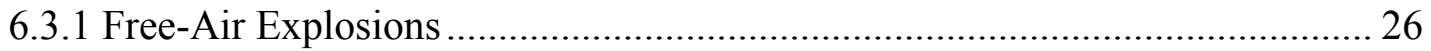

6.3.2 Side-On Explosions ……………………………………………………. 27

6.3.3 Reflected Blast Loads .............................................................................. 28

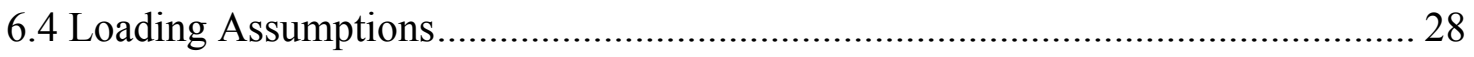


7.0 MATLAB ALGORITHM VERIFICATION ................................................... 35

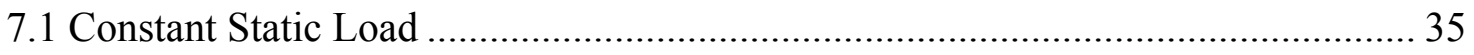

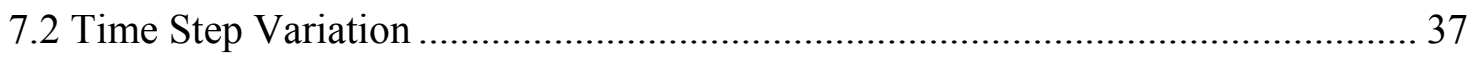

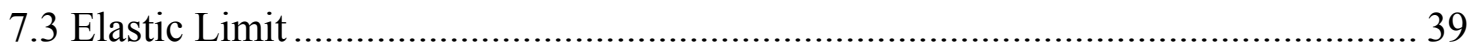

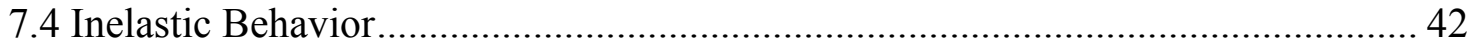

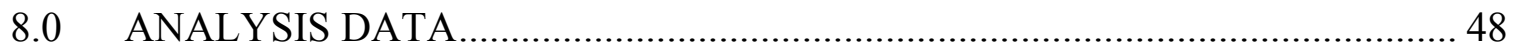

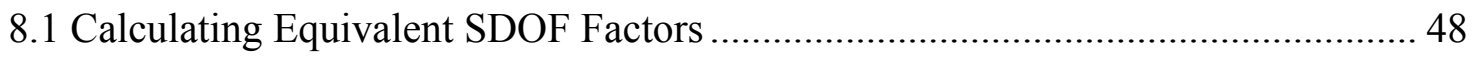

8.1.1 Stiffness Values ................................................................................... 48

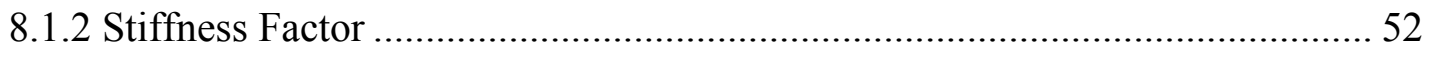

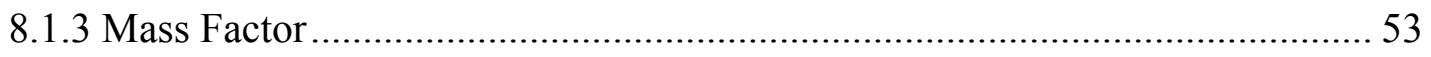

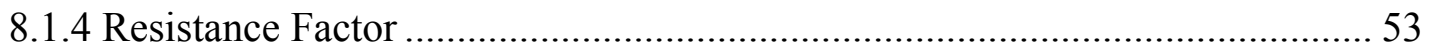

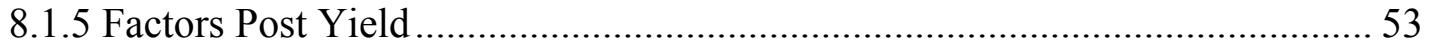

8.2 Loading Parameters................................................................................... 56

8.3 Output and Factors for Beam with Both Ends Fixed, Uniformly Distributed

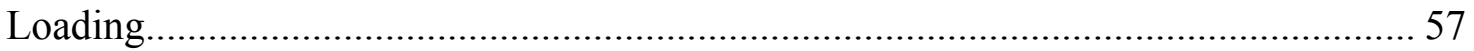

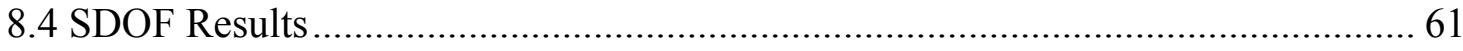

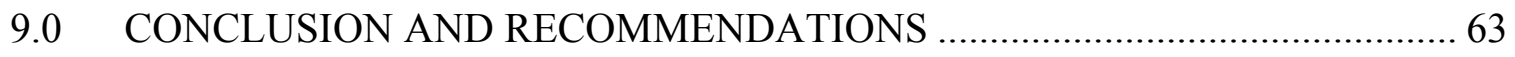

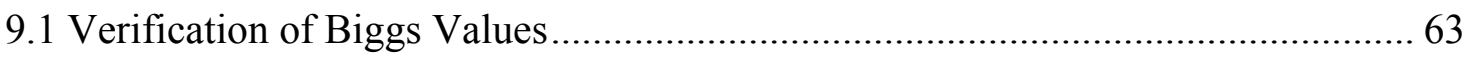

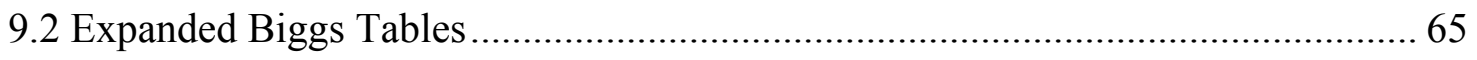

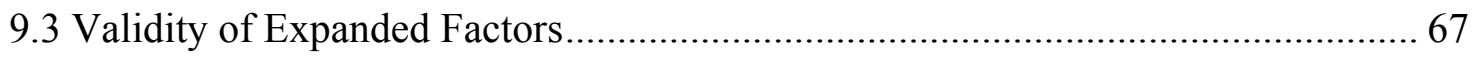

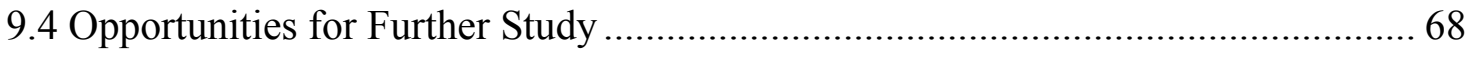

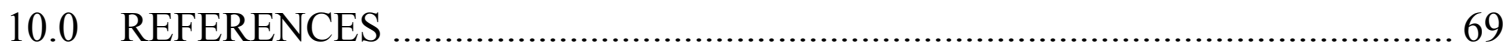

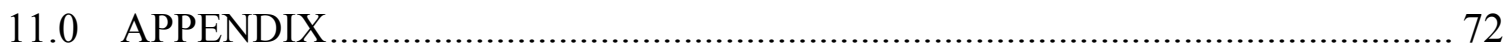

11.1 Example Derivation of Equivalent SDOF Factors (Biggs' Method) ................... 72

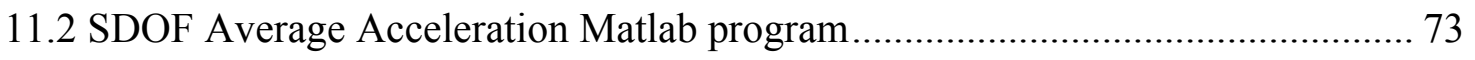


11.3 MDOF Average Acceleration Matlab program …........................................ 84

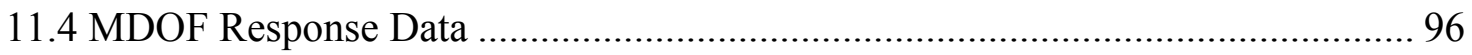

11.5 MDOF vs. SDOF Response Comparison Data ............................................... 103 


\section{LIST OF TABLES}

Table 1: Equivalent SDOF factors for simply supported beams ................................... 7

Table 2: Equivalent SDOF factors for beams with fixed ends ....................................... 7

Table 3: Newmark's Average Acceleration Method .................................................... 15

Table 4: Newmark's Average Acceleration Method ....................................................... 21

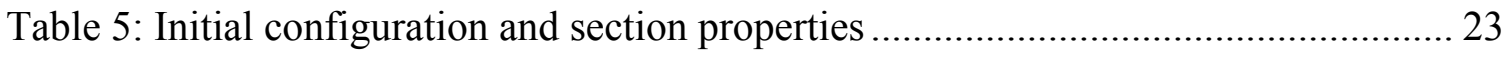

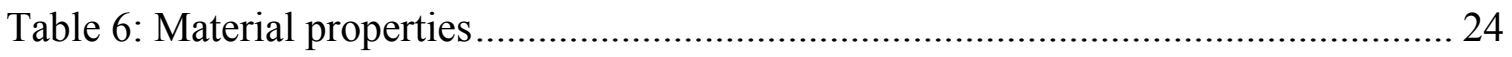

Table 7: Stiffness values for simply supported beam, triangular loading....................... 49

Table 8: Stiffness values - beam charts vs. MDOF ...................................................... 51

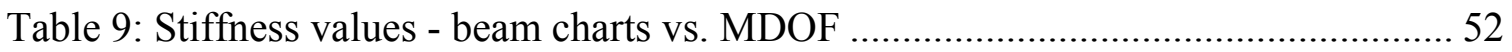

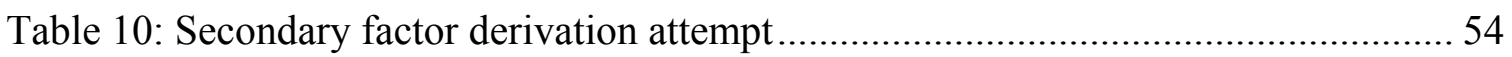

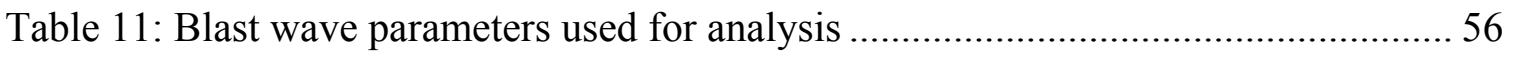

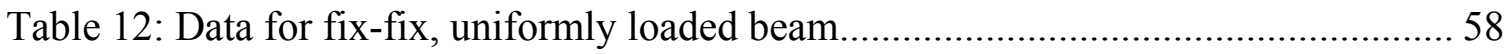

Table 13: Data for fix-fix, uniformly loaded beam...................................................... 59

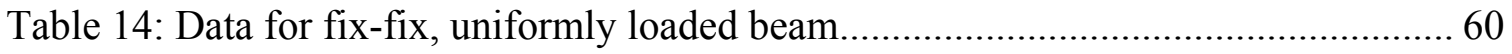

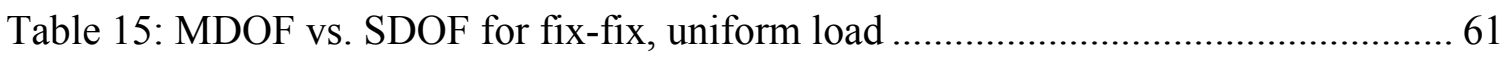

Table 16: SDOF transformation factors for beams with pin-pin boundary conditions .... 65

Table 17: SDOF transformation factors for beams with fix-fix boundary conditions...... 66

Table 18: Equivalent SDOF factors example ...................................................... 73

Table 19: Matlab algorithm for nonlinear numerical analysis of a SDOF system .......... 74

Table 20: Matlab algorithm for nonlinear numerical analysis of a MDOF system ......... 84

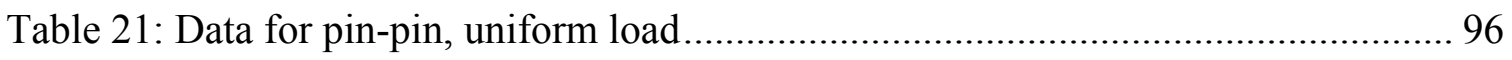

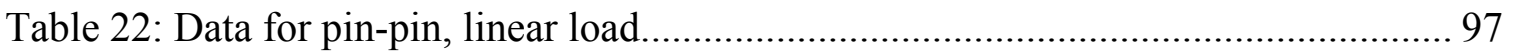

Table 23: Data for fix-fix, linear load .......................................................................... 98

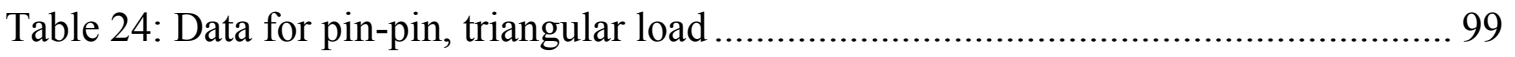

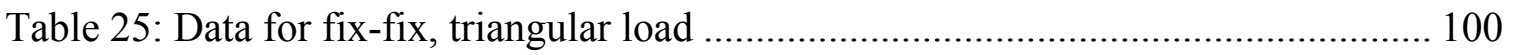

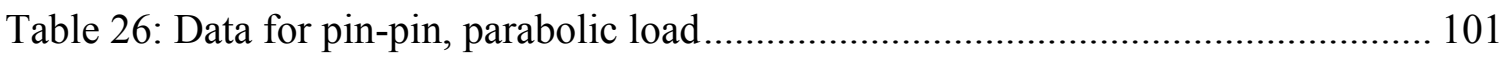

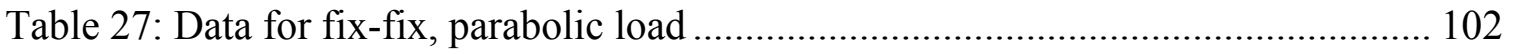

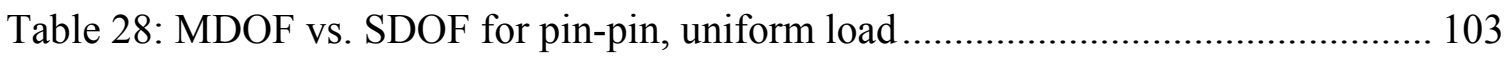

Table 29: MDOF vs. SDOF for pin-pin, linear load.................................................. 104

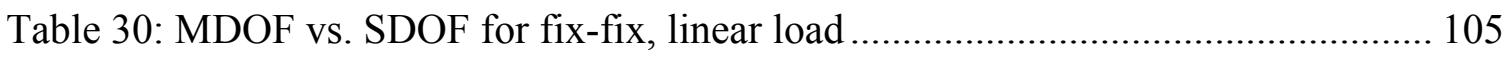

Table 31: MDOF vs. SDOF for pin-pin, triangular load ........................................... 106

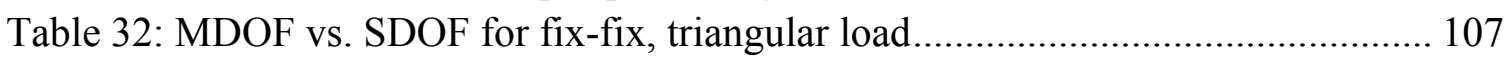

Table 33: MDOF vs. SDOF for pin-pin, parabolic load ............................................... 108

Table 34: MDOF vs. SDOF for fix-fix, parabolic load .............................................. 109 


\section{LIST OF FIGURES}

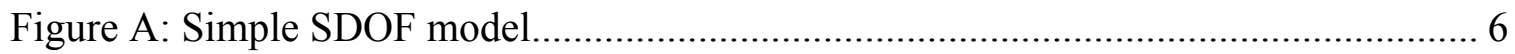

Figure B: SDOF system nonlinear behavior ............................................................ 11

Figure C: Free vibration solution by four numerical methods vs. the theoretical

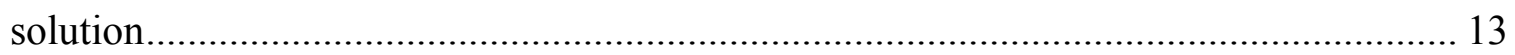

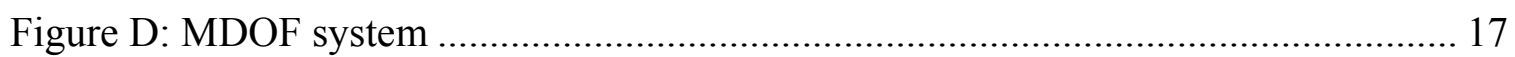

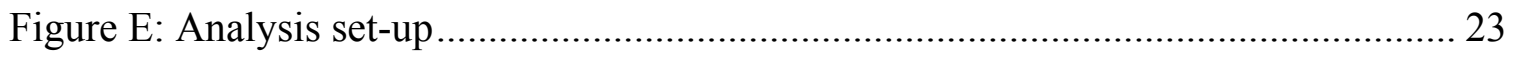

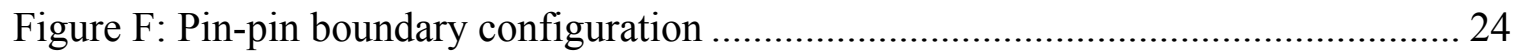

Figure G: Fixed-fixed boundary configuration.......................................................... 24

Figure H: Assumed Steel nonlinear behavior .......................................................... 25

Figure I: Typical pressure-time history of an airblast in free air .................................. 27

Figure J: Positive phase shock wave parameters for a hemispherical surface burst

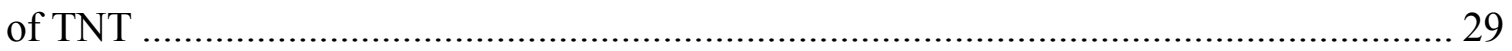

Figure K: Negative phase load pressure history ...................................................... 30

Figure L: Negative phase shock wave parameters for a hemispherical surface

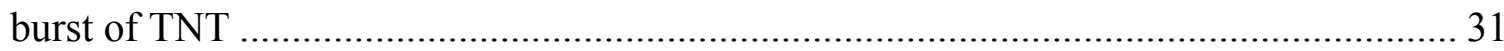

Figure M: Reflected pressure coefficient versus angle of incidence .............................. 32

Figure N: Scaled reflected impulse versus angle of incidence ................................... 33

Figure O: Uniformly distributed loading pattern ....................................................... 34

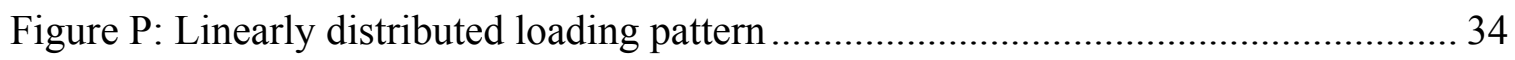

Figure Q: Triangular loading pattern ....................................................................... 34

Figure R: Parabolic loading pattern ........................................................................... 34

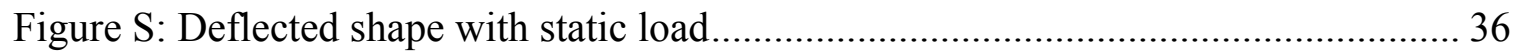

Figure T: Displacement time history with static load .............................................. 36

Figure U: $24 \mathrm{Ft}, 24-E l e m e n t$, uniformly loaded W24x131 beam with fixed ends ........... 37

Figure V: $\Delta \mathrm{t}$ vs. \% error for $24 \mathrm{ft}$ fixed end beam with uniform loading ....................... 38

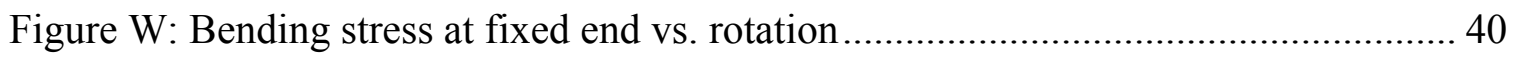

Figure $\mathrm{X}$ : Bending stress at midspan vs. rotation ............................................... 41

Figure Y: Bending stress time history with brief inelastic behavior ............................. 42

Figure Z: Resistance vs. displacement relationship.................................................... 43

Figure AA: Resistance vs. Midspan Deflection of $24 \mathrm{ft}$, uniformly loaded

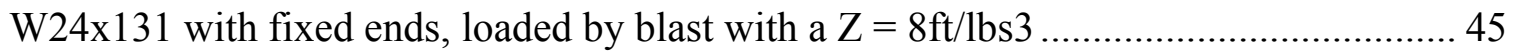

Figure BB: Bending stress diagram for $Z=8 \mathrm{ft} / \mathrm{lbs} 3$ at $\mathrm{t}=0.000902$ seconds.................. 45

Figure CC: Deflected shape diagram for $Z=8 \mathrm{ft} / \mathrm{lbs} 3$ at $\mathrm{t}=0.000902$ seconds ............... 45

Figure DD: Bending stress diagram for $Z=8 \mathrm{ft} / \mathrm{lbs} 3$ at $\mathrm{t}=0.002046$ seconds ................. 46

Figure EE: Deflected shape diagram for $Z=8 \mathrm{ft} / \mathrm{lbs} 3$ at $\mathrm{t}=0.002046$ seconds ............... 46

Figure FF: Bending stress diagram for $Z=8 \mathrm{ft} / \mathrm{lbs} 3$ at $\mathrm{t}=0.002112$ seconds .................. 46

Figure GG: Deflected shape diagram for $Z=8 \mathrm{ft} / \mathrm{lbs} 3$ at $\mathrm{t}=0.002112$ seconds ............... 46

Figure HH: Bending stress diagram for $\mathrm{Z}=8 \mathrm{ft} / \mathrm{lbs} 3$ at $\mathrm{t}=0.003133$ seconds ................. 46 
Figure II: Deflected shape diagram for $Z=8 \mathrm{ft} / \mathrm{lbs} 3$ at $\mathrm{t}=0.003133$ seconds ................. 46

Figure JJ: Bending stress diagram for $Z=8 \mathrm{ft} / \mathrm{lbs} 3$ at $\mathrm{t}=0.003378$ seconds................... 47

Figure KK: Deflected shape diagram for $\mathrm{Z}=8 \mathrm{ft} / \mathrm{lbs} 3$ at $\mathrm{t}=0.003378$ seconds ................ 47

Figure LL: Varying \% error against theoretical stiffness value due to \# of elements in beam for a simply supported, triangularly loaded, $24 \mathrm{ft}$ long, W24x131 50

Figure MM: Inelastic deflection from analysis (fixed ends) vs. theoretical elastic deflection (simply supported) . 55 


\section{LIST OF NOMENCLATURE}

\begin{tabular}{|c|c|}
\hline$D$ & distance from blast $(\mathrm{ft})$ \\
\hline$E$ & modulus of elasticity (ksi) \\
\hline$F(t)$ & force varying by time (kips) \\
\hline$F_{e}$ & effective force \\
\hline$F_{\text {eff }}(t)$ & effective force varying by time (kips) \\
\hline$F_{r}$ & point load \\
\hline$I$ & moment of inertia $\left(\mathrm{in}^{4}\right)$ \\
\hline$K_{\text {eff }}$ & effective stiffness \\
\hline$K_{L}$ & stiffness factor \\
\hline$K_{M}$ & mass factor \\
\hline$L$ & length (in) \\
\hline$M_{e}$ & effective mass (kips* ${ }^{*} \sec ^{2} /$ in) \\
\hline$M_{p}$ & plastic moment (k-in) \\
\hline$M_{r}$ & lumped mass \\
\hline$P_{S O}$ & side-on peak pressure (psi) \\
\hline$P_{S}(t)$ & side-on pressure at time $=\mathrm{t}(\mathrm{psi})$ \\
\hline$R$ & resistance (kips) \\
\hline$R_{m}$ & maximum resistance (kips) \\
\hline$T_{N}$ & n-th period \\
\hline$W$ & equivalent TNT weight (lbs) \\
\hline$Z_{X X}$ & plastic section modulus $\left(\mathrm{in}^{3}\right)$ \\
\hline$Z$ & scaled distance of TNT $\left(\mathrm{ft} / \mathrm{lbs}^{3}\right)$ \\
\hline$a_{0}$ & factor for mass damping \\
\hline$a_{1}$ & factor for stiffness damping \\
\hline$c$ & damping (kips*msec/in) \\
\hline$f_{y}$ & yield stress of steel under quasi-static loading (ksi) \\
\hline$f_{d y}$ & yield stress of steel under dynamic loading ( $\mathrm{ksi}$ ) \\
\hline $\mathrm{f}_{\mathrm{u}}$ & ultimate stress of steel under quasi-static loading (ksi) \\
\hline$f_{d u}$ & ultimate stress of steel under dynamic loading (ksi) \\
\hline$f_{1}$ & factor - used in Newmark's Average Acceleration Method \\
\hline$f_{2}$ & factor - used in Newmark's Average Acceleration Method \\
\hline$i_{S}$ & side-on impulse \\
\hline$k$ & stiffness (kips/in) \\
\hline$\hat{k}$ & Incremental stiffness (kips/in) \\
\hline$k_{e}$ & stiffness matrix of an element \\
\hline$k_{i}$ & stiffness for step i (kips/in) \\
\hline$k_{i+1}$ & stiffness for step i+1 (kips/in) \\
\hline 1 & length (in) \\
\hline$m$ & distributed mass (kips*msec ${ }^{2} /$ in $)$ \\
\hline$m_{e}$ & stiffness matrix of an element \\
\hline$\hat{p}_{i}$ & incremental load (k/in) \\
\hline$p$ & distributed load (k/in) \\
\hline$p_{0}$ & initial loading (kips) \\
\hline
\end{tabular}




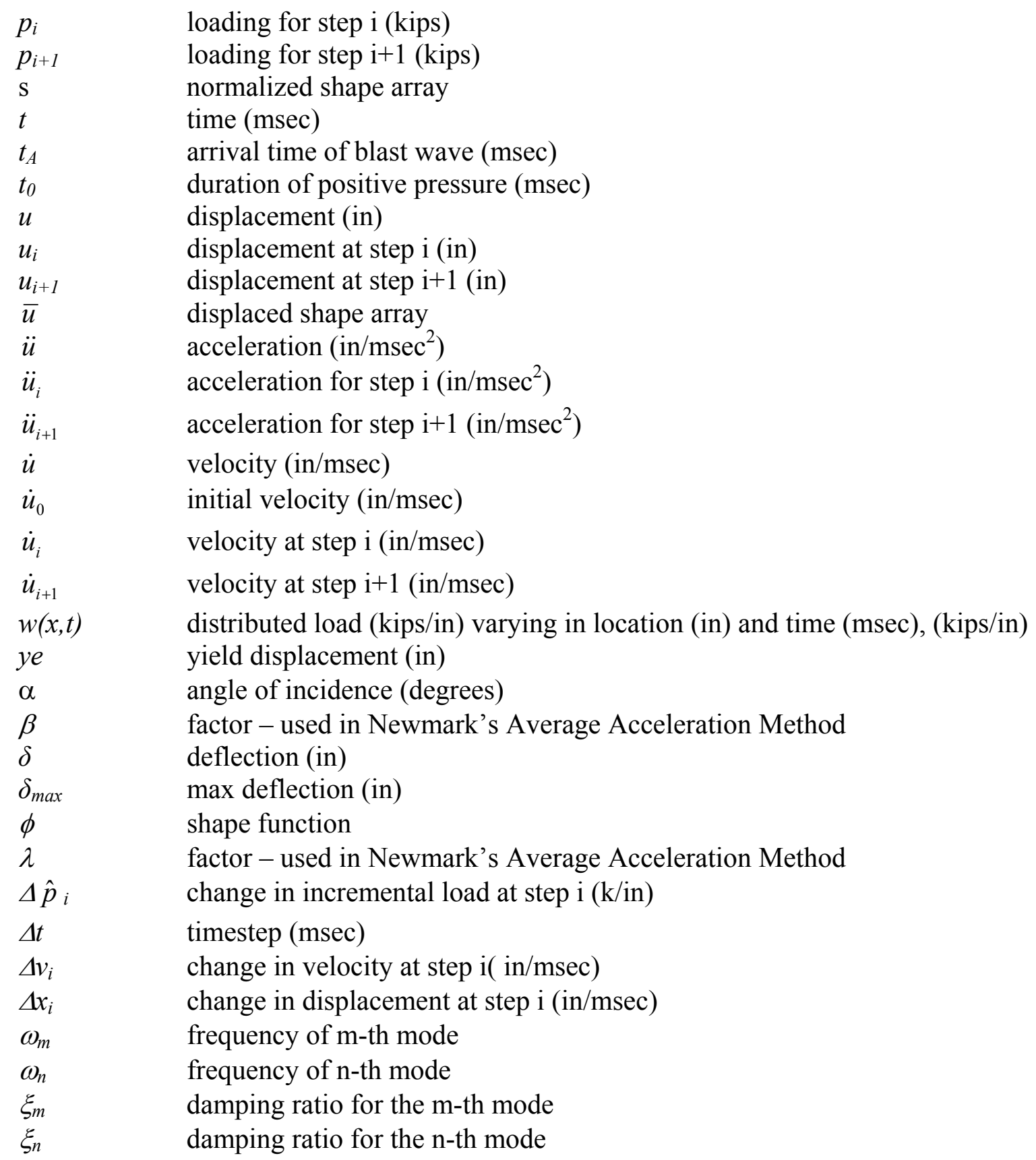




\subsection{INTRODUCTION}

This project studies the equivalent single-degree-of-freedom (SDOF) factors presented by John Biggs (1964). The study presents the derivation of these factors, a validation of the factors using a multi-degree-of-freedom (MDOF) numerical analysis, the accuracy of the SDOF analysis compared to the MDOF analysis, and suggests factors for other cases to expand on what is commonly known as the "Biggs Factors" table.

The material in this study is most applicable to the practice of blast analysis of steel beams. To put the study into context, a literature review and the state of practice of the blast analysis and design industry follows the introduction. Equivalent SDOF factors are discussed in Section 2. Numerical analysis methods are discussed in Section 3, while their application and procedures based on a SDOF idealization and MDOF idealization are discussed in Sections 4 and 5. Section 6 covers the set-up for the analyses and the assumptions built in to the set-up. Section 7 presents the verification process of the Matlab algorithms. Section 8 discusses the results from the analyses, while Section 9 discusses the conclusions of the study. All derivations or code not presented within the Sections are located in the appendices.

\subsection{Literature Review and State of Practice}

The equivalent SDOF method is regularly used in the blast analysis and design field. Blast loads are dynamic, and ductility is a key parameter in material response (Marchand and Alfawakhiri 2005); therefore, the use of dynamic analysis methods is 
imperative in modeling and understanding the behavior of the component under blast loads.

John Biggs, in his textbook Introduction to Structural Dynamics, outlined the equivalent SDOF method for analyzing component behavior. To convert a component into an equivalent SDOF system, equivalency factors are used to factor the assumed properties of the system. These equivalency factors are tabulated in John Biggs' textbook and are referred to commonly as Biggs' factors. This analysis method is accepted in the blast analysis and design industry as the first pass at estimating component behavior under blast loading. The field refers to this as the Simple SDOF Analysis Method (Conrath et al. 1999). The same theory in equivalent SDOF dynamics is included in other texts (Smith and Hetherington 1994), (Baker et al. 1983), and (Clough and Penzien 1975).

The United States Army Corps of Engineers - Protective Design Center distributes a program called SBEDS (Single-degree-of-freedom Blast Effects Design Spreadsheet). This excel spreadsheet is based on the theory presented by Biggs' dynamics and the document provided by the government titled Structures to Resist the Effects of Accidental Explosions (also referenced as Army TM 5-1300, NAVFAC P-397, and AFR 88-22). This spreadsheet is a norm in the industry as a SDOF analysis tool for component behavior due to blast.

The SBEDS manual provides a concise summary of blast loading, which is used to create the loading demands outlined in this study. This manual includes time-history loading equations and charts for the peak pressure and total impulse that can be expected Verification and Expansion of Single-Degree-of-Freedom Transformation Factors for Beams Using a Multi-Degree-of-Freedom Non-Linear Numerical Analysis Method 
due to given distance to charge ratios. Similar information can be found in textbooks by Smith and Hetherington 1994, Baker et al. 1983, and Mays and Smith 1995.

As a quick and rough method of analysis, the SDOF method has weaknesses that lead to inaccuracy in analysis results. The greatest weaknesses that Krauthammer (Krauthammer 1998) attributes to the SDOF system are the simple nonlinear structural behavior assumptions. One major assumption is the elastic-perfectly plastic assumption. Lawver (Lawver et al. 2003) exposed another weakness of the equivalent SDOF method through experiments. He subjected varying W14 columns to varying blast loads. He showed that the equivalent SDOF method is accurate for far or small charges, and that the SDOF method is unable to predict the component behavior for close or large charges. He concludes that the equivalent SDOF method could not capture local bending of the steel member web or flanges for the close or large charge conditions.

Dynamic nonlinear Finite Element analysis is the most accurate method available for studying component behavior under blast loading (Krauthammer 1998, Conrath et al. 1999). The FE method can capture local effects, and can allow the analyst to model a component response to match response observed through experiments. The FE method requires more time and expertise, and is often reserved for research, forensics, and for complex configurations that can't be modeled as SDOF systems. For the aforementioned reasons, and in order to cater the study for industry practice, the study focuses on the more economical equivalent SDOF method.

Verification and Expansion of Single-Degree-of-Freedom Transformation Factors for Beams Using a Multi-Degree-of-Freedom Non-Linear Numerical Analysis Method 


\subsection{Objective}

The first objective of this project is to validate Biggs' equivalent SDOF factors through the use of MDOF numerical analysis. The second objective is to validate the accuracy of the factors by comparing a SDOF response to the MDOF response. The third objective is to use the MDOF response to expand on the Equivalent SDOF Factors table adding linear, triangular, and parabolic load functions. The different loading patterns may exist when there is a near field - low impulse blast, or where the tributary width varies along the beam. The set-up that is used for the two methods is a steel wide-flange beam subjected to an air-blast load.

In order to validate the factors and the accuracy of the factors, the SDOF and MDOF models were programmed in Matlab using the Newmark's Average Acceleration numerical method. Response for analysis will not include damping or initial deflection; however, these options are included in the program and available for use.

\subsection{Limitations}

Theoretical models produce theoretical solutions, and limitations are caused by the assumptions made in creating the theoretical model. Such assumptions and limitations for this project are as follows:

- The analyses assume air-blast on the component. Fragments and their effects on the components are not addressed.

- The US government routinely performs blast test on structural components; however, the tests are not available to the public so the computer analysis cannot be compared to testing. ${ }^{1}$

\footnotetext{
${ }^{1}$ Personal correspondence between Shalva Marjanishvili, Ph.D., S.E., and Takayuki Yokoyama on March 25, 2008. Shalva Marjanishvili is the Technical Director of Hinman Consulting Engineers, Inc.

Verification and Expansion of Single-Degree-of-Freedom Transformation Factors for Beams Using a Multi-Degree-of-Freedom Non-Linear Numerical Analysis Method
} 
- Only the primary impulse load is considered, and subsequent impulse loads caused by diffractions are not considered.

- Shear action plays an important role in beam response (Nonaka 2000); however, shear failure and shear ductility are not considered.

- Failure of boundary conditions, or component supports, is not considered.

- Material mechanics are based on elastic, perfectly plastic.

- A pre-existing axial load would influence the response of the component, but no pre-existing forces in the member are considered. 


\subsection{SINGLE-DEGREE-OF-FREEDOM ANALYSIS}

A Single-degree-of-freedom (SDOF) system is a mathematical model where the component can only move along one axis as shown below.

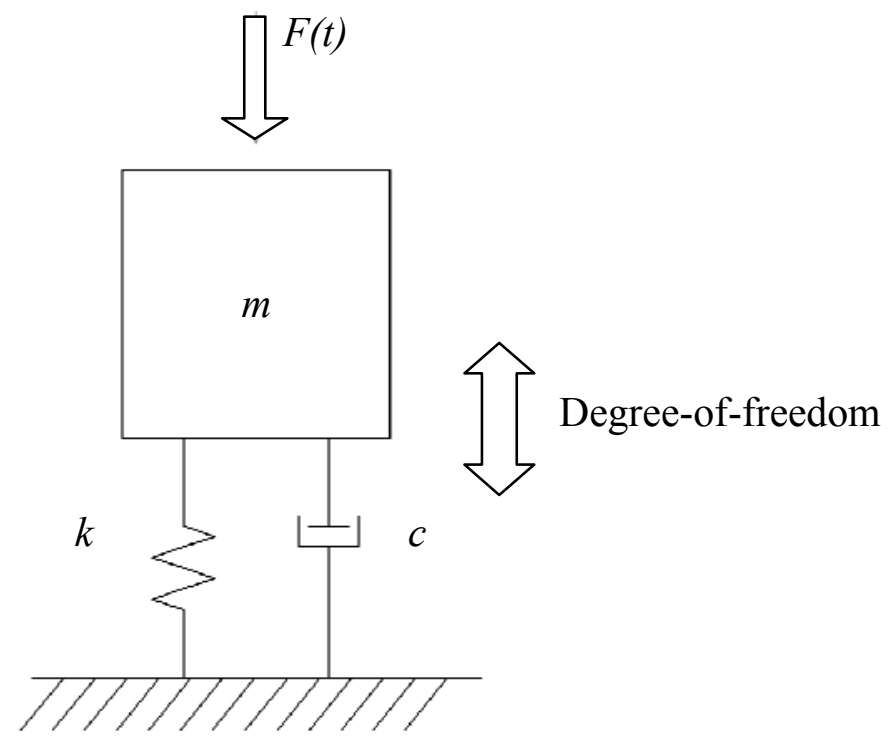

Figure A: Simple SDOF model

The system has a single force on the single mass with a stiffness value and a damping value. The motion of this model can be expressed using the equation shown below.

$$
m \ddot{u}(t)+c \dot{u}(t)+k u(t)=F_{e f f}(t)
$$

While the mass, damping, and stiffness stay the same; the force, acceleration, velocity, and displacement vary over time. The SDOF system is a simple spring-mass system that has the same work, strain, and kinetic energies at any given time, as the real model. In order to create a similar maximum displacement at the midspan; effective mass, force, and resistance terms must be used.

Verification and Expansion of Single-Degree-of-Freedom Transformation Factors for Beams Using a Multi-Degree-of-Freedom Non-Linear Numerical Analysis Method 


\subsection{Equivalent SDOF Factors}

Equivalent SDOF factors are used to obtain the effective mass, force, and resistance terms, and to make the SDOF system response equivalent to that of the real system. These equivalent SDOF factors are tabulated below.

Table 1: Equivalent SDOF factors for simply supported beams Source: Biggs 1964

\begin{tabular}{|c|c|c|c|c|c|}
\hline $\begin{array}{l}\text { Loading } \\
\text { Diagram }\end{array}$ & $\begin{array}{l}\text { Strain } \\
\text { Range }\end{array}$ & $\begin{array}{c}\text { Load } \\
\text { Factor } \\
K_{L} \\
\end{array}$ & $\begin{array}{c}\text { Mass } \\
\text { Factor } \\
K_{M} \\
\end{array}$ & $\begin{array}{c}\text { Maximum Resistance } \\
R_{m} \\
\end{array}$ & $\begin{array}{c}\text { Spring } \\
\text { Constant } \\
k\end{array}$ \\
\hline 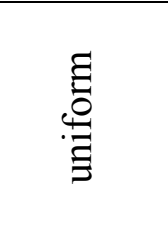 & $\begin{array}{l}\text { Elastic } \\
\text { Plastic }\end{array}$ & $\begin{array}{l}0.64 \\
0.50\end{array}$ & $\begin{array}{l}0.50 \\
0.33\end{array}$ & $\begin{array}{l}\frac{8 M_{p}}{L} \\
\frac{8 M_{p}}{L}\end{array}$ & $\begin{array}{c}\frac{384 E I}{5 L^{3}} \\
0\end{array}$ \\
\hline 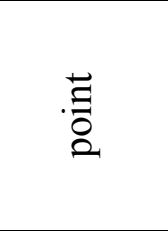 & $\begin{array}{l}\text { Elastic } \\
\text { Plastic }\end{array}$ & $\begin{array}{l}1.00 \\
1.00\end{array}$ & $\begin{array}{l}0.49 \\
0.33\end{array}$ & $\begin{array}{c}\frac{4 M_{p}}{L} \\
\frac{4 M_{p}}{L}\end{array}$ & $\begin{array}{c}\frac{48 E I}{L^{3}} \\
0\end{array}$ \\
\hline
\end{tabular}

Table 2: Equivalent SDOF factors for beams with fixed ends

Source: Biggs 1964

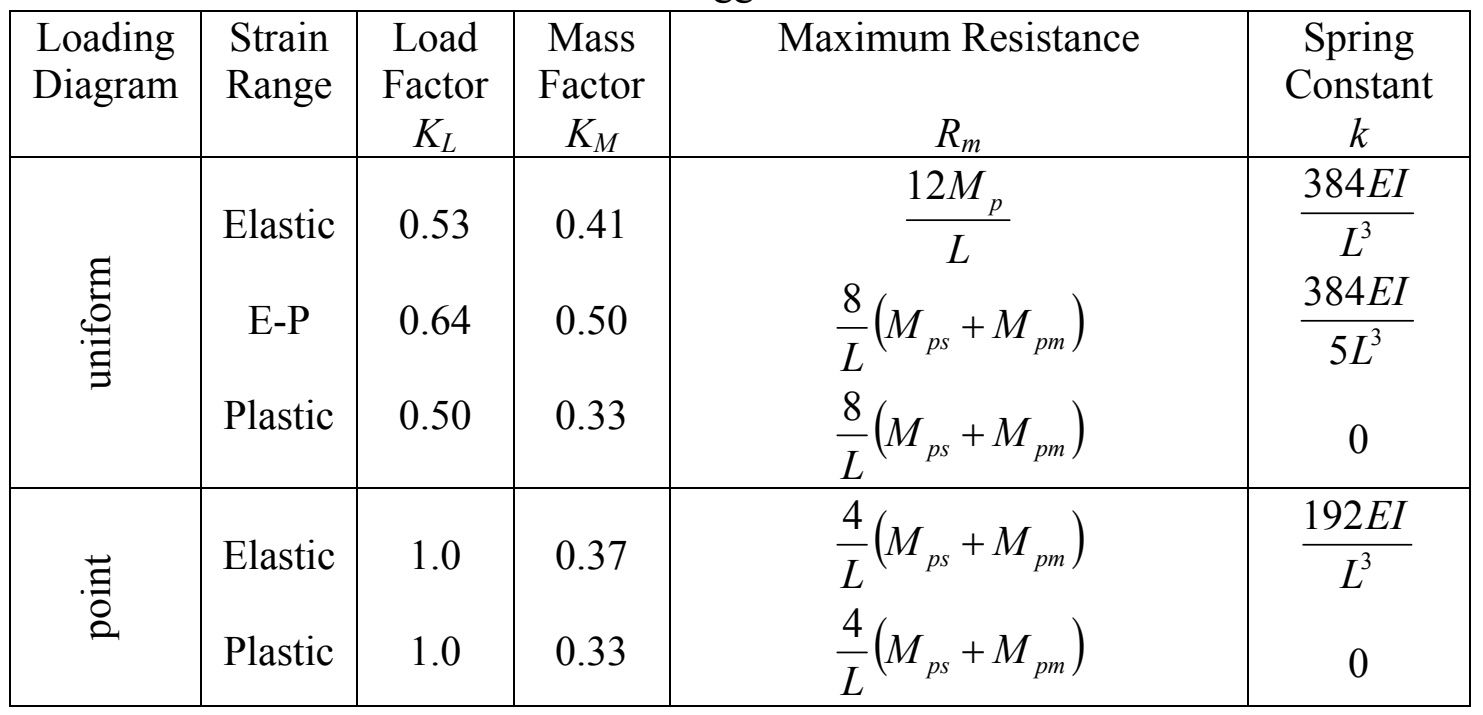

Verification and Expansion of Single-Degree-of-Freedom Transformation Factors for Beams Using a Multi-Degree-of-Freedom Non-Linear Numerical Analysis Method 
In order to solve for equivalent SDOF factors, deflected shape assumptions are made. Biggs uses the static deflected shape, normalized, so that the maximum deflection is one unit. This is called the shape function, and is used to solve for both mass and load transformation factors. The factors are then used as coefficients to the corresponding factors in Eq. 1 on page 6. The $\mathrm{m}$ and $\mathrm{k}$ values are based on the static deflection shape with the maximum deflection normalized to one unit.

The following subsections describe the derivation process of the equivalent SDOF factors; an example derivation can be found in Section 11.1.

\subsubsection{Mass Factor}

The mass factor can be defined as "the ratio of equivalent mass to the actual total mass of the structure"; setting the mass factor, $\mathrm{K}_{\mathrm{M}}$, equal to $\mathrm{M}_{\mathrm{e}}$ (equivalent mass) divided by $M_{t}$ (actual total mass). The equation for $M_{e}$ is shown below (Biggs 1964).

$$
M_{e}=\sum_{r=1}^{j} M_{r} \phi_{r}^{2}
$$

for lumped masses, or

$$
M_{e}=\int m \phi^{2}(x) d x
$$

for a distributed mass.

The mass factor, $\mathrm{K}_{\mathrm{M}}$, then, is the effective mass, $\mathrm{M}_{e}$, divided by the true mass. 


$$
K_{M}=\frac{\sum^{r} M_{r} \phi_{r}}{\sum^{r} M_{r}}
$$

for lumped masses, or

$$
K_{M}=\frac{\int^{L} m \phi^{2}(x) d x}{m L}
$$

for a distributed mass.

This mass factor is used to convert the actual mass value to the equivalent system mass value in the SDOF equation of motion.

\subsubsection{Load Factor}

Like the mass factor, the load factor can also be defined as the ratio of the equivalent to the actual. The equation for the equivalent load, $F_{e}$, is shown below (Biggs 1964).

$$
F_{e}=\sum_{r=1}^{j} F_{r} \phi_{r}
$$

for concentrated loads, or

$$
F_{e}=\int^{L} p(x) \phi(x) d x
$$

For a distributed load.

The stiffness factor, $\mathrm{K}_{\mathrm{L}}$, then, is the effective stiffness, $\mathrm{K}_{\mathrm{e}}$, divided by the true stiffness.

$$
F_{e}=\frac{\sum^{j} F_{r} \phi_{r}}{\sum^{r} F_{r}}
$$

Verification and Expansion of Single-Degree-of-Freedom Transformation Factors for Beams Using a Multi-Degree-of-Freedom Non-Linear Numerical Analysis Method 
For concentrated loads, or

$$
K_{L}=\frac{\int^{L} p \phi(x) d x}{p L}
$$

For a distributed load.

This stiffness factor is used to factor the stiffness value in the SDOF equation of motion.

\subsubsection{Resistance}

Stiffness can be defined as the load needed to cause a unit displacement. The resistance of an element is defined as the load resisted by the component and the corresponding deflection. The maximum resistance for a failure mechanism is the load resisted by the component when a hinge forms. Due to this resistance and load relationship, the resistance (and stiffness) factor is equal to the load factor. Like the load and mass factor, the resistance factor is also the ratio of the equivalent resistance to the actual resistance.

\subsection{Yield}

With large impulse loads, the component will yield. This needs to be reflected in the SDOF analysis. The static force required to cause a yielding moment in the beam is set as the maximum resistance value. Once the force reaches this maximum resistance value, a new shape function is used, and along with it, new load, mass, and resistance factors. The result is a resistance versus displacement curve as shown in Figure B for a uniformly loaded beam with both ends fixed.

Verification and Expansion of Single-Degree-of-Freedom Transformation Factors for Beams Using a Multi-Degree-of-Freedom Non-Linear Numerical Analysis Method 


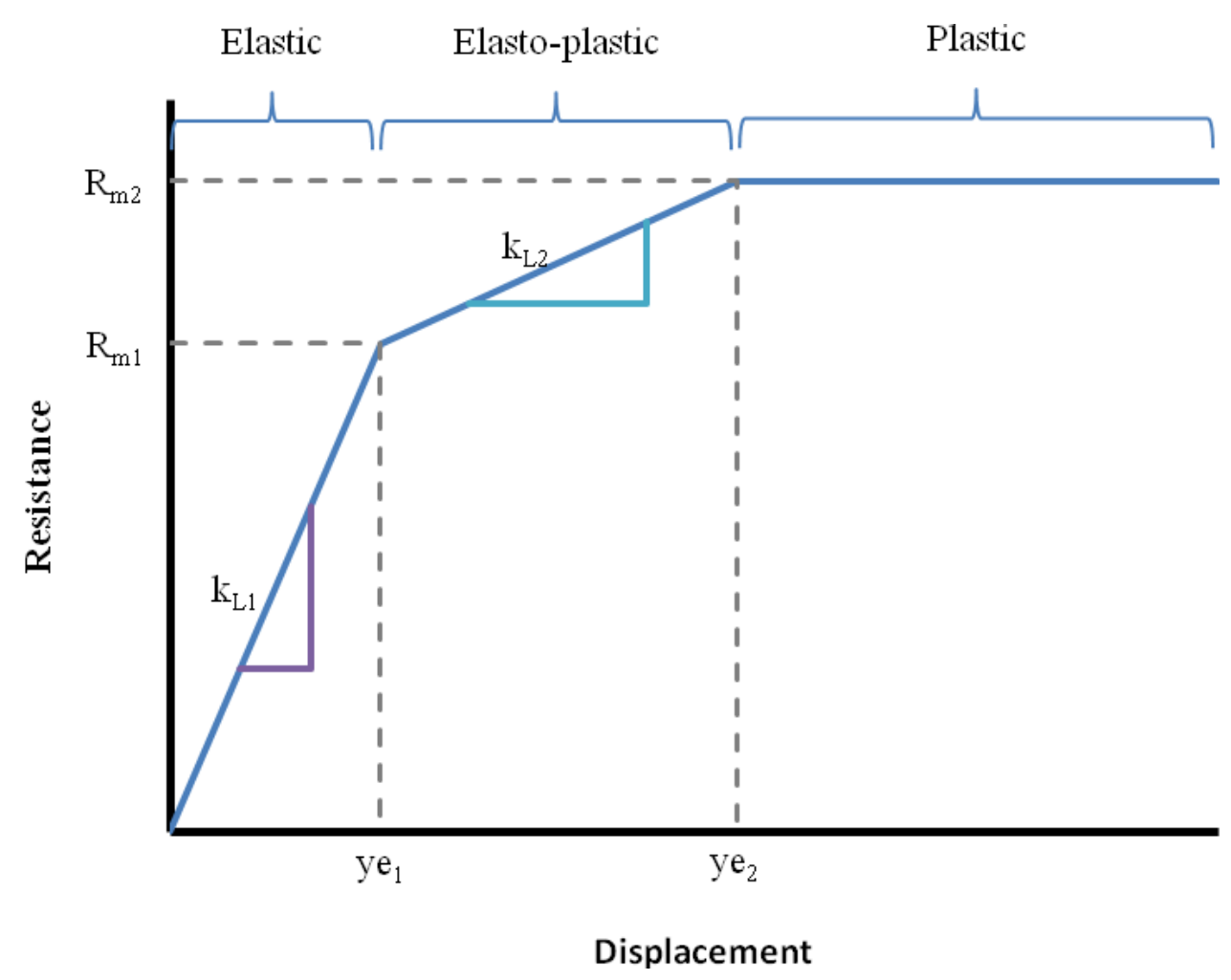

Figure B: SDOF system nonlinear behavior

The graph in Figure B shows the nonlinear behavior of the system. For the uniformly loaded beam with both ends fixed, there are three stages in behavior: elastic, elasto-plastic, and plastic. The system behaves elastically until the first resistance value, $\mathrm{R}_{\mathrm{m} 1}$, is reached. At this resistance value, hinges form on either end of the beam, and the beam now behaves similar to a uniformly loaded, simply supported beam. The third hinge forms at $\mathrm{R}_{\mathrm{m} 2}$, at which point the system loses its stiffness and behaves plastically.

With the established factors, the SDOF model can be run through the Newmark's Average Acceleration numerical procedure to estimate the maximum component deflection due to a blast load.

Verification and Expansion of Single-Degree-of-Freedom Transformation Factors for Beams Using a Multi-Degree-of-Freedom Non-Linear Numerical Analysis Method 


\subsection{NUMERICAL ANALYSIS METHODS}

Based on Section 2.0 a basic equation for solving a dynamics problem is shown below as Eq. 10.

$$
m \ddot{u}(t)+c \dot{u}(t)+k u(t)=F_{\text {eff }}(t)
$$

If the mass $(m)$, damping $(c)$, and stiffness $(k)$ are constant over time $(t)$; the acceleration $(\ddot{u})$, velocity $(\dot{u})$, and displacement $(u)$ can be calculated for a given at time ( $t$ ) by solving the equation. Because the loading varies over time, and the stiffness changes due to the material and geometric nonlinearity; the acceleration, velocity, and displacement have to be solved in time increments in order to capture the behavior of the system over time. Numerical analysis methods are used to perform the time-step evaluations of such systems.

Before selecting Newmark's Average Acceleration method, there were three other numerical analysis methods considered for this study: Central Difference, Newmark's Linear Acceleration, and Wilson- $\theta$ Method (Chopra 2007).

The results obtained from all numerical methods include computational errors caused by the different assumptions made by each method between every timestep. Figure $\mathbf{C}$ below shows the comparison of the different numerical methods to the theoretical solution. 


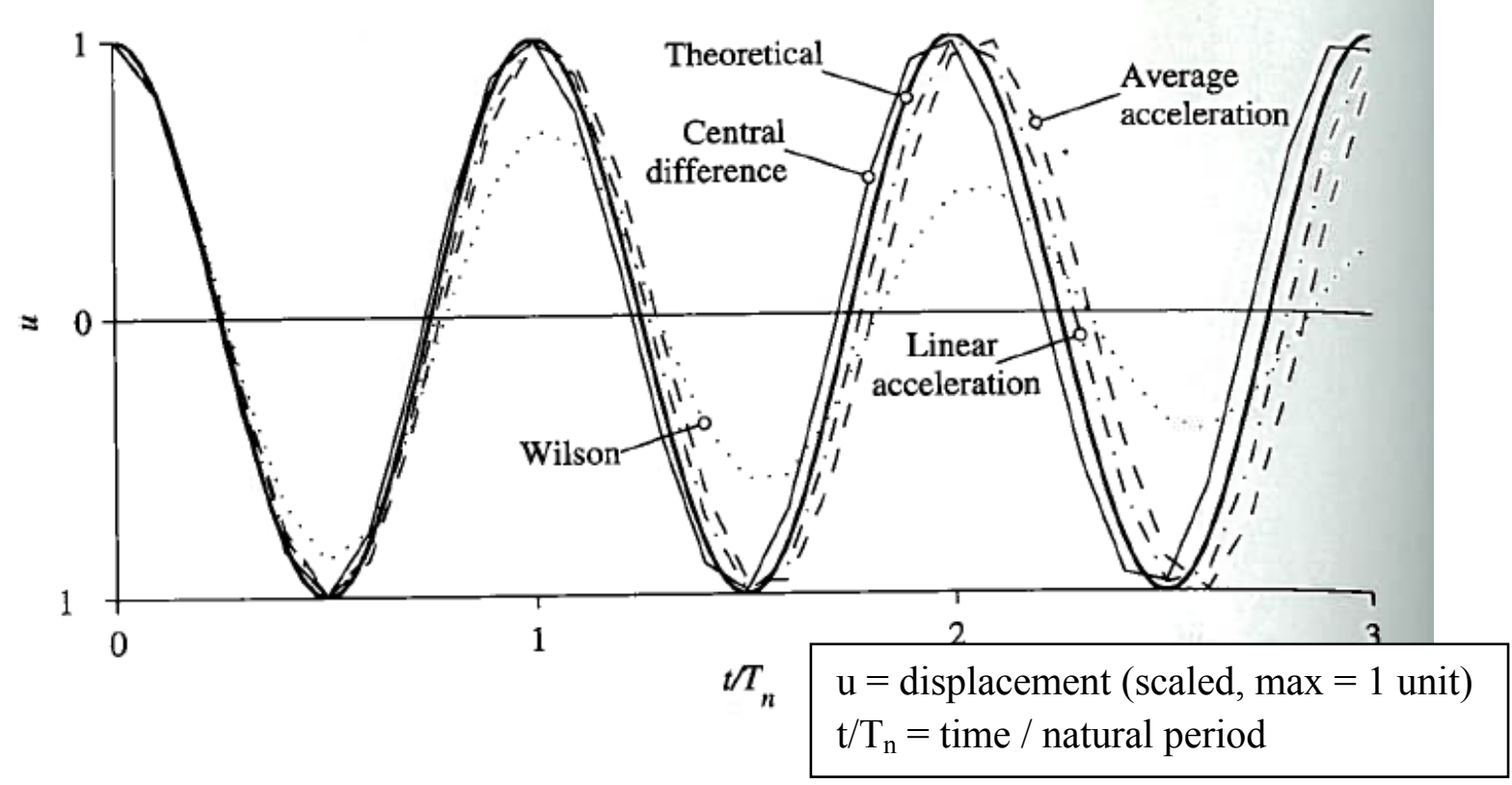

Figure C: Free vibration solution by four numerical methods vs. the theoretical solution

Source: Chopra 2007

Wilson- $\theta$ method shows the biggest diversion from the theoretical solution as the amplitude decreases every period. This amplitude decrease is caused by numerical damping which is built in to the method. While the central difference method, the average acceleration method, and the linear acceleration method all predict the displacement amplitude accurately, the period varies slightly from the theoretical solution.

Figure $\mathbf{C}$ from above shows that as the timestep increases relative to the natural period of the single-degree-of-freedom (SDOF) system, the central difference method's inaccuracy increases rapidly. For the SDOF system, Newmark's Average Acceleration method and the Linear Acceleration method appear to be the more accurate methods.

After ruling out Wilson- $\theta$ method and the central difference method from above, the two remaining method options are the average and linear acceleration methods. The 
remaining methods are compared using a multi-degree-of-freedom (MDOF) system. The linear MDOF system produces similar results to the SDOF system, and therefore, the linear acceleration is the most accurate method; however, when the MDOF system becomes a nonlinear system, the linear acceleration method runs into computational stability issues. In a MDOF nonlinear system, the stability of the solution depends on the timestep to period ratio of the highest mode of the system. Even though the higher modes of the system have negligible contribution to the overall behavior of the system, they are important to the stability of the analysis. The highest mode of the system depends on the number of elements used in the MDOF model. This project discretizes the beams into at least 24 elements, so the periods of the higher modes become very small. The small period of the highest mode requires the timestep for the analysis to be even shorter or the solution "blows up" due to the computational instability. When the timestep becomes too small, the calculation time becomes too long and impractical.

Because of the numerical procedure stability issue, using an unconditionally stable method is practical. The Average Acceleration method is unconditionally stable and does not have numerical damping (Wilson- $\theta$ method); therefore, the average acceleration method is used in this project. The step-by-step procedure of Newmark's Average Acceleration method is introduced and described in the SDOF and MDOF sections (Section 4.0 and Section 5.0). 


\subsection{NEWMARK'S AVERAGE ACCELERATION SINGLE-DEGREE- OF-FREEDOM ANALYSIS PROCEDURE}

The Newmark's Average Acceleration numerical procedure is shown in Table 3.

Table 3: Newmark's Average Acceleration Method

Source: Chopra 2007 - modified

For Average Acceleration, $\gamma=\frac{1}{2}$ and $\beta=\frac{1}{4}$

1.0 Initial Calculations

$$
1.1 \ddot{u}=\frac{p_{0}-c \dot{u}_{0}-k u_{0}}{m}
$$

2.0 Iterative Calculations

2.1 Determine tangent stiffness $k_{i}$

$$
2.2 \hat{k}_{i}=k_{i}+\frac{\gamma}{\beta \Delta t} c+\frac{1}{\beta(\Delta t)^{2}} m
$$$$
2.3 f_{1}=\frac{1}{\beta \Delta t} m+\frac{\gamma}{\beta} c \text { and } f_{2}=\frac{1}{2 \beta} m+\Delta t\left(\frac{\gamma}{2 \beta}-1\right) c
$$

$2.4 \Delta \hat{p}_{i}=\Delta p_{i}+f_{1} \dot{u}_{i}+f_{2} \ddot{u}_{i}$

$2.5 \Delta u_{i}=\frac{\hat{p}_{i}}{\hat{k}_{i}}$

$2.6 \Delta \dot{u}_{i}=\frac{\gamma}{\beta \Delta t} \Delta u_{i}-\frac{\gamma}{\beta} \dot{u}_{i}+\Delta t\left(1-\frac{\gamma}{2 \beta}\right) \ddot{u}_{i}$

$2.7 u_{i+1}=u_{i}+\Delta u_{i}, \dot{u}_{i+1}=\dot{u}_{i}+\Delta \dot{u}_{i}$

$2.8 \ddot{u}_{i+1}=\frac{p_{i+1}-c \dot{u}_{i+1}-k u_{i+1}}{m}$

3.0 Repeat steps 2.1 through 2.8 
The method outlined above is an iterative procedure where there is an initial acceleration, velocity, and displacement at every time step. Every time step involves several equations. Steps 2.1 and 2.2 are used to check the effective mass and stiffness needed for the time step. The effective mass and stiffness changes only when the expected yield deflection is reached. Steps 2.5 and 2.6 use the initial acceleration, velocity, and displacement of the time step to calculate the change in displacement and velocity in the time step. Note that for the Average Acceleration Method, the acceleration component of step 2.6 is equal to zero, and only the change and displacement and the velocity affect the change in velocity. Step 2.8 is a step that is modified compared to the procedure in (Chopra 2007). The procedure in (Chopra 2007) uses the equation $\ddot{u}_{i+1}=\ddot{u}_{i}+$ $\Delta \ddot{u}_{i}$. For this study, the equation is replaced by step 2.8 which forces equilibrium to ensure there is minimal gain or loss of energy in the system. This step calculates the acceleration for the next time step, and completes the calculation for a time step. 


\subsection{MULTI-DEGREE-OF-FREEDOM ANALYSIS}

In order to measure the accuracy of the Biggs' single-degree-of-freedom (SDOF) factors, the output from the SDOF system must be compared to the output of a more accurate method of analysis. The multi-degree-of-freedom (MDOF) system is used to create the output for comparison.

\subsection{Multi-Degree-of-Freedom Model}

This project uses a MDOF system to help create the advanced SDOF method. MDOF in this project means the component being studied is broken up into multiple elements, with each component having two degrees of freedom on either end as shown below in Figure D.

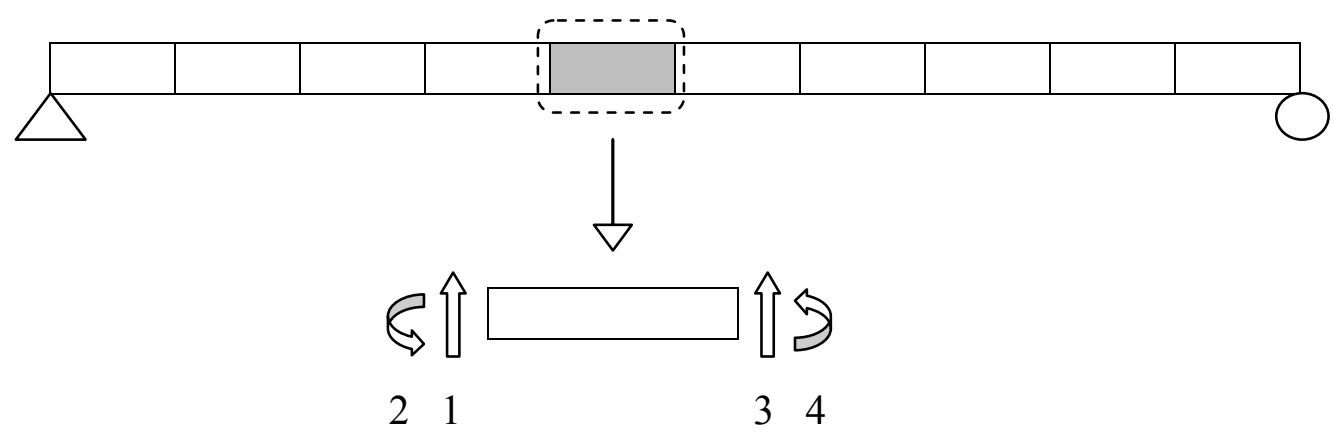

Figure D: MDOF system

The first degree of freedom for each component moves in the same axis as the SDOF system, and the second degree of freedom for each component is a rotational movement.

Verification and Expansion of Single-Degree-of-Freedom Transformation Factors for Beams Using a Multi-Degree-of-Freedom Non-Linear Numerical Analysis Method 
Eq. 1 still applies to the MDOF system; however, each variable is represented as a vector or a matrix. The stiffness matrix is comprised of uniform beam segment stiffness matrices. A stiffness matrix for a beam segment is shown below.

$$
k_{e}=\frac{2 E I}{L^{3}}\left[\begin{array}{cccc}
6 & 3 L & -6 & 3 L \\
3 L & 2 L^{2} & -3 L & L^{2} \\
-6 & -3 L & 6 & -3 L \\
3 L & L^{2} & -3 L & 2 L
\end{array}\right]
$$

In the equation above, $\mathrm{k}_{\mathrm{e}}$ represents the stiffness matrix of a single uniform beam segment while L represents the length of the same segment. The beam is expected to respond inelastically when it is loaded with a blast impulse. To capture the transition that occurs between elastic behavior and inelastic behavior, the internal forces and the stiffness matrices are evaluated at every time step. If the internal moment of an element exceeds the material and section capacity, a new stiffness matrix is formed for the particular element. The pin-fixed stiffness matrix, depending on which end becomes pinned, can be substituted by one of the two stiffness matrices shown below.

$$
k_{e}=\frac{E I}{L^{3}}\left[\begin{array}{cccc}
3 & 0 & -3 & 3 L \\
0 & 0 & 0 & 0 \\
-3 & 0 & 3 & -3 L \\
3 L & 0 & -3 L & 3 L^{2}
\end{array}\right]
$$

or 


$$
k_{e}=\frac{E I}{L^{3}}\left[\begin{array}{cccc}
3 & 3 L & -3 & 0 \\
3 L & 3 L^{2} & -3 L & 0 \\
-3 & -3 L & 3 & 0 \\
0 & 0 & 0 & 0
\end{array}\right]
$$

When the first node, in this case the left node, becomes plastic or pinned, matrix Eq. 12 is used to replace the original stiffness matrix. When the second node, or the right node, becomes pinned, matrix Eq. 13 is used to replace the original stiffness matrix.

The mass matrix used in the study is shown below.

$$
m_{e}=\frac{\bar{m} L}{420}\left[\begin{array}{cccc}
156 & 22 L & 54 & -13 L \\
22 L & 4 L^{2} & 13 L & -3 L^{2} \\
54 & 13 L & 156 & -22 L \\
-13 L & -3 L^{2} & -22 L & 4 L^{2}
\end{array}\right]
$$

(Clough and Penzien 1975) present two ways to form a mass matrix, the lumpedmass matrix and the consistent-mass matrix. For this study, the consistent-mass matrix is used. The consistent-mass matrix is more accurate than the lumped-mass matrix because it couples the adjacent degrees of freedom. The downside is that it also can take more computational effort compared to the lumped-mass matrix (Clough and Penzien 1975).

One situation where an explicit damping matrix is needed is for "nonlinear responses, for which the mode shapes are not fixed but are changing with changes of stiffness" (Clough and Penzien 1975). Because the above criterion is met in this project, the Rayleigh Damping method is used to form an explicit damping matrix. The damping matrix is formed by adding the factored mass and stiffness matrices together as shown below in Eq.15.

Verification and Expansion of Single-Degree-of-Freedom Transformation Factors for Beams Using a Multi-Degree-of-Freedom Non-Linear Numerical Analysis Method 


$$
c=a_{0} m+a_{1} k
$$

Where $a_{0}$ and $a_{1}$ are factors that need to be solved for, and in order to do so, two natural frequencies (modes) and the damping ratios for those frequencies must be determined. The natural frequencies can be found by solving for the Eigen values, and the damping ratio can be assumed. Once the natural frequencies $\omega_{\mathrm{m}}$ and $\omega_{\mathrm{n}}$ for the $\mathrm{m}^{\text {th }}$ and $\mathrm{n}^{\text {th }}$ modes are selected along with the damping ratios $\xi_{\mathrm{m}}$ and $\xi_{\mathrm{n}}$, the factors $a_{0}$ and $a_{1}$ can be solved using Eq.16 below.

$$
\left\{\begin{array}{c}
\xi_{m} \\
\xi_{n}
\end{array}\right\}=\frac{1}{2}\left[\begin{array}{cc}
1 / \omega_{m} & \omega_{m} \\
1 / \omega_{n} & \omega_{n}
\end{array}\right]\left\{\begin{array}{l}
a_{0} \\
a_{1}
\end{array}\right\}
$$

The factors $a_{0}$ and $a_{1}$ can then be inserted into Eq. 15 for the damping matrix.

This method of deriving a damping matrix causes the damping effect to be high on modes that are less or significantly higher than the two selected significant modes. This may cause some inaccuracy to the behavior of the beam; however, damping out the higher modes allows the analysis to run with larger time steps.

The loading matrix is a two dimensional matrix with the rows corresponding to the degrees of freedom of the system and the columns corresponding to the loading pattern for each timestep. For this project, the magnitude of the load varies with time to follow the typical pressure time-history of a blast while the loading distribution over the length of the beam stays constant.

Verification and Expansion of Single-Degree-of-Freedom Transformation Factors for Beams Using a Multi-Degree-of-Freedom Non-Linear Numerical Analysis Method 


\subsection{Newmark's Average Acceleration Method in MDOF}

The Newmark's Average Acceleration numerical procedure for a multi-degree-offreedom (MDOF) system is the same as the process for a single-degree-of-freedom (SDOF) system shown in Table 3, and shown again below in Table 4.

Table 4: Newmark's Average Acceleration Method

Source: Chopra 2007 - modified

For Average Acceleration, $\gamma=\frac{1}{2}$ and $\beta=\frac{1}{4}$

1.0 Initial Calculations

$1.1 \ddot{u}=m^{-1}\left(p_{0}-c \dot{u}_{0}-k u_{0}\right)$

$1.2 f_{1}=\frac{1}{\beta \Delta t} m+\frac{\gamma}{\beta} c$ and $f_{2}=\frac{1}{2 \beta} m+\Delta t\left(\frac{\gamma}{2 \beta}-1\right) c$

2.0 Iterative Calculations

$2.1 \Delta \hat{p}_{i}=\Delta p_{i}+f_{1} \dot{u}_{i}+f_{2} \ddot{u}_{i}$

2.2 Determine tangent stiffness $k_{i}$

$2.3 \hat{k}_{i}=k_{i}+\frac{\gamma}{\beta \Delta t} c+\frac{1}{\beta(\Delta t)^{2}} m$

$2.4 \Delta u_{i}=\frac{\hat{p}_{i}}{\hat{k}_{i}}$

$2.5 \Delta \dot{u}_{i}=\frac{\gamma}{\beta \Delta t} \Delta u_{i}-\frac{\gamma}{\beta} \dot{u}_{i}$

$2.6 u_{i+1}=u_{i}+\Delta u_{i}, \dot{u}_{i+1}=\dot{u}_{i}+\Delta \dot{u}_{i}$

$2.7 \ddot{u}_{i+1}=m^{-1}\left(p_{i+1}-c \dot{u}_{i+1}-k u_{i+1}\right)$

3.0 Repeat steps 2.1 through 2.7

Verification and Expansion of Single-Degree-of-Freedom Transformation Factors for Beams Using a Multi-Degree-of-Freedom Non-Linear Numerical Analysis Method 
Most of the steps in the procedures between the MDOF and SDOF steps are the same with two exceptions. The main difference is the variables. MDOF uses matrices and vectors for every step instead of the single values used for the SDOF variables.

Another difference between the two systems is the re-evaluation process of the stiffness matrix for each iteration. In the SDOF system, the stiffness value was changed when the resistance in the system reached a certain force. This instant change in the stiffness value creates a bilinear system. In the MDOF system, the resistance is evaluated for each node of every element in the beam. The stiffness in each element is a bilinear system, but globally creates a curved transition from elastic to plastic.

Similar to the modification made to the SDOF procedure, the equation for solving the acceleration for the next time step is a modification to the procedure outlined in (Chopra 2007). This modification is made to ensure there is minimal gain or loss of energy in the system.

Verification and Expansion of Single-Degree-of-Freedom Transformation Factors for Beams Using a Multi-Degree-of-Freedom Non-Linear Numerical Analysis Method 


\subsection{ANALYSIS SET UP}

This Section outlines the analysis set up. The set up includes beam configuration, material properties, and loading. Figure $\mathbf{E}$ is a graphical representation of the basic component set up used for the analyses.

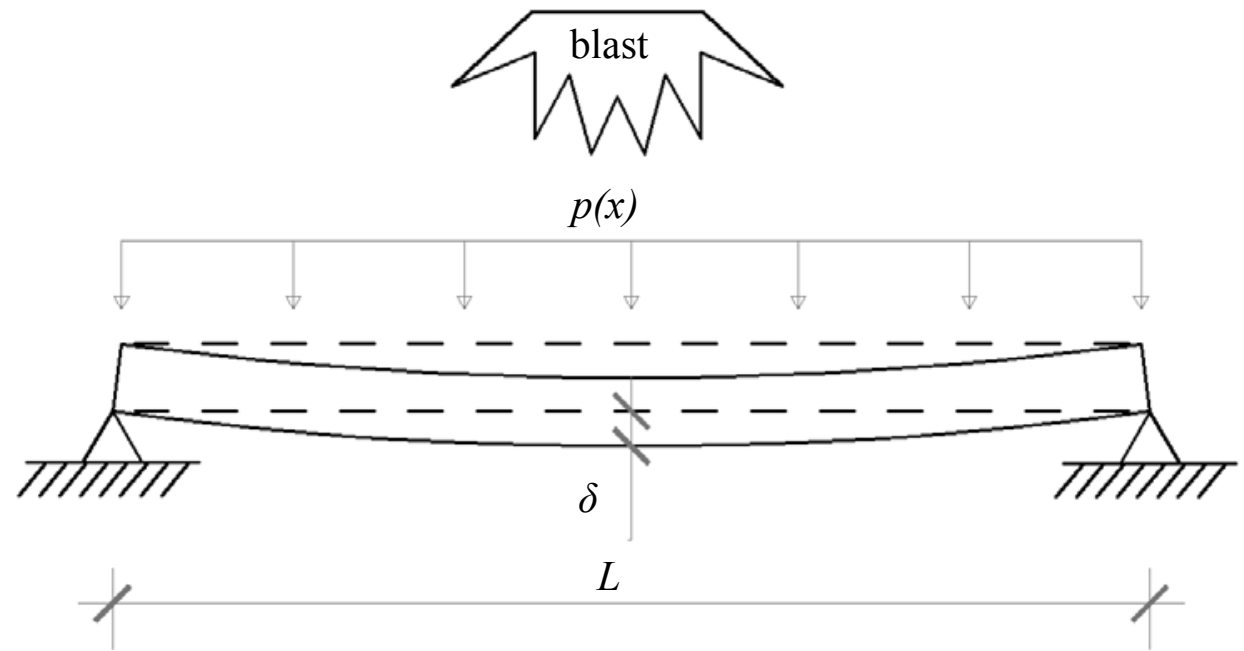

Figure E: Analysis set-up

The component is a single-span steel beam with the simulated load coming from above.

\subsection{Beam Configuration}

The beam configuration is shown in Figure $\mathbf{E}$. The geometric properties of the beam are shown in Table 5.

Table 5: Initial configuration and section properties

$\begin{array}{ll}\text { Beam section } & \text { W24x131 } \\ \text { Length } & \mathrm{L}=24 \mathrm{ft} \\ \text { Moment of inertia } & \mathrm{I}=4020 \mathrm{in}^{4} \\ \text { Plastic modulus } & \mathrm{Z}_{\mathrm{XX}}=370 \mathrm{in}^{3}\end{array}$

Verification and Expansion of Single-Degree-of-Freedom Transformation Factors for Beams Using a Multi-Degree-of-Freedom Non-Linear Numerical Analysis Method 
Boundary conditions are either pinned or fixed at each end. The supports are infinitely rigid in translation. If the support is a pinned-support, there is no rotational stiffness, and if the support is a fixed-support, the rotational stiffness is infinite. The program allows the beam to carry initial dead and live loads, with an initial deflection caused by the static loads; however, this function is not included in the analysis for this project. The beam is assumed to be sufficiently braced laterally so that the beam behavior is based on the section properties.

There are two types of beam configurations that are used for analysis in this study:

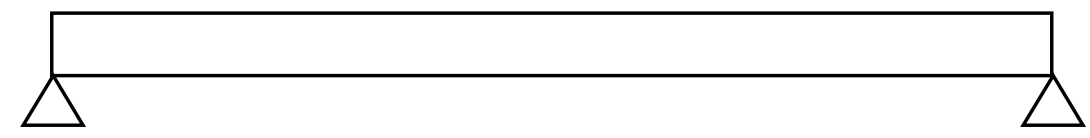

Figure F: Pin-pin boundary configuration

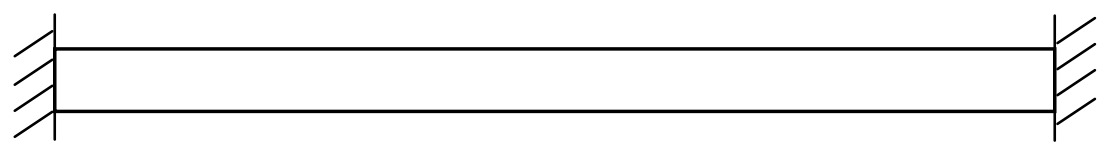

Figure G: Fixed-fixed boundary configuration

The configurations above are used with different loading conditions.

\subsection{Material Properties}

Material properties of the steel beam are shown in Table 6 and Figure $\mathbf{H}$.

Table 6: Material properties

$\begin{array}{ll}\text { Steel } & \text { A572 } \\ \text { Modulus of elasticity } & \mathrm{E}_{\mathrm{s}}=29000 \mathrm{ksi} \\ \text { Yield strength } & \mathrm{f}_{\mathrm{y}}=50 \mathrm{ksi}\end{array}$

Verification and Expansion of Single-Degree-of-Freedom Transformation Factors for Beams Using a Multi-Degree-of-Freedom Non-Linear Numerical Analysis Method 


\section{Material Behavior}

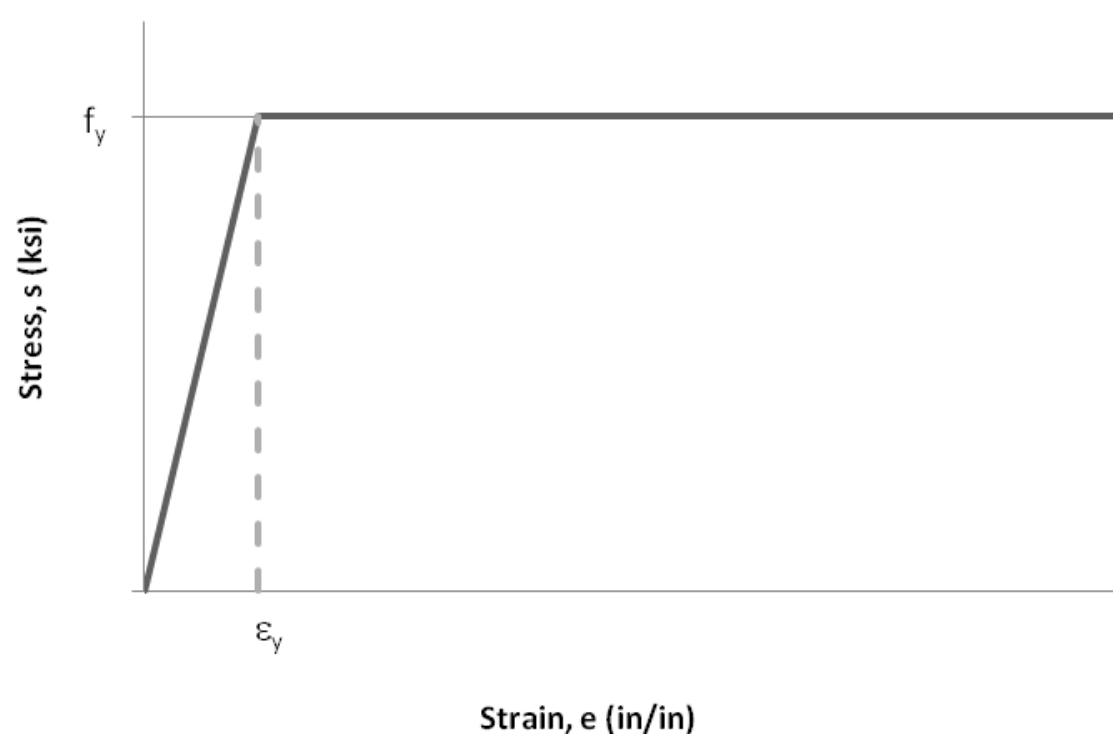

Figure H: Assumed Steel nonlinear behavior

The AISC Steel Construction Manual indicates that the expected yield strength of an A572 grade steel is $55 \mathrm{ksi}$. TM5-1300 indicates that the dynamic yield strength is greater than the quasi-static yield strength, and calls it a strain rate increase (U.S.

Department of the Army 1990). Considering the two sources, the $\mathrm{f}_{\mathrm{y}}=50 \mathrm{ksi}$ assumption made in Table 6 is erroneous and yield strength should be around 65 ksi under impulse loads with short durations; however, this 50 ksi assumption will not influence the data as long as the yield strength is consistent between the multi-degree-of-freedom (MDOF) and single-degree-of-freedom (SDOF) analyses.

As shown in Figure $\mathbf{H}$, the material is assumed to behave elastic, perfectly plastic. Elastic, perfectly plastic means that $\mathrm{f}_{\mathrm{y}}$ is the absolute maximum yield stress the material can see, and there is no residual stiffness beyond yield.

Verification and Expansion of Single-Degree-of-Freedom Transformation Factors for Beams Using a Multi-Degree-of-Freedom Non-Linear Numerical Analysis Method 


\subsection{Definitions of Blast Load types}

For this study, an explosion is defined as "an extremely rapid release of energy in the form of light, heat, sound, and a shock wave" (FEMA 427). In structural blast analysis and design, the shock wave defines the loading criteria. This study uses detonation, a type of explosion, as the source for the blast load. In a detonation, the shock wave travels faster than the speed of sound and the wave front causes an instantaneous rise in pressure to the atmosphere.

For any explosion, the charge weight and the standoff distance are used to determine the shock wave load at a given point. The pressure time history is based on TNT explosive weight and standoff. If any other explosive is used, equivalency charts are used to determine the equivalent TNT weight.

In this project, the structural component being studied is oriented perpendicular to the direction of the shock wave. The loading in this case is referred to as a reflected blast load; however, free-air explosions and side-on explosions are presented first to help explain the dynamics of reflected blast loads.

\subsubsection{Free-Air Explosions}

Free-air explosions describe blast wave parameters in the open: There is no material obstructing the wave. The point of interest is closer to the blast source than any other surface. The pressure change over time at a point in space is shown in Figure I. 


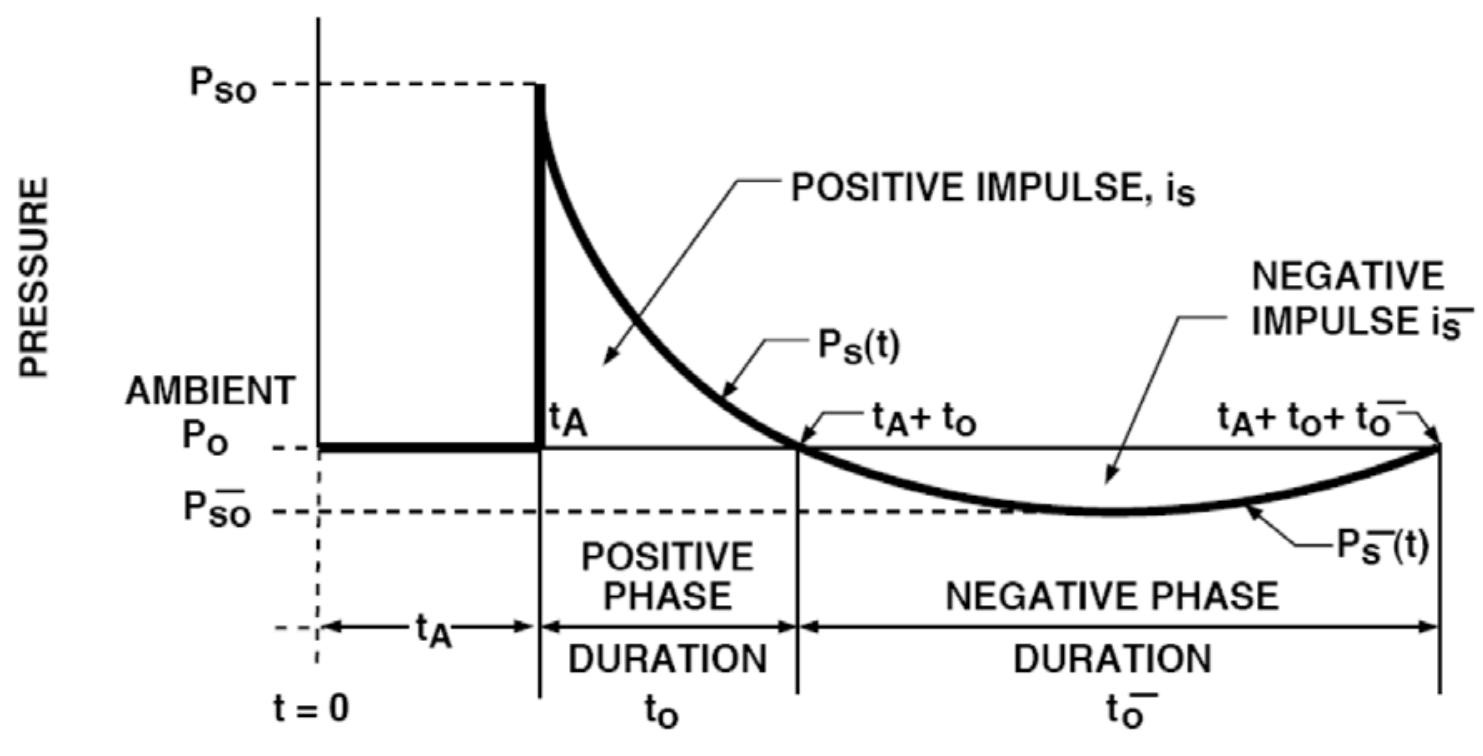

TIME AFTER EXPLOSION

Figure I: Typical pressure-time history of an airblast in free air Source: U.S. Army Corps of Engineers 2008

Figure I shows that the pressure suddenly increases as the blast wave-front hits the point of interest and decreases as the wave passes through the point of interest. Once the wave front passes through the point of interest, a negative phase is caused by a suction pressure right behind the wave. This suction pressure ends when the point of interest regains the atmospheric pressure.

\subsubsection{Side-On Explosions}

In most cases, there is a surface closer to the explosion than to the point in space under speculation, e.g. ground. This means that the point under speculation receives a reflected shock wave in addition to the direct shock wave. In this case, the two shock waves are assumed to travel simultaneously to form a hemispherical wave front. The 
combined shock wave peak pressure is approximately equal to 1.8 times a free-air explosion at any given point (U.S. Army Corps of Engineers 2008).

\subsubsection{Reflected Blast Loads}

Side-on loads can be used for components parallel to the shock wave direction. When the component orientation is not completely parallel to the shock wave direction, the component experiences reflected pressure. The difference in the angle of the component orientation relative to the blast source is called the angle of incidence. The peak pressure loaded on a given point on a component is the side-on pressure multiplied by the reflected pressure coefficient depending on the angle of incidence.

\subsection{Loading Assumptions}

The loading demands used in this project are based on the blast loading values and equations outlined in the SBEDS manual. All blast loads in SBEDS assume a hemispherical surface burst, with the pressure-time history identical to Figure I.

The positive phase of the blast load acts in the same direction as the shock wave. This positive phase is modeled by the equation below (U.S. Army Corps of Engineers 2008).

$$
P_{S}(t)=P_{S O}\left[1-\left(\frac{t-t_{A}}{t_{0}}\right)\right] e^{-\left(\frac{t-t_{A}}{\theta}\right)}
$$

Where: $\quad P_{s}(t)=$ shock overpressure as a function of time

$\mathrm{P}_{\mathrm{so}}=$ peak side-on overpressure

$\mathrm{t}=$ detonation time

$\mathrm{t}_{\mathrm{A}}=$ arrival time of initial shock front

$\mathrm{t}_{0}=$ positive phase duration

$\theta=$ shape constant of pressure waveform

Verification and Expansion of Single-Degree-of-Freedom Transformation Factors for Beams Using a Multi-Degree-of-Freedom Non-Linear Numerical Analysis Method 
The shape constant of pressure waveform can be solved for by taking the integral of Eq. 17 and setting it equal to the impulse; the parameters for this equation, along with the impulse value, can be found in Figure $\mathbf{J}$.

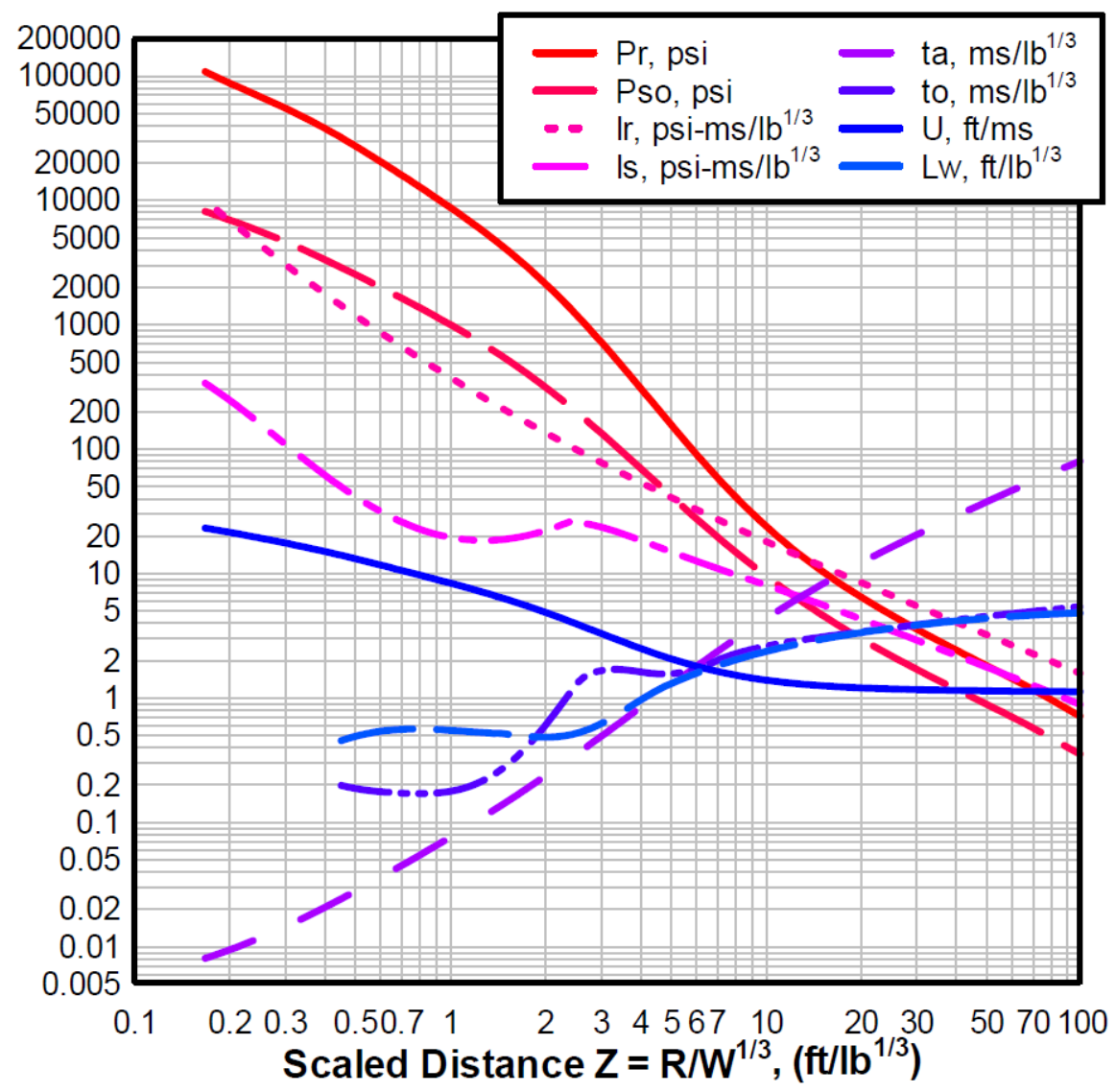

Figure J: Positive phase shock wave parameters for a hemispherical surface burst of TNT

Source: U.S Army Corps of Engineers 2008

Where: $\quad \operatorname{Pr}=$ peak reflected pressure $(\mathrm{psi})$

Pso $=$ peak side-on pressure $(\mathrm{psi})$

$\mathrm{Ir}=$ reflected impulse $\left(\mathrm{psi}-\mathrm{ms} / \mathrm{lb}^{1 / 3}\right)$

Is $=$ side-on impulse $\left(\mathrm{psi}-\mathrm{ms} / \mathrm{lb}^{1 / 3}\right)$

$\mathrm{ta}=$ arrival time of shock $\left(\mathrm{ms} / \mathrm{lb}^{1 / 3}\right)$

to $=$ shock (positive phase) duration $\left(\mathrm{ms} / \mathrm{lb}^{1 / 3}\right)$

$\mathrm{U}=$ shock front velocity $(\mathrm{ft} / \mathrm{ms})$

$\mathrm{Lw}=$ shock wavelength $\left(\mathrm{ft} / \mathrm{lb}^{1 / 3}\right)$

Verification and Expansion of Single-Degree-of-Freedom Transformation Factors for Beams Using a Multi-Degree-of-Freedom Non-Linear Numerical Analysis Method 
All the parameters can be read off Figure $\mathbf{J}$ given the scaled distance, $Z$. The scaled distance is a function of the blast standoff distance and the equivalent TNT mass of the blast. The equation to solve for the scaled distance is shown as:

$$
Z=\frac{R}{W^{1 / 3}}
$$

Where: $\quad \mathrm{R}=$ standoff distance from blast $(\mathrm{ft})$

$$
\mathrm{W}=\text { equivalent TNT mass (lbs) }
$$

The negative phase pressure time-history and equation in SBEDS is shown in Figure K.

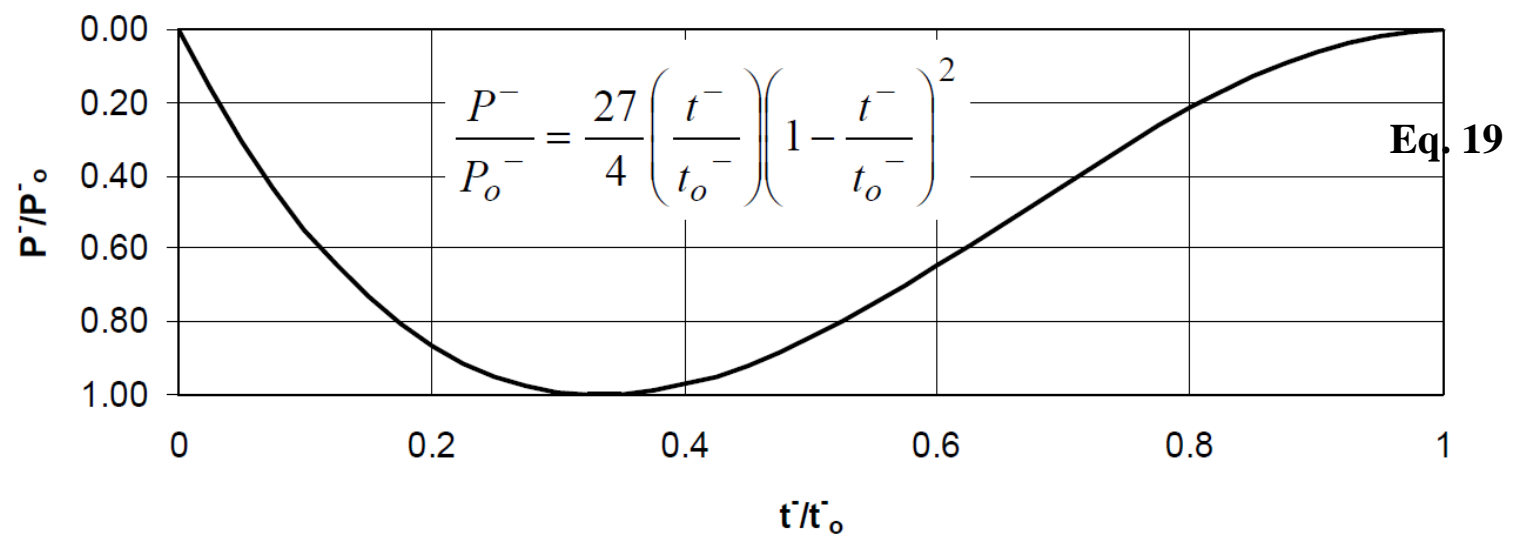

Figure K: Negative phase load pressure history

Source: U.S Army Corps of Engineers 2008

$$
\begin{gathered}
t^{-}=t^{1^{-}} C p^{-} \\
C p^{-}=\frac{i^{-}}{i^{1^{-}}}
\end{gathered}
$$

Eq. 21

Where: $\quad \mathrm{P}_{\mathrm{o}}^{-}=$peak negative pressure

$\mathrm{t}_{\mathrm{o}}{ }^{-}=$negative phase duration

$\mathrm{t}^{-}=$corrected time after first negative pressure determined from equation

$\mathrm{t} \mathrm{t}^{\prime}=$ time after first negative pressure

$\mathrm{Cp}^{-}=$correction factor for time after first negative pressure preserving actual impulse $\mathrm{i}^{-}$

$\mathrm{i}^{\prime-}=$ negative phase impulse calculated initially with integral of equation in Eq. 19 with $\mathrm{t}^{-}=\mathrm{t}^{\text {'- }}$

$\mathrm{i}^{-}=$actual negative phase impulse from empirical prediction method from Figure L.

Verification and Expansion of Single-Degree-of-Freedom Transformation Factors for Beams Using a Multi-Degree-of-Freedom Non-Linear Numerical Analysis Method 
Some of the parameters for Eq. 19 can be obtained from the figure below.

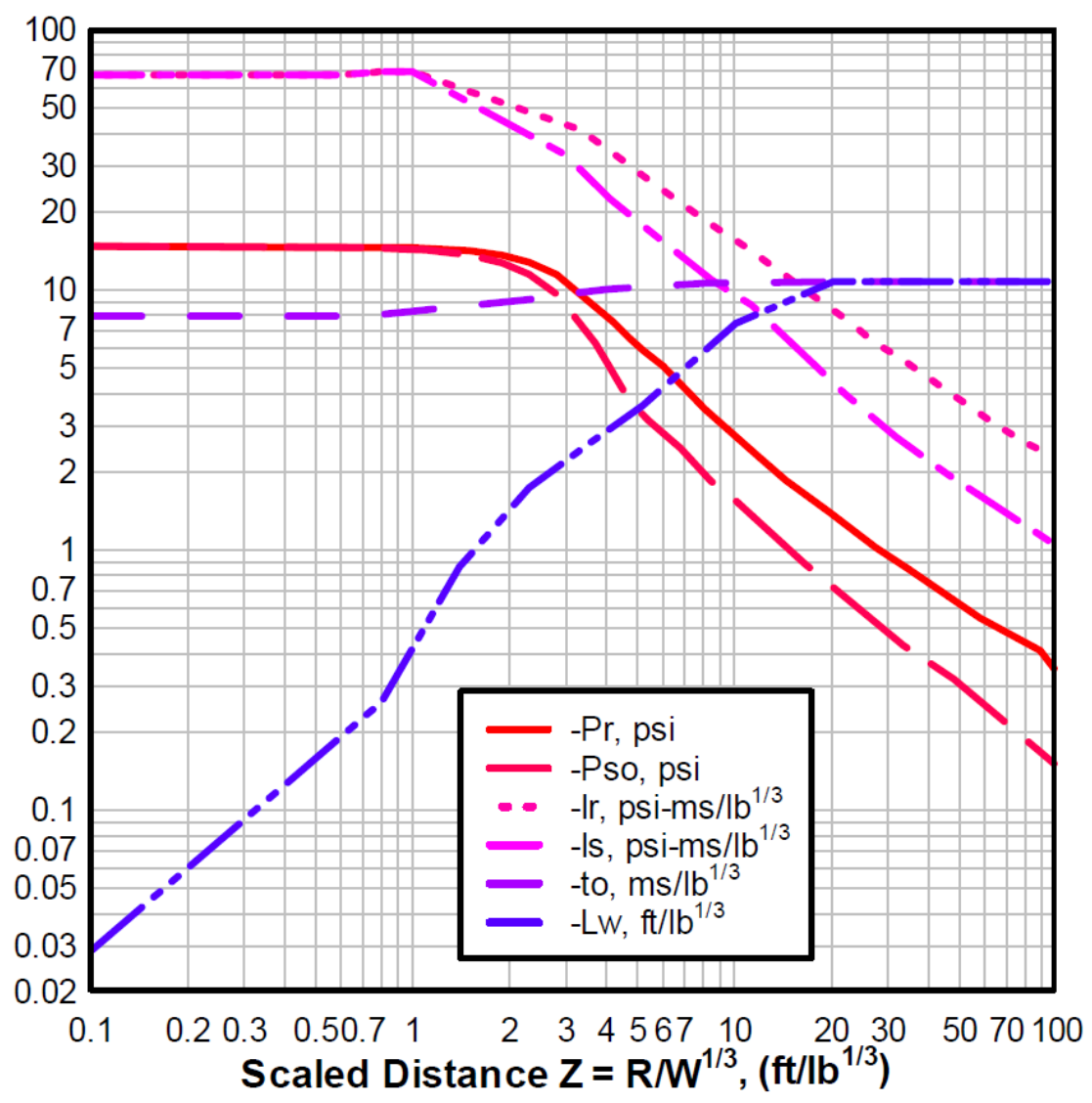

Figure L: Negative phase shock wave parameters for a hemispherical surface burst of TNT

Source: U.S Army Corps of Engineers 2008

Where: $\quad-\operatorname{Pr}=$ peak negative reflected pressure $(\mathrm{psi})$

$-\mathrm{Pso}=$ peak negative side-on pressure $(\mathrm{psi})$

$-\mathrm{Ir}=$ negative reflected impulse $\left(\mathrm{psi}-\mathrm{ms} / \mathrm{lb}^{1 / 3}\right)$

-Is $=$ negative side-on impulse $\left(\mathrm{psi}-\mathrm{ms} / \mathrm{lb}^{1 / 3}\right)$

-to $=$ shock (negative phase) duration $\left(\mathrm{ms} / \mathrm{lb}^{1 / 3}\right)$

$-\mathrm{LW}=$ negative shock wavelength $\left(\mathrm{ft} / \mathrm{lb}^{1 / 3}\right)$

The pressure time history Figure $\mathbf{J}$ and Figure $\mathbf{L}$ are for side-on bursts. When the

shock wave hits a component, blast loads are reflected, and thus the pressure-time history

changes. Appropriate modifications can be made by examining the angle of incidence, $\alpha$.

Verification and Expansion of Single-Degree-of-Freedom Transformation Factors for Beams Using a Multi-Degree-of-Freedom Non-Linear Numerical Analysis Method 
The angle of incidence is $0^{\circ}$ when the blast wave front travels perpendicular to the component and 90 degrees when the blast wave front travels parallel to the component. The figure below shows values for the reflected pressure coefficient, $\mathrm{C}_{\mathrm{Ra}}$, which can be multiplied to the peak side-on pressure taken from Figure $\mathbf{J}$ and Figure $\mathbf{L}$.

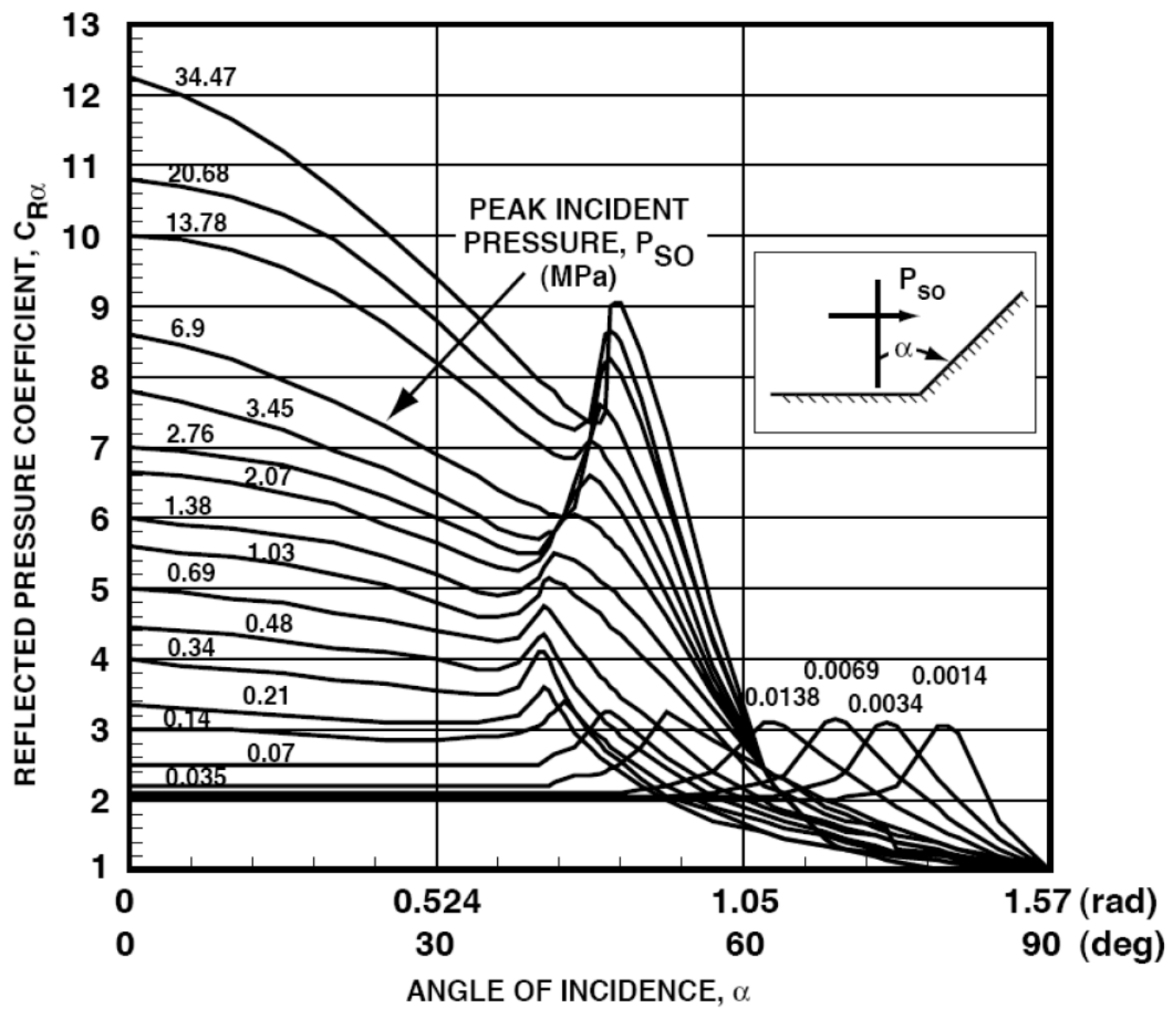

Figure M: Reflected pressure coefficient versus angle of incidence Source: U.S. Army Corps of Engineers 2008)

If the angle of incidence is 0 degrees, the peak pressure can be found from Figure $\mathbf{J}$ and, as $\mathrm{P}_{\mathrm{r}}$. Figure $\mathbf{N}$ shows the scaled reflected impulse due to the angle of incidence.

Verification and Expansion of Single-Degree-of-Freedom Transformation Factors for Beams Using a Multi-Degree-of-Freedom Non-Linear Numerical Analysis Method 


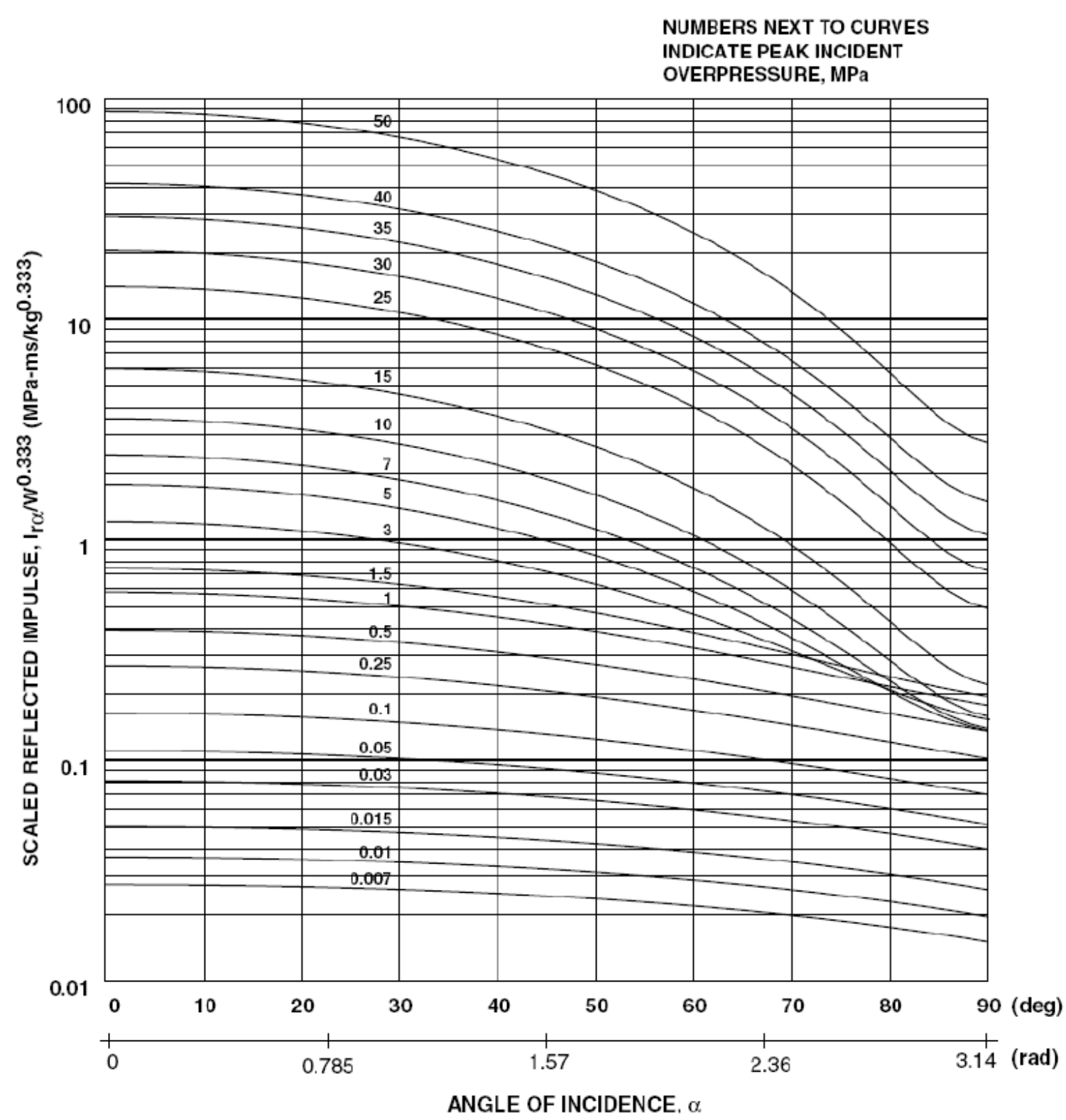

Figure N: Scaled reflected impulse versus angle of incidence

Source: U.S. Army Corps of Engineers 2008

As indicated by the vertical scale on Figure $\mathbf{N}$, the scaled reflected impulse can be multiplied to the cube root of the charge mass to obtain the reflected impulse.

Once the pressure history is derived, it is applied on the beam in several different patterns show below:

Verification and Expansion of Single-Degree-of-Freedom Transformation Factors for Beams Using a Multi-Degree-of-Freedom Non-Linear Numerical Analysis Method 


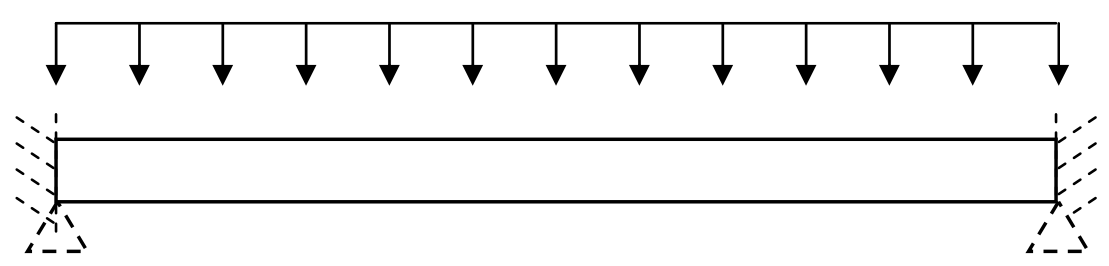

Figure O: Uniformly distributed loading pattern

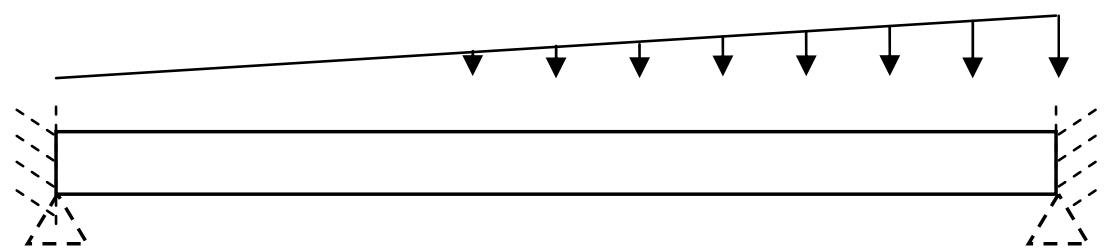

Figure P: Linearly distributed loading pattern

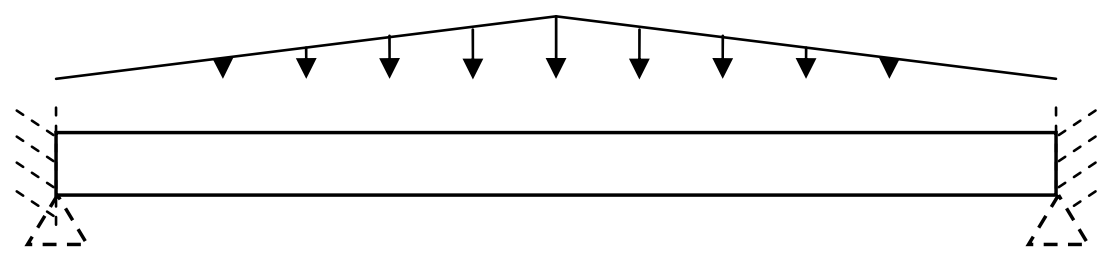

Figure Q: Triangular loading pattern

(With Peak Loading at the Midpoint of Beam)

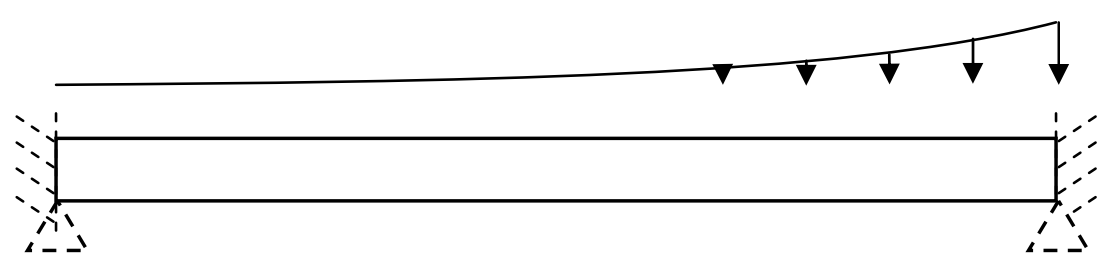

Figure R: Parabolic loading pattern 


\subsection{MATLAB ALGORITHM VERIFICATION}

Once the algorithm was written in Matlab, several checks were completed, and are shown in this Section. These checks were made to verify that the program works as intended and to minimize any code errors that may exist. The checks include: constant load, time-step variation, and the elastic limit, dynamic inelastic response vs. theoretical inelastic response.

All checks are done with the analysis set up described in Section 6.

\subsection{Constant Static Load}

With a constant static load applied during the analysis, the beam should deflect and oscillate with the average deflection around the theoretical static deflection. Figure $\mathbf{S}$ and Figure $\mathbf{T}$ below show the deflected shape of a 24 feet long, W24x131 beam, with both ends fixed, and with a uniform load of $12.1 \mathrm{klf}$. 


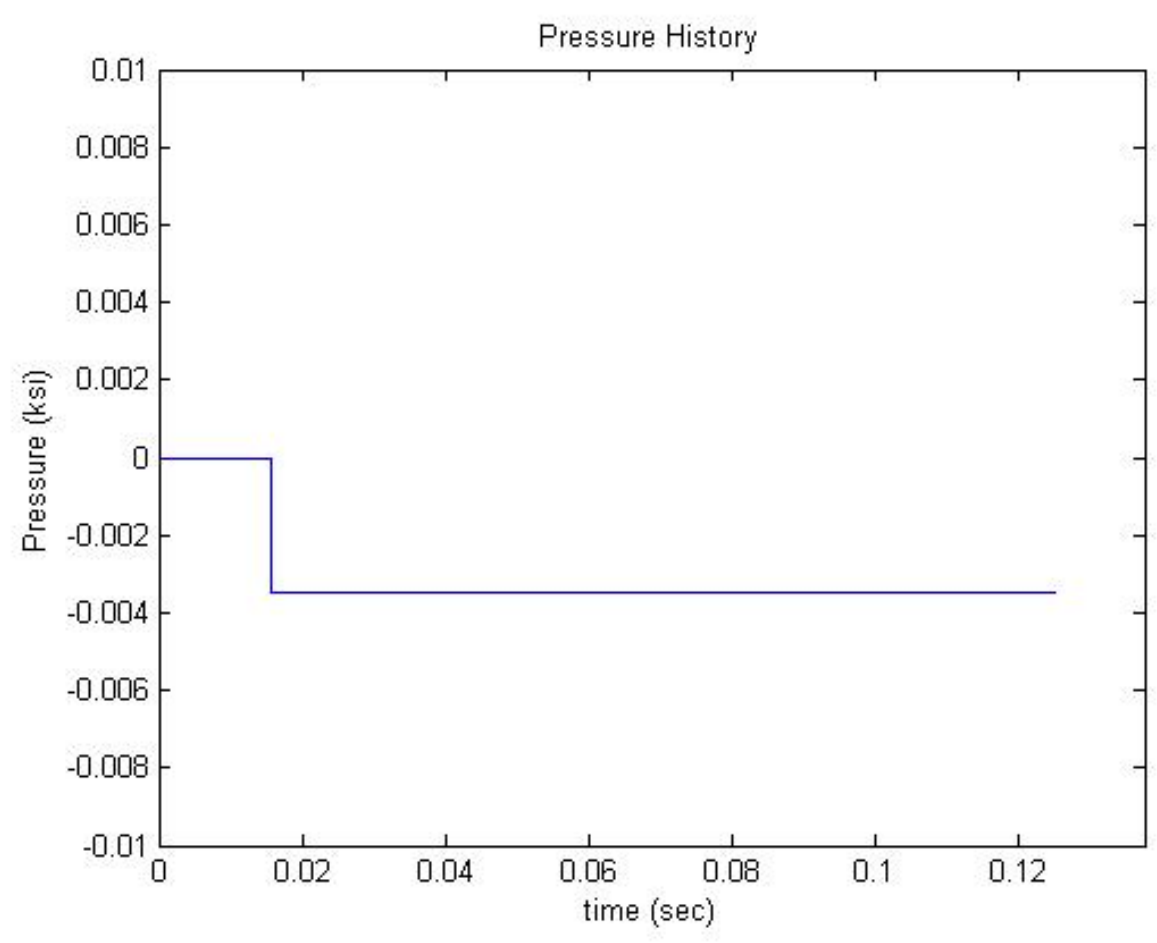

Figure S: Deflected shape with static load

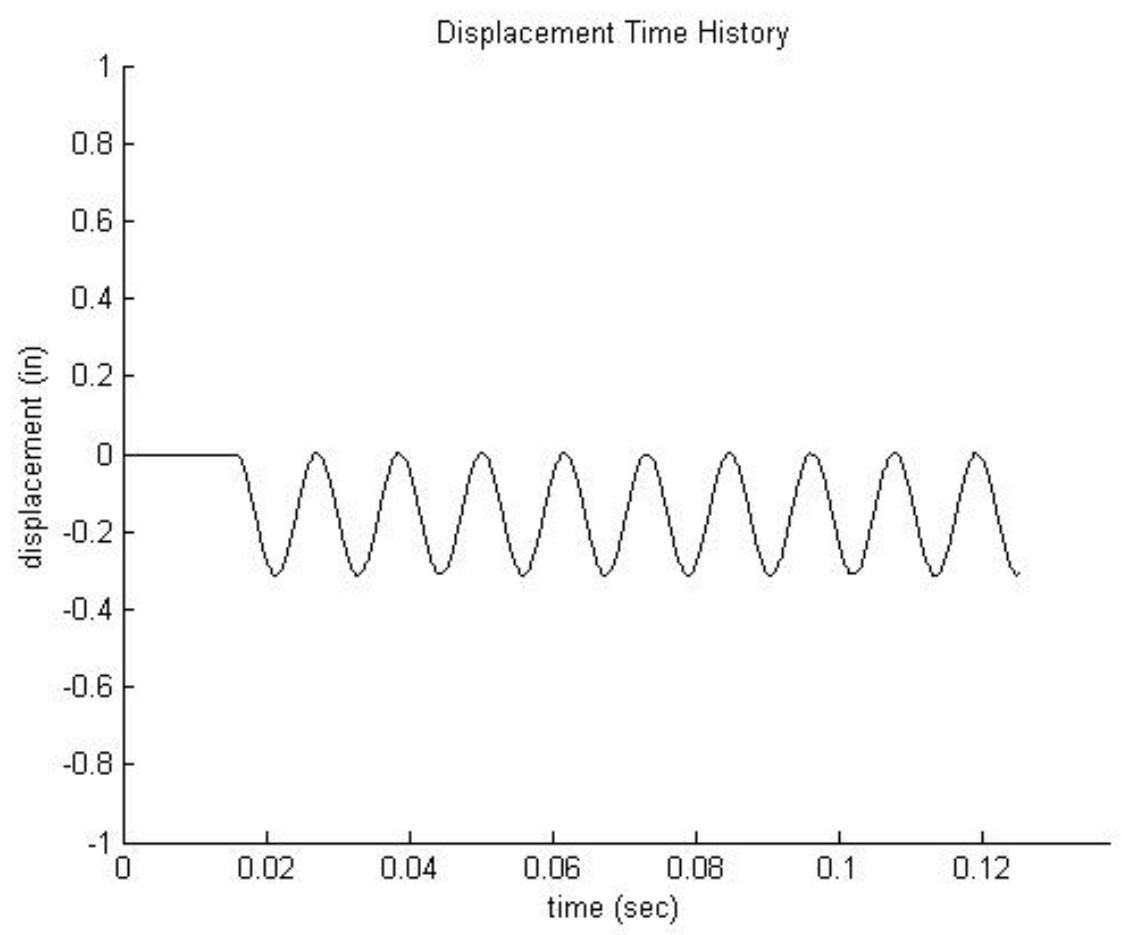

Figure T: Displacement time history with static load

Verification and Expansion of Single-Degree-of-Freedom Transformation Factors for Beams Using a Multi-Degree-of-Freedom Non-Linear Numerical Analysis Method 
The constant load is introduced after a few milliseconds as shown in the figures.

Once the load is applied, the system has an average period of 0.0115 seconds, and oscillates between 0.00408 inches and -0.31387 inches with an average deflection of 0.1549 inches. This is consistent with the theoretical first-mode period of $T_{n}=\frac{2 \pi}{\sqrt{k / m}}=0.0115$ seconds (solved using equivalent SDOF model with Biggs' factors), the theoretical amplitude of $u(t)=\left(u_{s t}\right)_{0}(1-\cos (\sqrt{k} / m \times t))=0.31$ inches, and the theoretical static deflection of $\delta(.5 x)=\frac{w l^{4}}{384 E I}=0.1550 \mathrm{in}$.

\subsection{Time Step Variation}

For Newmark's average acceleration method, (Weaver and Johnston 1987) suggest a timestep $\left(\Delta_{t}\right)$ equal to $T_{n} / 5$, where $T_{n}$ is the period of the highest mode, to ensure accuracy for all modes: however, also states that $T_{n} / 10$ is commonly used. Chopra (2007) and Weaver and Johnston (1987) both show proof that the average acceleration method is unconditionally stable. This study includes the following exploration of timestep variation vs. accuracy using the average acceleration method for the beam shown below in Figure U.

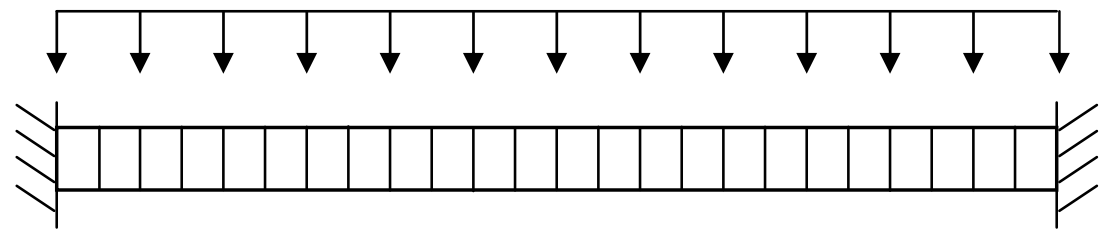

Figure U: 24 Ft, 24-Element, uniformly loaded W24x131 beam with fixed ends

Verification and Expansion of Single-Degree-of-Freedom Transformation Factors for Beams Using a Multi-Degree-of-Freedom Non-Linear Numerical Analysis Method 
The beam in Figure U is a 24 foot, 24-element, uniformly loaded W24x131 with fixed ends. The analyses are tested on a TNT equivalent scaled distance $(Z)$ of $12 \mathrm{ft} / \mathrm{lbs}^{3}$ (the pressure and impulse values are located on Table 11). For reference, the period of the $46^{\text {th }}$ mode is $8.96 \times 10^{-6}$ seconds $\left(8.96 \times 10^{-3} \mathrm{~ms}\right)$. Using the rule of thumb for Newmark's linear acceleration method, the timestep of $\mathrm{T}_{\mathrm{n}} / 10$ (or $8.96 \times 10^{-7}$ seconds) is used as the base timestep. Assuming $\mathrm{T}_{\mathrm{n}} / 10$ will provide the exact answer for maximum displacement, the timestep variation study checks how the maximum displacement varies with increasing timesteps. Percent error is calculated relative to the response for timestep equal to $\mathrm{T}_{\mathrm{n}} / 10$. Figure $\mathbf{V}$ below shows the percent error trend with varying timesteps.

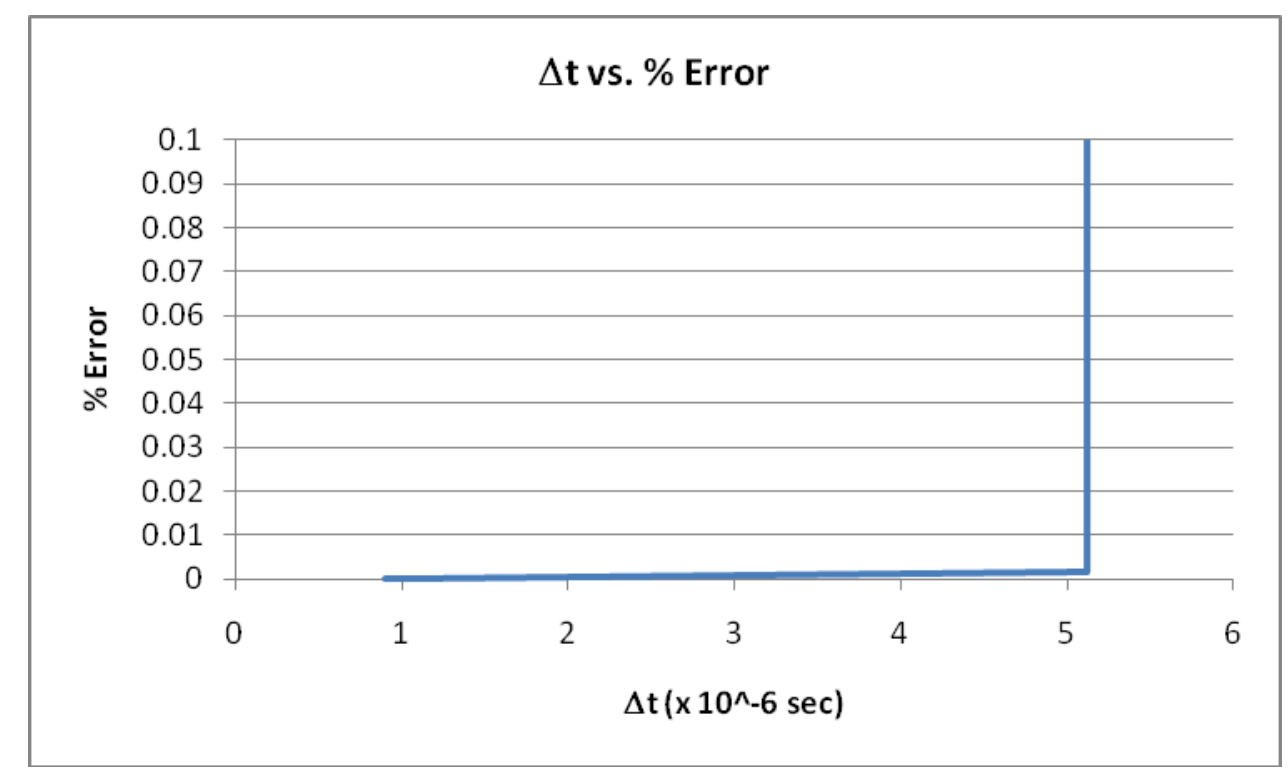

Figure V: $\Delta \mathrm{t}$ vs. \% error for $24 \mathrm{ft}$ fixed end beam with uniform loading

$$
\left(\mathrm{Z}=12 \mathbf{f t} / \mathbf{l b s}^{3}\right)
$$

The percent error of the solution gradually increases until $\Delta \mathrm{t}=5.1 \times 10^{-6} \mathrm{sec}$ (about $\mathrm{T}_{\mathrm{n}} / 1.8$ ), at which point the analysis is no longer producing a reasonable solution. This shows that the program is accurate at the suggested $\Delta t=T_{n} / 5$ suggested by Weaver Verification and Expansion of Single-Degree-of-Freedom Transformation Factors for Beams Using a Multi-Degree-of-Freedom Non-Linear Numerical Analysis Method 
and Johnston (1987), and this limit of $\Delta t=T_{n} / 5$ is not an issue for the Matlab program. This accuracy graph should show a gradual increase in percent error ${ }^{2}$, indicating a possible error in the program. In order to keep the solution accurate in all cases, the study uses a timestep of $5.0 \times 10^{-7} \mathrm{sec}$. For the W24x131 spanning 24 feet with fixed ends, this timestep is equivalent to about $\mathrm{T}_{46} / 18$. For the W24x131 spanning 24 feet with pinned ends, this timestep is equivalent to about $\mathrm{T}_{48} / 18$. Note that the fixed degrees of freedom are taken out of the matrices in the analysis iterations. The study suggests that the $46^{\text {th }}$ mode and the $48^{\text {th }}$ mode for the fixed ends and pinned ends cases respectively, are the highest important modes for accuracy.

\subsection{Elastic Limit}

The elastic limit check shows that the system can switch back and forth between elastic behavior and inelastic behavior on a 24 feet long W24x131 beam, fixed on both ends. The loading pressure is scaled to a magnitude of $0.2 \mathrm{ksi}$, which forces the beam to barely reach the elastic limit state. This switch can be shown through the moment vs. rotation hysteresis, Figure $\mathbf{X}$.

${ }^{2}$ Personal correspondence between Graham Archer, Ph.D., and Takayuki Yokoyama on March 31, 2011. 


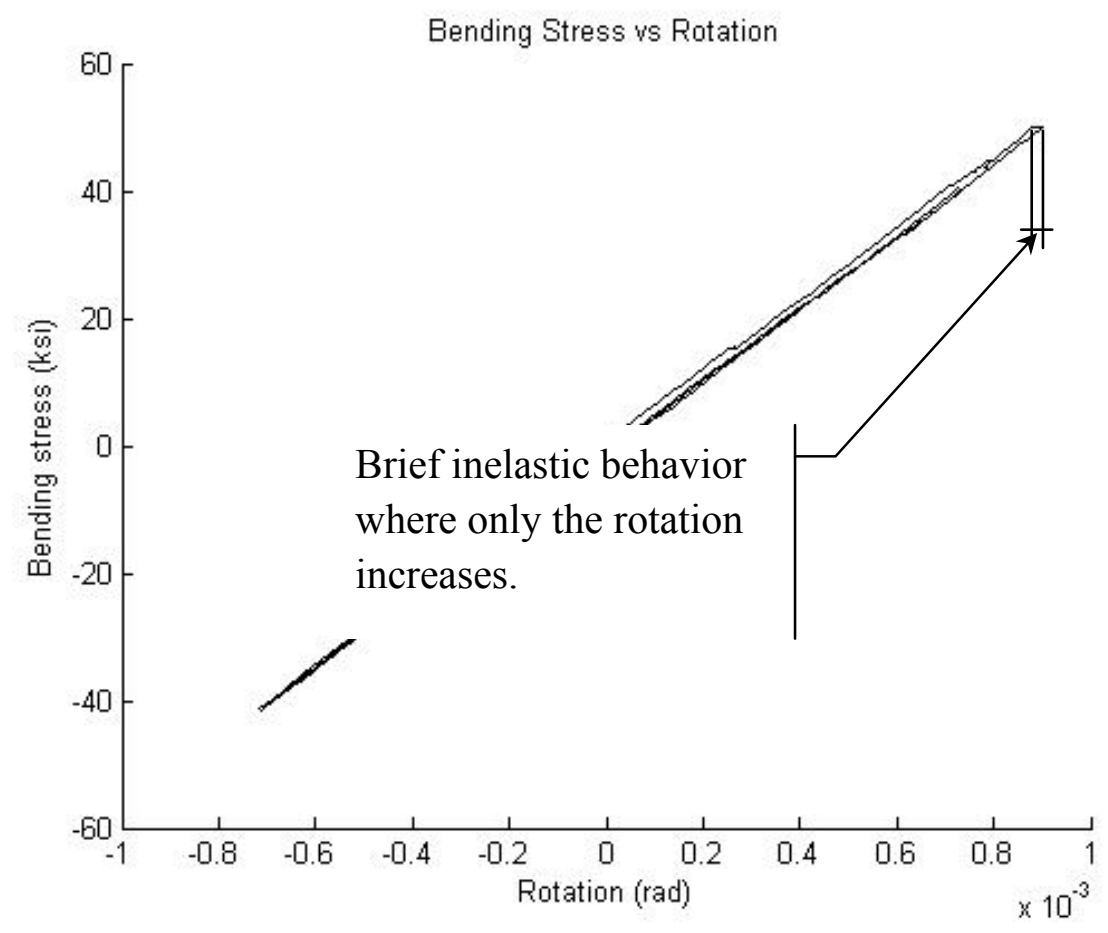

Figure W: Bending stress at fixed end vs. rotation

As expected, the moment vs. rotation figure shows that the there is a linear relationship between the moment stress and rotation until the moment stress reaches 50 ksi. Once the moment stress reaches $50 \mathrm{ksi}$, the figure shows little inelastic behavior where only the rotation continues to increase, the element then snaps back to elastic behavior. While the ends go plastic, the midspan stays elastic as shown in Figure $\mathbf{X}$. 


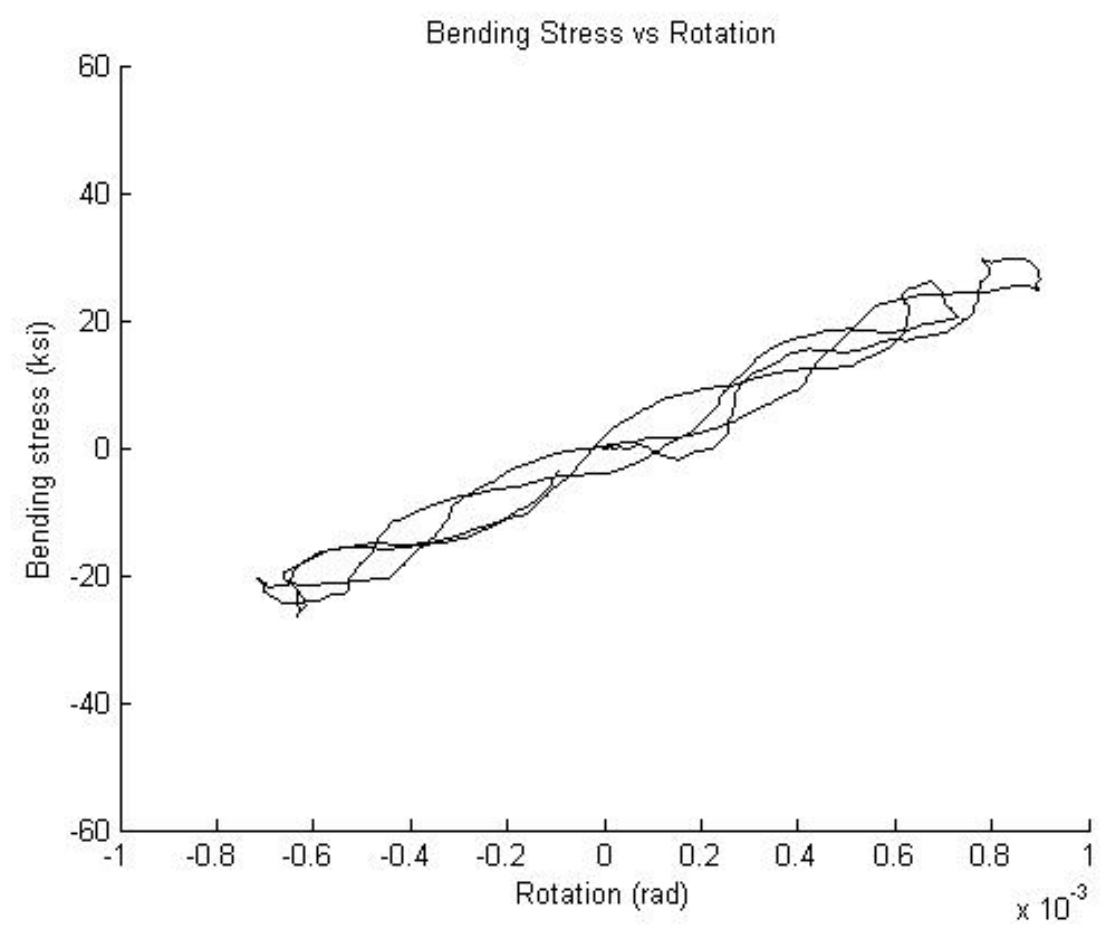

Figure X: Bending stress at midspan vs. rotation

Two quick observations can be made from the figure above. The first is that the bending versus rotation relationship is not perfectly linear. This non-linear relationship is probably due to multiple modes being activated by the fast and high-impulse loading. The second observation is that the maximum bending stress is about $25 \mathrm{ksi}$ as expected, which is half of the bending stress at the two fixed ends. The two observations can also be seen in Figure Y. 


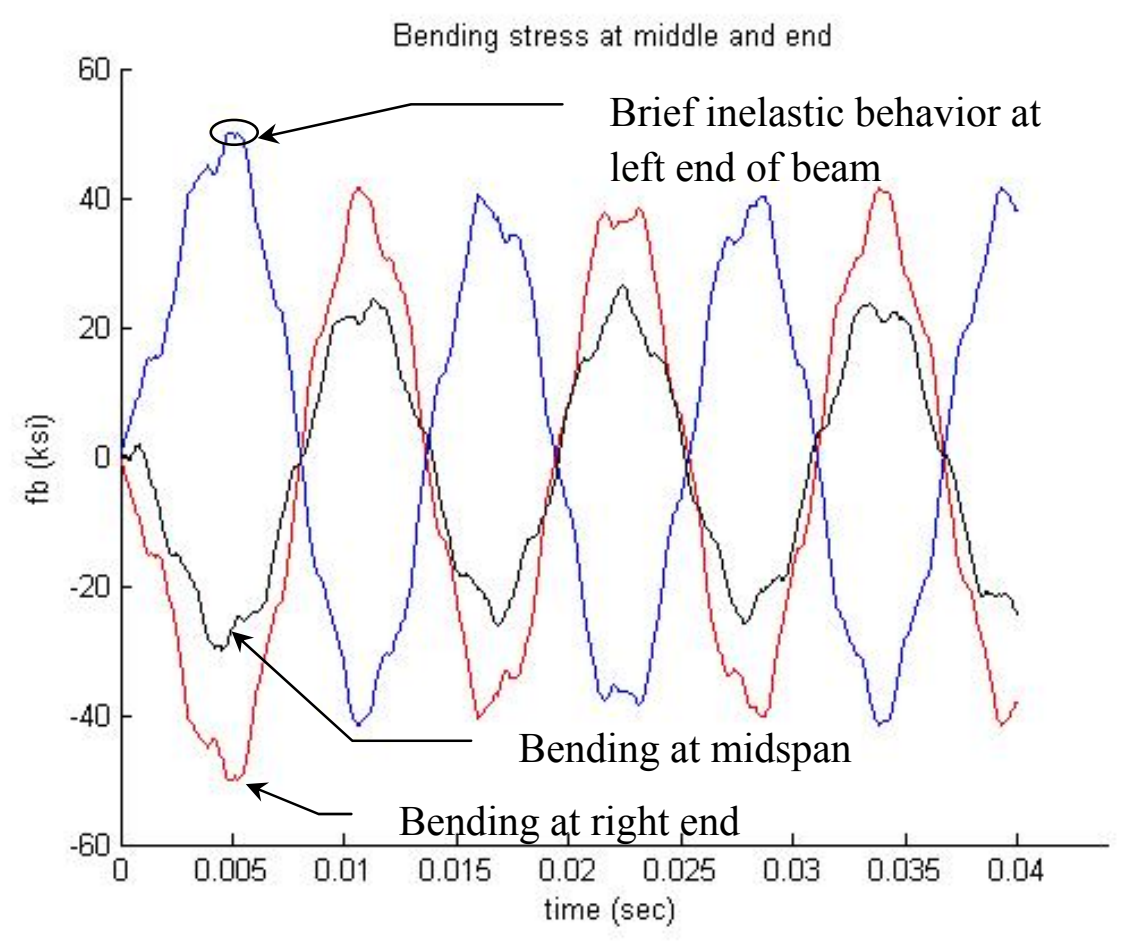

Figure Y: Bending stress time history with brief inelastic behavior

The figure above shows the bending stress time history at both ends and the midspan. Again, the stress limit is at $50 \mathrm{ksi}$ and the ends of the beam shows a brief instance of inelastic behavior while the stress at the midspan is about half the stress compared to the two ends.

\subsection{Inelastic Behavior}

The inelastic behavior check shows the change in overall stiffness of the beam as it is loaded. Figure $\mathbf{Z}$ below shows the resistance (as defined in Section 2.1.3) versus displacement relationship for four time histories compared to the theoretical SDOF relationship defined by Biggs. 


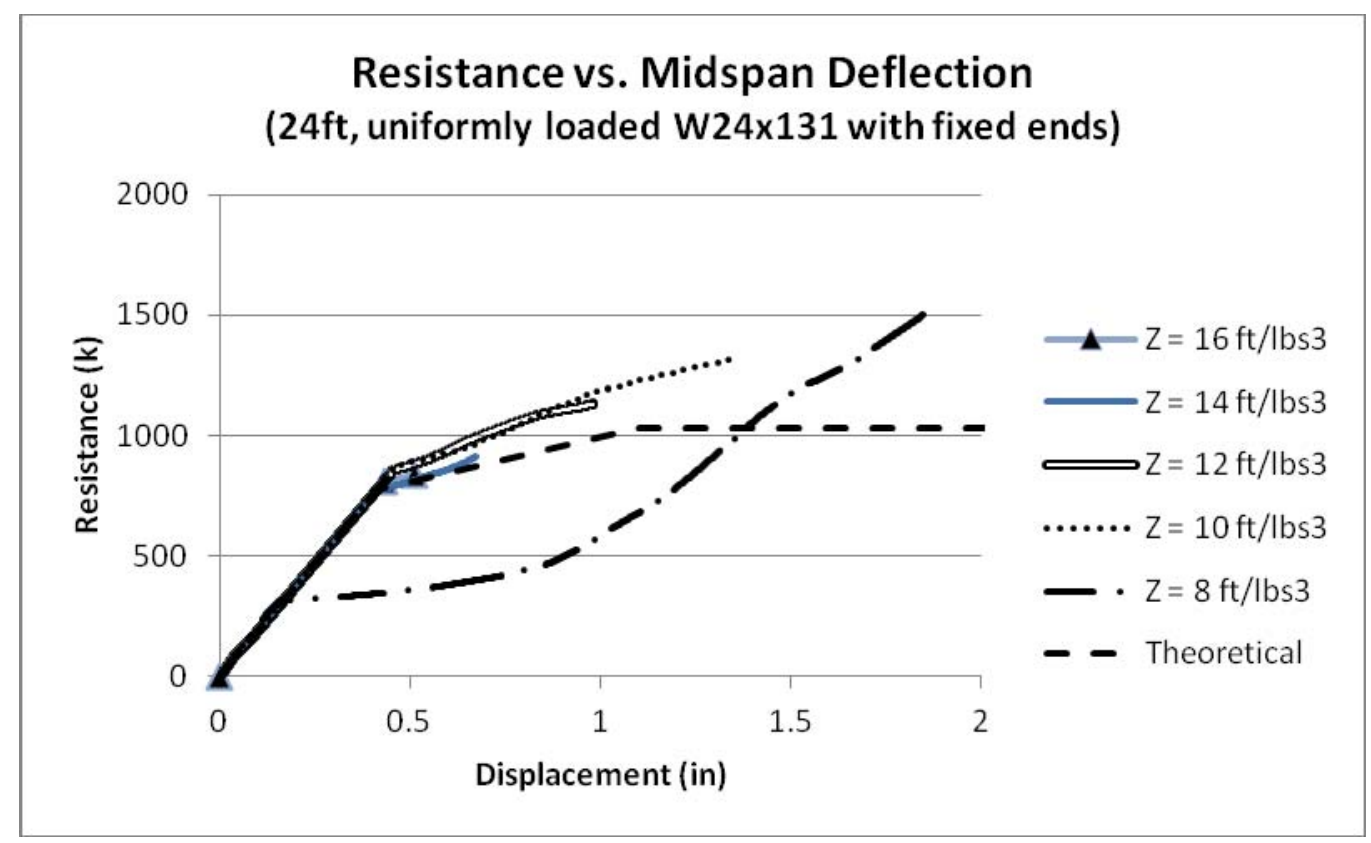

Figure Z: Resistance vs. displacement relationship

The figure above shows the resistance versus displacement time history for TNT scaled distances $(\mathrm{Z})$ of $16 \mathrm{ft} / \mathrm{lbs}^{3}, 14 \mathrm{ft} / \mathrm{lbs}^{3}, 12 \mathrm{ft} / \mathrm{lbs}^{3}, 10 \mathrm{ft} / \mathrm{lbs}^{3}$, and $8 \mathrm{ft} / \mathrm{lbs}^{3}$. Note that the resistance versus displacement time history goes as far as the maximum displacement, and the elastic oscilation after the peak deflection is not included in the plots. The fifth plot is the theoretical resistance vs. displacement relationship for a SDOF idealization as defined by Biggs. In all cases, the stiffness for the elastic range match the theoretical stiffness. The first kink in any line represents hinge formation at the beam ends, and the beam transitions into an elasto-plastic behavior. The second kink in the theoretical line indicates the hinge in the midspan of the beam, at which point the system theoretically becomes perfectly plastic. This perfectly plastic behavior assumption is not reflected in the MDOF response because hinges still resist rotation, and the other elements continue to absorb more force. The mismatch between the theoretical SDOF response and the 
MDOF response after the midspan hinge is more of a reflection of the SDOF system's shortcoming in the nonlinear behavior assumption.

For the $\mathrm{Z}=8 \mathrm{ft} / \mathrm{lbs}^{3}$ case, the nonlinear behavior starts at a low resistance value of about $320 \mathrm{k}$ while the other cases show nonlinear behavior at around $700-800 \mathrm{k}-$ this behavior is noticed in every case at low $\mathrm{Z}$ values (discussed in Section 8.3). This discrepancy is consistent with the observation of (Lawver et al. 2003) that the SDOF method is unable to predict the component behavior for close or large charges. Figure AA through Figure MM are shown below to further explore this $Z=8 \mathrm{ft} / \mathrm{lbs}^{3}$ case. 


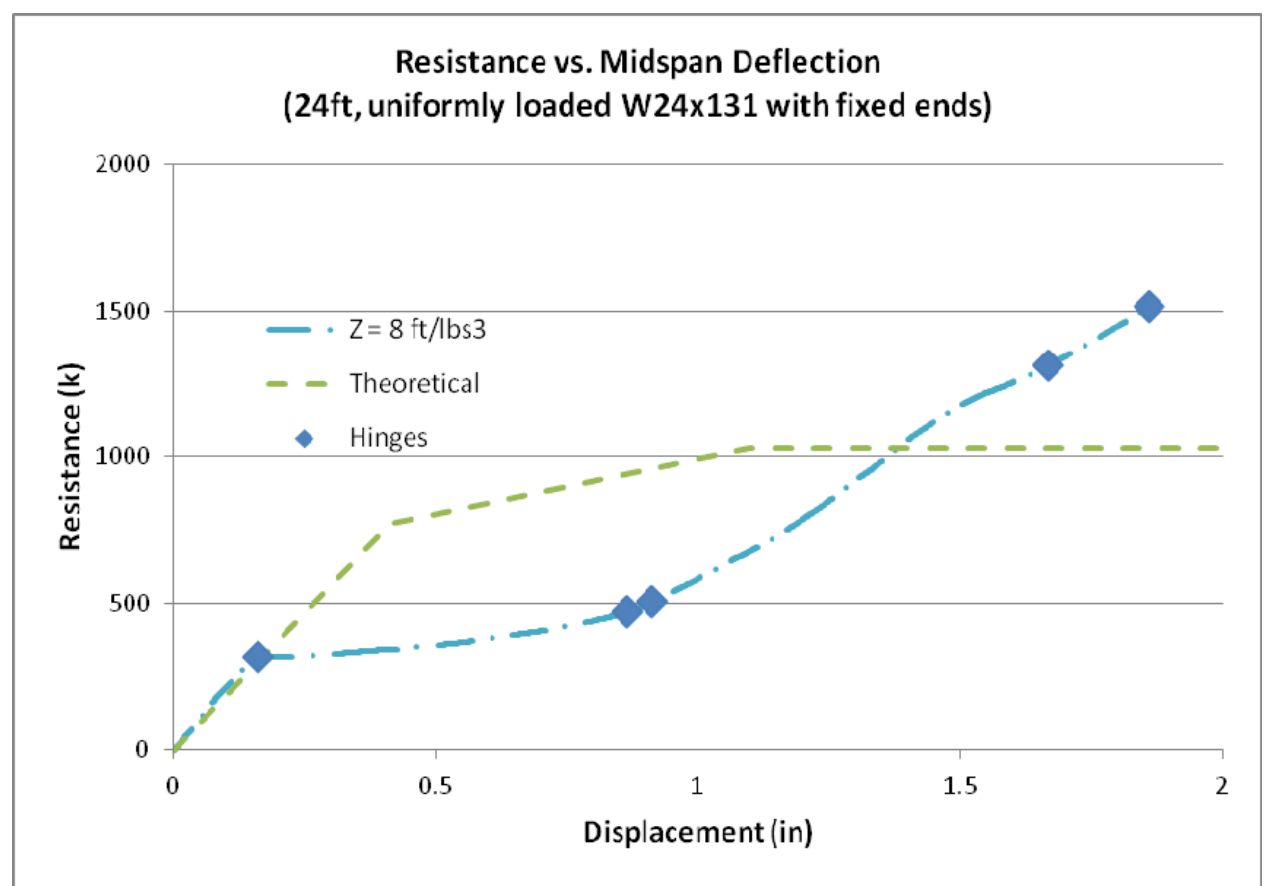

Figure AA: Resistance vs. Midspan Deflection of $24 \mathrm{ft}$, uniformly loaded W24x131 with fixed ends, loaded by blast with a $\mathrm{Z}=8 \mathrm{ft} / \mathrm{lbs} 3$

Bending Stress Diagram at $0.000902 \mathrm{sec}$

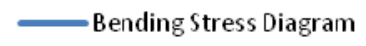

- Hinges

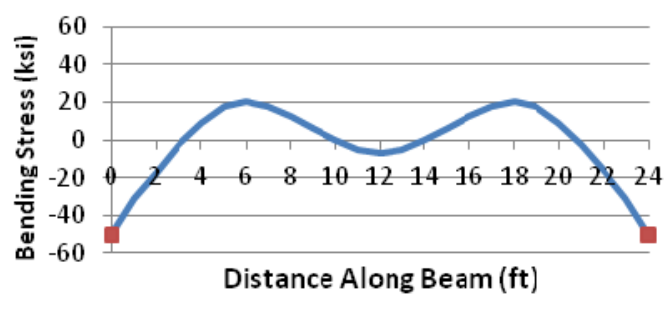

Figure BB: Bending stress diagram for $\mathrm{Z}=\mathbf{8 f t} \mathrm{t} / \mathrm{lbs} 3$ at $\mathrm{t}=\mathbf{0 . 0 0 0 9 0 2}$ seconds
Deflected Shape at $0.000902 \mathrm{sec}$

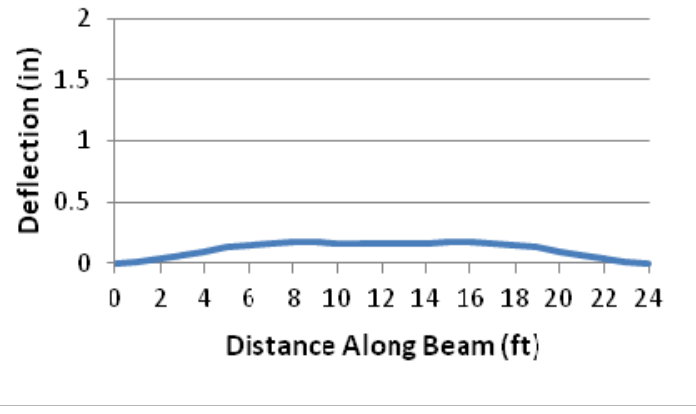

Figure CC: Deflected shape diagram for $\mathrm{Z}=\mathbf{8 f t} / \mathrm{lbs} 3$ at $\mathrm{t}=\mathbf{0 . 0 0 0 9 0 2}$ seconds

Verification and Expansion of Single-Degree-of-Freedom Transformation Factors for Beams Using a Multi-Degree-of-Freedom Non-Linear Numerical Analysis Method 
Bending Stress Diagram at $0.002046 \mathrm{sec}$

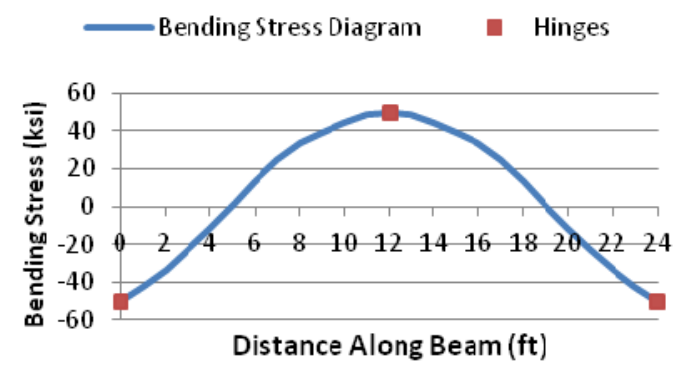

Figure DD: Bending stress diagram for $\mathrm{Z}=\mathbf{8 f t} / \mathrm{lbs} 3$ at $\mathrm{t}=\mathbf{0 . 0 0 2 0 4 6}$ seconds

Bending Stress Diagram at $0.002112 \mathrm{sec}$

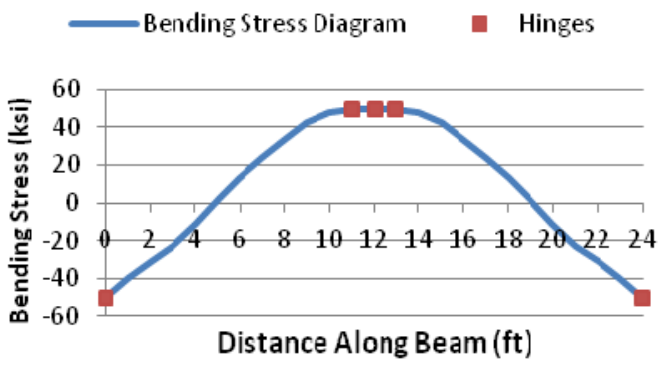

Figure FF: Bending stress diagram for $\mathrm{Z}=\mathbf{8 f t} \mathrm{t} / \mathrm{lbs} 3$ at $\mathrm{t}=\mathbf{0 . 0 0 2 1 1 2}$ seconds

Bending Stress Diagram at $0.003133 \mathrm{sec}$

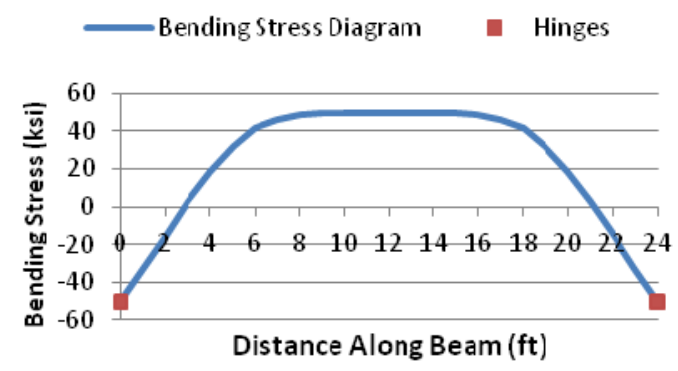

Figure $\mathrm{HH}$ : Bending stress diagram for $\mathrm{Z}=\mathbf{8 f t} \mathrm{t} / \mathrm{lbs} 3$ at $\mathrm{t}=\mathbf{0 . 0 0 3 1 3 3}$ seconds

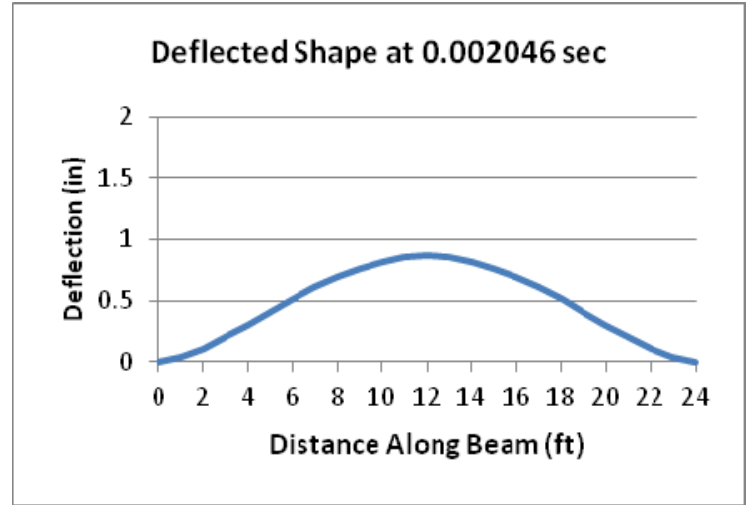

Figure EE: Deflected shape diagram for $\mathrm{Z}=\mathbf{8 f t} \mathrm{t} / \mathrm{lbs} 3$ at $\mathrm{t}=\mathbf{0 . 0 0 2 0 4 6}$ seconds

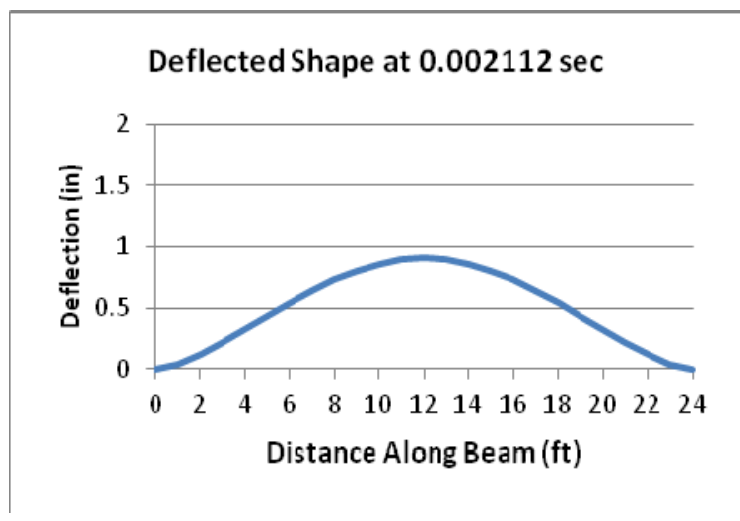

Figure GG: Deflected shape diagram for $\mathrm{Z}=\mathbf{8 f t} / \mathrm{lbs} 3$ at $\mathrm{t}=\mathbf{0 . 0 0 2 1 1 2}$ seconds

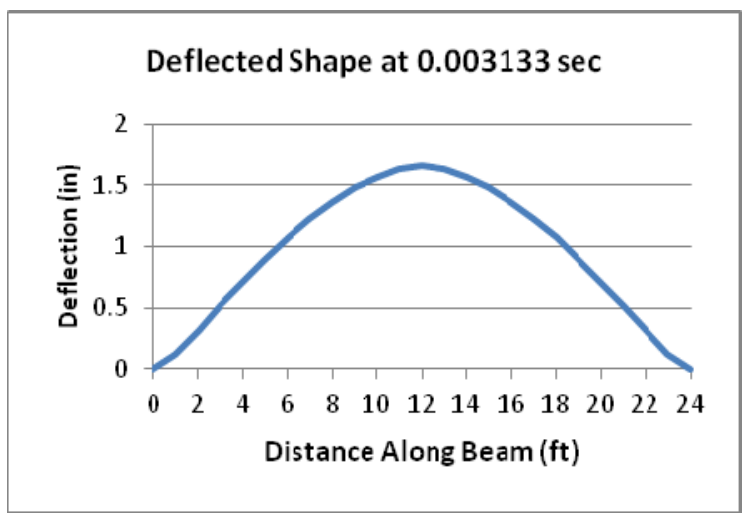

Figure II: Deflected shape diagram for $\mathrm{Z}=\mathbf{8 f t} / \mathrm{lbs} 3$ at $\mathrm{t}=\mathbf{0 . 0 0 3 1 3 3}$ seconds

Verification and Expansion of Single-Degree-of-Freedom Transformation Factors for Beams Using a Multi-Degree-of-Freedom Non-Linear Numerical Analysis Method 


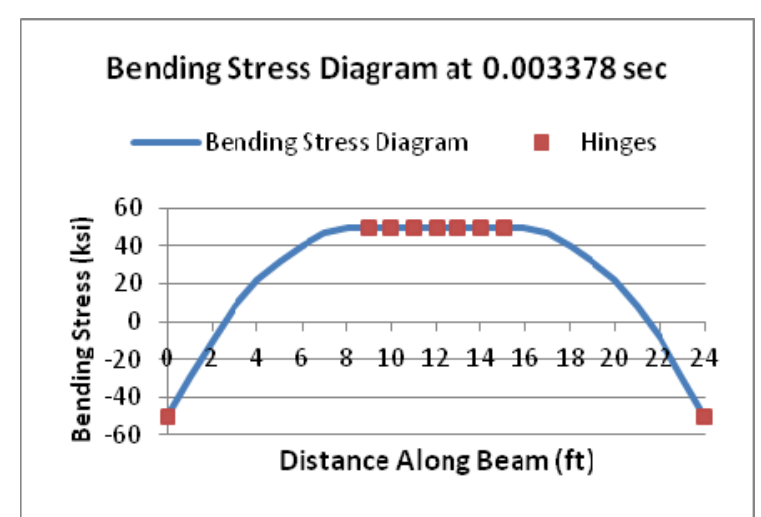

Figure JJ: Bending stress diagram for

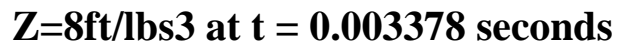

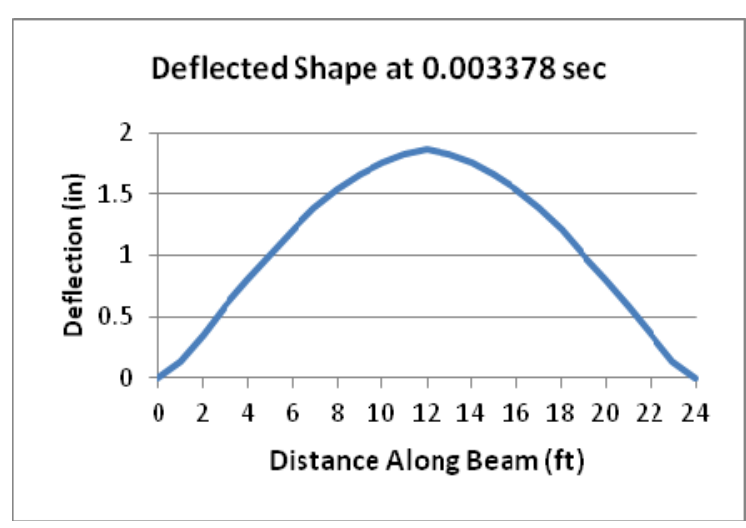

Figure KK: Deflected shape diagram for $\mathrm{Z}=\mathbf{8 f t} / \mathrm{lbs} 3$ at $\mathrm{t}=\mathbf{0 . 0 0 3 3 7 8}$ seconds

This unexpected response is likely related to the load magnitude and application time. When the load is applied fast, there is no time to develop a quasi-static deflected shape with the same hinging sequence as the theoretical SDOF system. This is shown in

Figure BB. The hinges on the ends occur as expected; however, the bending diagram and the deflected shape do not reflect what is expected from a quasi-static case. In other words, the fast loading affects beam stresses locally before the beam can distribute the load globally and respond like a statically loaded beam. As shown in Figure Z, the lesser magnitude and slower application of the load has enough time to develop the quasi-static deflected shape and follows the SDOF resistance curve.

The inelastic behavior check confirms that the MDOF Matlab program written for this study captures the inelastic response to blast demands better than the SDOF method. 


\subsection{ANALYSIS DATA}

\subsection{Calculating Equivalent SDOF Factors}

The multi-degree-of-freedom (MDOF) numerical analysis allows for a new and different way, from Biggs, to derive the equivalent single-degree-of-freedom (SDOF) factors. The following subsections describe how the data taken from the MDOF is used to create the equivalent SDOF factors.

\subsubsection{Stiffness Values}

The Biggs method of creating the stiffness value was discussed in Section 2 and an example derivation is given in Section 11.1. The stiffness values for a beam using Biggs and the MDOF method are the same because the values are based on static deflection.

The first study for producing stiffness values takes a simply supported beam with triangular loading, and varies the element mesh size. Using the MDOF method with static loads, the values using different mesh sizes are tabulated, in Table 7, against the theoretical stiffness values. 
Table 7: Stiffness values for simply supported beam, triangular loading

- Theoretical vs. MDOF

E 29000 ksi

I 4020 in $^{4}$

peak load $2.4 \mathrm{klf}=0.2 \mathrm{in} / \mathrm{ft}$

length $24 \mathrm{ft} \quad=288$ in

Total load (k) $\quad 28.8 \quad \mathrm{k}$

\begin{tabular}{|ll|c|c|c|c|}
\hline \multicolumn{2}{|c|}{ Mesh Size } & $\begin{array}{c}\text { Matlab } \\
\text { Deflection } \\
\text { (in) }\end{array}$ & $\mathrm{X}$ & $\begin{array}{c}\text { Beam } \\
\text { Chart } \\
\text { X }\end{array}$ & \% diff \\
\hline $6 \mathrm{ft}$ & (4 elements) & 0.0884 & 66.78 & 60.00 & $11.30 \%$ \\
\hline $3 \mathrm{ft}$ & (8 elements) & 0.0958 & 61.59 & 60.00 & $2.65 \%$ \\
\hline $2 \mathrm{ft}$ & (12 elements) & 0.0972 & 60.70 & 60.00 & $1.17 \%$ \\
\hline $1.5 \mathrm{ft}$ & (16 elements) & 0.0977 & 60.39 & 60.00 & $0.65 \%$ \\
\hline $1.2 \mathrm{ft}$ & (20 elements) & 0.0979 & 60.25 & 60.00 & $0.42 \%$ \\
\hline $1 \mathrm{ft}$ & (24 elements) & 0.0981 & 60.17 & 60.00 & $0.28 \%$ \\
\hline $0.5 \mathrm{ft}$ & (48 elements) & 0.0983 & 60.04 & 60.00 & $0.07 \%$ \\
\hline $0.25 \mathrm{ft}$ & (96 elements) & 0.0983 & 60.01 & 60.00 & $0.02 \%$ \\
\hline
\end{tabular}

Where $\quad \mathrm{X}=([$ total load $] /[$ Matlab deflection $]) *\left(\mathrm{~L}^{3} / \mathrm{EI}\right)$

Beam Chart $\mathrm{X} \quad=\left(\mathrm{EI} / \mathrm{L}^{3}\right) /[$ max deflection per AISC $]$

The table above is represented in Figure LL.

Verification and Expansion of Single-Degree-of-Freedom Transformation Factors for Beams Using a Multi-Degree-of-Freedom Non-Linear Numerical Analysis Method 


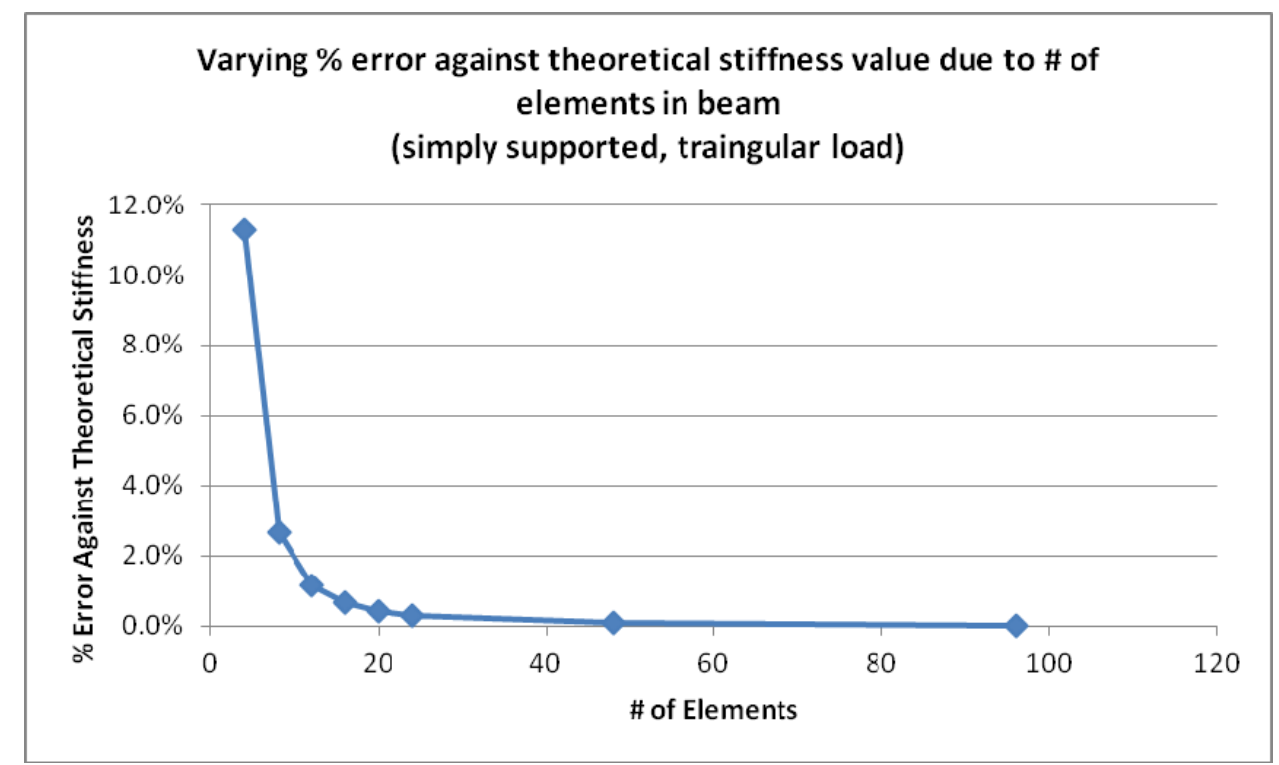

Figure LL: Varying \% error against theoretical stiffness value due to \# of elements in beam for a simply supported, triangularly loaded, $24 \mathrm{ft}$ long, W24x131

Table 7 and Figure LL show that as the mesh size decreases (meanwhile, the number of elements increase), the error of the stiffness value against the theoretical stiffness value also decreases. Given that the study is based on a $24 \mathrm{ft}$ beam, discretized to 24 elements, and that the stiffness value error is minimal, the rest of the stiffness values calculated by the MDOF program are also based on discretizing the beam into 24 elements.

To confirm that the stiffness value error is minimal for the other boundary condition and loading cases, the stiffness values for the cases below are compared to the theoretical stiffness values.

- Simply supported beam with uniformly distributed load (pin-pin uniform)

- Simply supported beam with linear loading starting with 0 klf on one end (pin-pin linear) 
- Simply supported beam, distributed load with peak loading in the middle (pin-pin triangular)

- Beam with fixed end supports and uniformly distributed load (fix-fix uniform)

The cases listed above are tabulated in Table 8.

Table 8: Stiffness values - beam charts vs. MDOF

\begin{tabular}{|c|c|c|c|c|c|}
\hline $\begin{array}{l}\text { E } \\
\text { I } \\
\text { peak load } \\
\text { length }\end{array}$ & $\begin{array}{r}29000 \\
4020 \\
2.4 \\
24 \\
\end{array}$ & $\begin{array}{l}\text { ksi } \\
\text { in } \\
\text { klf } \\
\mathrm{ft}\end{array}$ & $\begin{aligned} & 0.2 \mathrm{i} \\
&= 288 \mathrm{i} \\
&\end{aligned}$ & & \\
\hline $\begin{array}{c}\text { Boundary } \\
\text { Conditions and } \\
\text { Loading Pattern }\end{array}$ & $\begin{array}{l}\text { Total } \\
\text { Load } \\
(\mathrm{k})\end{array}$ & \begin{tabular}{|c|} 
Matlab \\
Deflection \\
(in) \\
\end{tabular} & X & $\begin{array}{l}\text { Beam } \\
\text { Chart } \\
\text { X }\end{array}$ & $\%$ diff \\
\hline pin-pin uniform & 57.6 & 0.1535 & 76.91 & 76.80 & $0.1 \%$ \\
\hline fix-fix uniform & 57.6 & 0.0307 & 384.00 & 384.00 & $0.0 \%$ \\
\hline pin-pin linear & 28.8 & 0.0767 & 76.91 & 76.69 & $0.3 \%$ \\
\hline pin-pin triangle & 28.8 & 0.0981 & 60.17 & 60.00 & $0.3 \%$ \\
\hline
\end{tabular}

Because the errors for the cases in Table 8 are all minimal, we can derive some other stiffness values by using the program. The additional combinations of boundary conditions and loading patterns listed below are shown in Table 9:

- Simply supported beam with a parabolic distributed load (pin-pin parabola)

- Beam with fixed end supports, with linear loading starting with $0 \mathrm{klf}$ on one end (fix-fix linear)

- Beam with fixed end supports, distributed load with peak loading in the middle (fix-fix triangular)

- Beam with fixed end supports, with a parabolic distributed load (fix-fix parabola) 


\begin{tabular}{|c|c|c|c|c|}
\hline E & 29000 & ksi & \multirow{4}{*}{\multicolumn{2}{|c|}{$\begin{array}{l}=0.2 \mathrm{in} / \mathrm{ft} \\
=288 \mathrm{in}\end{array}$}} \\
\hline I & 4020 & in $^{4}$ & & \\
\hline peak load & 2.4 & klf & & \\
\hline length & 24 & $\mathrm{ft}$ & & \\
\hline Boundary & Total & Matlab & \multirow[b]{2}{*}{$\mathrm{X}$} & \\
\hline $\begin{array}{l}\text { Conditions and } \\
\text { Loading Pattern }\end{array}$ & $\begin{array}{l}\text { Load } \\
(\mathrm{k})\end{array}$ & $\begin{array}{l}\text { Deflection } \\
\text { (in) }\end{array}$ & & \\
\hline fix-fix linear & 28.8 & 0.0154 & 383.0 & \\
\hline fix-fix triangle & 28.8 & 0.0214 & 275.2 & \\
\hline pin-pin parabola & 19.2 & 0.0457 & 86.1 & \\
\hline fix-fix parabola & 19.2 & 0.0088 & 444.8 & \\
\hline Where & & otal 1 & [Mat & deflection $]) *\left(\mathrm{~L}^{3} / \mathrm{EI}\right)$ \\
\hline Beam Chart X & $=(\mathrm{El}$ & {$[\max d e$} & ection $\mathrm{pe}$ & A AISC] \\
\hline
\end{tabular}

\subsubsection{Stiffness Factor}

The effective stiffness of the system is based on the generalized shape when the beam yields. The program records the time-step when the first node reaches yield. At the time step that the first node reaches yield stress, the generalized shape is taken and scaled so that the maximum deflection $=1$, and the effective stiffness of the system can be solved by using the following equation.

$$
\begin{array}{cc} 
& K_{\text {eff }}=s^{\prime} K s \\
\text { Where } & s=\frac{\bar{x}}{\delta_{\max }}
\end{array}
$$

$\mathrm{K}_{\text {eff }}$ is a scalar value and can be compared directly to the static stiffness values. 


$$
K_{L}=\frac{K_{e f f}}{k}
$$

\subsubsection{Mass Factor}

The mass factor is derived with the same process as the stiffness factor. The equation for the effective mass is shown below.

$$
M_{e f f}=s^{\prime} M s
$$

$\mathrm{K}_{\text {eff }}$ is a scalar value and can be compared directly to the static stiffness values.

$$
K_{M}=\frac{M_{e f f}}{m l}
$$

\subsubsection{Resistance Factor}

The resistance factor can be calculated by using the scaled deflection vector used for the stiffness and mass factors, the stiffness matrix, and the deflection vector as shown in the equation below.

$$
R_{m}=-S^{\prime} K x
$$

\subsubsection{Factors Post Yield}

The transformation factors used by Biggs assume that the beam has a new configuration after the first node(s) yield. For a uniformly loaded beam with fixed ends, the post-yield beam becomes a simply supported beam (as explained in Section 2.2). The same concept was applied in the MDOF numerical method; however, the factors derived from the Biggs' assumptions on nonlinear behavior are not consistent to the factors derived using the MDOF analysis. Derived values for a uniformly loaded beam with fixed ends are shown below.

Verification and Expansion of Single-Degree-of-Freedom Transformation Factors for Beams Using a Multi-Degree-of-Freedom Non-Linear Numerical Analysis Method 
Table 10: Secondary factor derivation attempt

\begin{tabular}{|c|c|c|c|}
\hline Factor & Biggs & MDOF method & $\%$ difference \\
\hline $\mathrm{K}_{\mathrm{L} 1}$ & 0.53 & 0.5096 & $3.8 \%$ \\
\hline $\mathrm{K}_{\mathrm{M} 1}$ & 0.41 & 0.3900 & $4.5 \%$ \\
\hline $\mathrm{R}_{\mathrm{m} 1}$ & $12 \mathrm{Mp} / \mathrm{L}$ & $13.6 \mathrm{Mp} / \mathrm{L}$ & $13.3 \%$ \\
\hline $\mathrm{K}_{\mathrm{L} 2}$ & 0.64 & 2.9195 & $356 \%$ \\
\hline $\mathrm{K}_{\mathrm{M} 2}$ & 0.50 & 0.3513 & $29.7 \%$ \\
\hline $\mathrm{R}_{\mathrm{m} 2}$ & $16 \mathrm{Mp} / \mathrm{L}$ & - & - \\
\hline
\end{tabular}

$\mathrm{Z}=10$ (See Table 11: Blast wave parameters used for analysis)

The secondary shape assumption, that the beam with fixed ends behaves like a simply supported beam after hinges form on either end, does not produce reasonable factors. This assumption does not work despite having a similar deflected shape. The figure below shows the inelastic deflected shape from the analysis (with the elastic shape subtracted) and the theoretical elastic deflected shape of a simply supported beam, both scaled to a max deflection of one unit. 


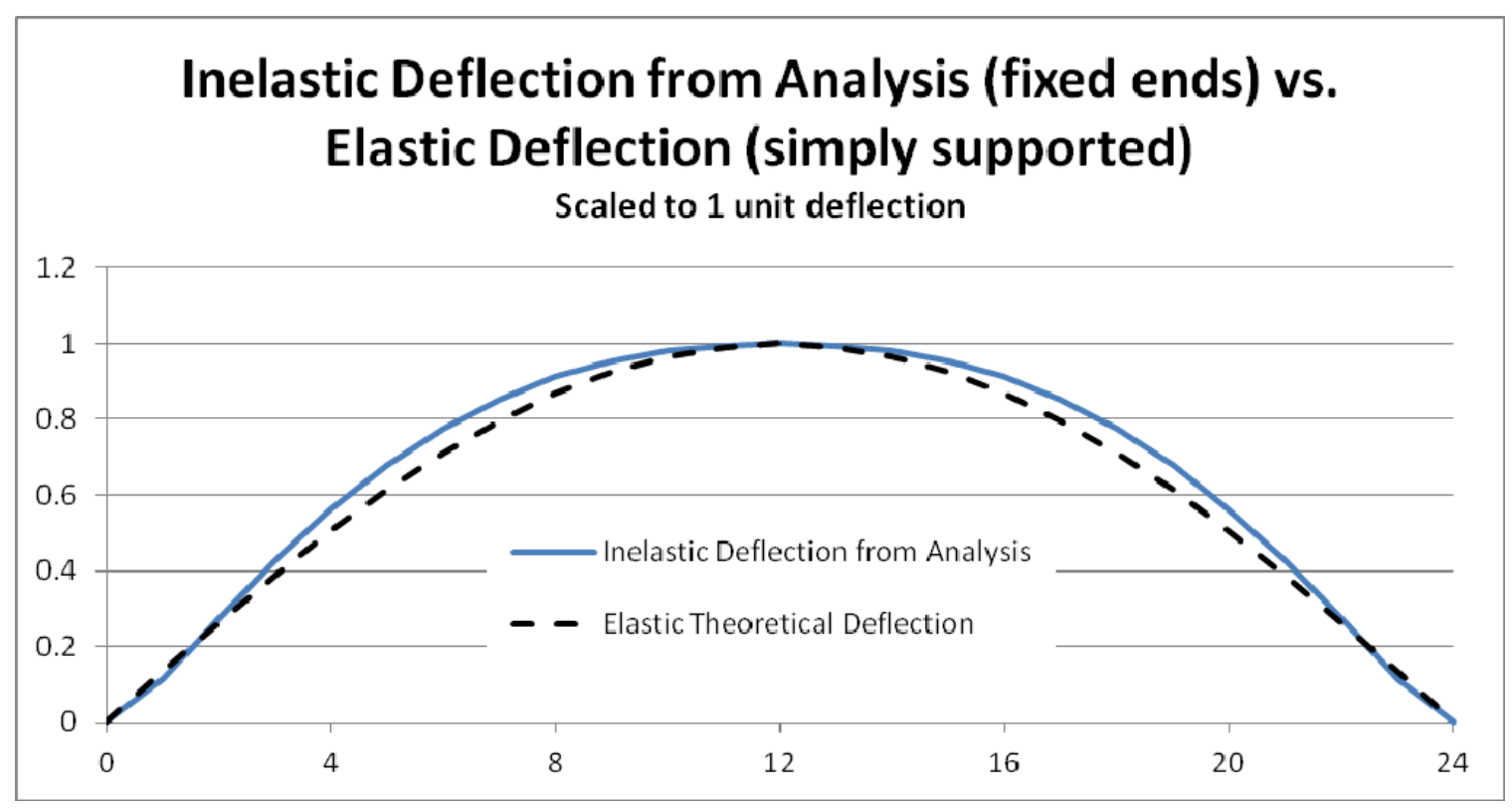

Figure MM: Inelastic deflection from analysis (fixed ends) vs. theoretical elastic deflection (simply supported)

While having a similar deflected shape, Eq. 22 through Eq. 27 do not produce the expected factors close to Biggs' factors. Therefore, the $\mathrm{K}_{\mathrm{L} 2}$ and $\mathrm{K}_{\mathrm{M} 2}$ factors post-yield in this study are based on the elastic $\mathrm{K}_{\mathrm{L}}$ and $\mathrm{K}_{\mathrm{M}}$ factors of the assumed post-yield beam configuration. This means that in the case above, the $\mathrm{K}_{\mathrm{L}}$ and $\mathrm{K}_{\mathrm{M}}$ factors of a pin-pin configuration are used as the $\mathrm{K}_{\mathrm{L} 2}$ and $\mathrm{K}_{\mathrm{M} 2}$ factors for the post-yield calculations for a fixfix beam with uniformly distributed loading. As seen in figure $\mathbf{Z}$ in Section 7.4, the elasto-plastic stiffness slope is similar to the theoretical SDOF stiffness slope, making this a decent assumption. Also as seen in Figure Z, there is no clear stiffness change indicating the next hinge forming, making the collapse mechanism difficult to model for a SDOF system. This study assumes the collapse mechanism that Biggs suggested;

Verification and Expansion of Single-Degree-of-Freedom Transformation Factors for Beams Using a Multi-Degree-of-Freedom Non-Linear Numerical Analysis Method 
however, the post yield behavior should be a topic to explore in order to better model the collapse progression.

\subsection{Loading Parameters}

In order to fill in the rest of the SDOF equivalent factors table, several loading cases were run through the MDOF numerical analysis algorithm. The blast wave parameters applied to each beam geometry and loading pattern are listed on Table $\mathbf{1 1}$ below.

Table 11: Blast wave parameters used for analysis

\begin{tabular}{|c|c|c|c|}
\hline $\mathrm{Z}$ & $\operatorname{Pr}$ & $\mathrm{Ir}$ & $\mathrm{t}_{0}$ \\
\hline 30 & 0.0036 & 0.009 & 6.5 \\
\hline 25 & 0.0046 & 0.013 & 7.34 \\
\hline 20 & 0.0065 & 0.021 & 8.58 \\
\hline 15 & 0.0105 & 0.038 & 10.36 \\
\hline 14 & 0.0119 & 0.044 & 10.82 \\
\hline 13 & 0.0137 & 0.052 & 11.34 \\
\hline 12 & 0.0161 & 0.061 & 11.9 \\
\hline 11 & 0.0193 & 0.074 & 12.5 \\
\hline 10.5 & 0.0214 & 0.082 & 12.8 \\
\hline 10 & 0.0239 & 0.091 & 13.12 \\
\hline 9.5 & 0.0269 & 0.101 & 13.42 \\
\hline 9 & 0.0307 & 0.113 & 13.72 \\
\hline 8.5 & 0.0353 & 0.128 & 14 \\
\hline 8 & 0.0412 & 0.146 & 14.24 \\
\hline
\end{tabular}

Note: $\mathrm{Z}=\frac{D}{W^{1 / 3}}$ where $\mathrm{D}=$ distance (ft) and $\mathrm{W}=$ =equivalent TNT weight (lbs)

(See Section 6.4)

Verification and Expansion of Single-Degree-of-Freedom Transformation Factors for Beams Using a Multi-Degree-of-Freedom Non-Linear Numerical Analysis Method 
The Z-value stops at $8 \mathrm{ft} / \mathrm{lbs}^{3}$ because the analyses showed that the factors become inconsistent between $13 \mathrm{ft} / \mathrm{lbs}^{3}$ and $9 \mathrm{ft} / \mathrm{lbs}^{3}$. This data is, however, is consistent with the observation made in Section 7.4. When the impulse is too large and too fast, hinges form due to local forces, before the beam can develop the quasi-static deflected shape assumed by the Bigg's method. This reinforces the idea that the SDOF equivalent factors are only accurate for far or small charges, as stated in Section 1 of this study.

\subsection{Output and Factors for Beam with Both Ends Fixed, Uniformly}

\section{Distributed Loading}

The maximum deflection and the factors (calculated according to Section 8.2) are tabulated below in Table 12. 
Table 12: Data for fix-fix, uniformly loaded beam

\begin{tabular}{|c|c|c|c|c|}
\hline $\mathrm{Z}$ & $\mathrm{K}_{\mathrm{L}}$ & $\mathrm{K}_{\mathrm{M}}$ & $\begin{array}{c}\mathrm{R}_{\mathrm{m}} \\
\left(\mathrm{M}_{\mathrm{p}} / \mathrm{L}\right)\end{array}$ & $\begin{array}{c}\delta_{\max } \\
\text { (in) }\end{array}$ \\
\hline 30 & 0.5105 & 0.3904 & - & 0.167 \\
\hline 25 & 0.5114 & 0.3917 & - & 0.227 \\
\hline 20 & 0.5129 & 0.3933 & - & 0.340 \\
\hline 15 & 0.5454 & 0.4117 & 12.2 & 0.569 \\
\hline 14 & 0.5369 & 0.4084 & 12.2 & 0.631 \\
\hline 13 & 0.5274 & 0.4036 & 12.4 & 0.843 \\
\hline 12 & 0.5132 & 0.3935 & 12.7 & 1.090 \\
\hline 11 & 0.5077 & 0.3863 & 12.8 & 1.563 \\
\hline 10.5 & 0.5082 & 0.3881 & 12.6 & 1.930 \\
\hline 10 & 0.5125 & 0.3928 & 11.8 & 2.438 \\
\hline 9.5 & 0.8992 & 0.4886 & 9.8 & 3.126 \\
\hline 9 & 1.4337 & 0.5738 & 7.2 & 4.100 \\
\hline 8.5 & 1.7339 & 0.5943 & 5.7 & 5.592 \\
\hline 8 & 2.0666 & 0.5935 & 5.7 & 7.918 \\
\hline Average & 0.52 & 0.40 & 12.4 & - \\
\hline
\end{tabular}

Note: W24x131 beam, $\mathrm{L}=24 \mathrm{ft}$, Tributary width $=24 \mathrm{ft}, \mathrm{f}_{\mathrm{y}}=50 \mathrm{ksi}$, angle of incidence $=0$.

The factors that are similar in range are averaged and declared as the factors for the equivalent SDOF factors. In this case, $\mathrm{K}_{\mathrm{L}}$ and $\mathrm{K}_{\mathrm{M}}$ are only averaged between $\mathrm{Z}=30$ $\mathrm{ft} / \mathrm{lbs}^{3}$ and $\mathrm{Z}=10 \mathrm{ft} / \mathrm{lbs}^{3}$ because $\mathrm{Z}=9.5 \mathrm{ft} / \mathrm{lbs}^{3}$ seems to be the limit for accurate factors. Over the $\mathrm{Z}$ range of $10 \sim 30 \mathrm{ft} / \mathrm{lbs}^{3}$, the average $\mathrm{K}_{\mathrm{L}}$ is 0.52 , and $\mathrm{K}_{\mathrm{M}}$ is 0.40 . The average for $\mathrm{R}_{\mathrm{m}}$ doesn't include $\mathrm{Z}=20 \mathrm{ft} / \mathrm{lbs}^{3}$ through $\mathrm{Z}=30 \mathrm{ft} / \mathrm{lbs}^{3}$ because the beam remains elastic at these demands. Otherwise, the average $R_{m}$ is about $12.4 \mathrm{Mp} / \mathrm{L}$. Besides $R_{m}$, which 
fluctuates with different cases, these values are further verified by running more cases altering beam size, beam length, and tributary area. The data for these other cases are tabulated below in Table 13 and Table 14.

Table 13: Data for fix-fix, uniformly loaded beam

\begin{tabular}{|c|c|c|c|c|}
\hline Z & $\mathrm{K}_{\mathrm{L}}$ & $\mathrm{K}_{\mathrm{M}}$ & $\begin{array}{c}\mathrm{R}_{\mathrm{m}} \\
\left(\mathrm{M}_{\mathrm{p}} / \mathrm{L}\right)\end{array}$ & $\begin{array}{l}\delta_{\max } \\
\text { (in) }\end{array}$ \\
\hline 30 & 0.5084 & 0.3877 & - & 0.296 \\
\hline 25 & 0.5102 & 0.3899 & - & 0.406 \\
\hline 20 & 0.5465 & 0.4121 & 11.1 & 0.611 \\
\hline 15 & 0.5101 & 0.3905 & 13.4 & 1.268 \\
\hline 14 & 0.5067 & 0.3851 & 13.0 & 1.632 \\
\hline 13 & 0.5077 & 0.3879 & 13.3 & 2.194 \\
\hline 12 & 0.5199 & 0.3987 & 13.1 & 3.050 \\
\hline 11 & 1.5435 & 0.5855 & 4.8 & 4.666 \\
\hline 10.5 & 1.719 & 0.5936 & 4.8 & 5.908 \\
\hline 10 & 1.9516 & 0.5960 & 4.7 & 7.534 \\
\hline 9.5 & 2.2209 & 0.5904 & 4.4 & 9.741 \\
\hline 9 & 3.1734 & 0.6175 & 3.0 & 12.841 \\
\hline 8.5 & 3.6983 & 0.6337 & 2.8 & 17.199 \\
\hline 8 & 5.2258 & 0.6473 & 2.1 & 23.393 \\
\hline Average & 0.52 & 0.39 & 12.8 & \\
\hline
\end{tabular}

Note: W21x93 beam, $\mathrm{L}=24 \mathrm{ft}$, Tributary width $=24 \mathrm{ft}, \mathrm{f}_{\mathrm{y}}=50 \mathrm{ksi}$, angle of incidence $=0$. 
Table 14: Data for fix-fix, uniformly loaded beam

\begin{tabular}{|c|c|c|c|c|}
\hline $\mathrm{Z}$ & $\mathrm{K}_{\mathrm{L}}$ & $\mathrm{K}_{\mathrm{M}}$ & $\begin{array}{c}\mathrm{R}_{\mathrm{m}} \\
\left(\mathrm{M}_{\mathrm{p}} / \mathrm{L}\right)\end{array}$ & $\begin{array}{l}\delta_{\max } \\
\text { (in) }\end{array}$ \\
\hline 30 & 0.5054 & 0.3844 & - & 0.308 \\
\hline 25 & 0.5063 & 0.3854 & - & 0.429 \\
\hline 20 & 0.5080 & 0.3872 & - & 0.658 \\
\hline 15 & 0.5228 & 0.3855 & 10.4 & 1.186 \\
\hline 14 & 0.5102 & 0.3908 & 10.9 & 1.436 \\
\hline 13 & 0.5049 & 0.3826 & 10.8 & 1.867 \\
\hline 12 & 0.5050 & 0.3844 & 11.1 & 2.480 \\
\hline 11 & 1.0711 & 0.5199 & 4.7 & 3.463 \\
\hline 10.5 & 1.4567 & 0.5769 & 4.0 & 4.257 \\
\hline 10 & 1.6582 & 0.5908 & 4.0 & 5.425 \\
\hline 9.5 & 1.9123 & 0.5955 & 3.9 & 6.810 \\
\hline 9 & 2.4088 & 0.5899 & 3.2 & 8.828 \\
\hline 8.5 & 3.2461 & 0.6194 & 2.4 & 11.653 \\
\hline 8 & 3.868 & 0.6384 & 2.3 & 15.790 \\
\hline Average & 0.51 & 0.39 & 10.8 & \\
\hline
\end{tabular}

Note: W24x131 beam, $\mathrm{L}=30 \mathrm{ft}$, Tributary width $=24 \mathrm{ft}, \mathrm{f}_{\mathrm{y}}=50 \mathrm{ksi}$, angle of incidence $=0$.

In both cases shown in Table 13 and Table 14, the factors are only reasonable down to $\mathrm{Z}=12 \mathrm{ft} / \mathrm{lbs}^{3}$. As mentioned in Section 7.4 and Section 8.2, this is because the deflected shape at lower $\mathrm{Z}$ values are no longer consistent with the theoretical quasi-static deflected shapes as assumed by the Biggs' method.

All other cases discussed in Section 8.1.1 are run and tabulated and located in Table 21 through Table 27 in the Appendix. 


\subsection{SDOF Results}

In order to validate the Transformation Factors table, each case studied using MDOF is run through a SDOF analysis as well. The data for a Fix-fix beam under uniform load is shown in Table 15 below.

Table 15: MDOF vs. SDOF for fix-fix, uniform load

\begin{tabular}{|c|c|c|c|}
\hline $\mathrm{Z}$ & $\begin{array}{c}\text { MDOF } \\
\text { (in) }\end{array}$ & $\begin{array}{l}\text { SDOF } \\
\text { (in) }\end{array}$ & $\%$ Difference \\
\hline 30 & 0.167 & 0.164 & -2.0 \\
\hline 25 & 0.227 & 0.224 & -1.7 \\
\hline 20 & 0.340 & 0.335 & -1.4 \\
\hline 15 & 0.569 & 0.643 & 13.0 \\
\hline 14 & 0.631 & 0.797 & 26.2 \\
\hline 13 & 0.843 & 1.023 & 21.4 \\
\hline 12 & 1.090 & 1.222 & 12.1 \\
\hline 11 & 1.563 & 1.580 & 1.1 \\
\hline 10.5 & 1.930 & 1.868 & -3.2 \\
\hline 10 & 2.438 & 2.265 & -7.1 \\
\hline 9.5 & 3.126 & 2.812 & -10.1 \\
\hline 9 & 4.100 & 3.618 & -11.8 \\
\hline 8.5 & 5.592 & 4.836 & -13.5 \\
\hline 8 & 7.918 & 6.651 & -16.0 \\
\hline
\end{tabular}

Note: $\mathrm{W} 24 \mathrm{x} 131$ beam, $\mathrm{L}=24 \mathrm{ft}$, Tributary width $=24 \mathrm{ft}, \mathrm{f}_{\mathrm{y}}=50 \mathrm{ksi}$, angle of incidence $=0$.

The analysis was only run until $\mathrm{Z}=8 \mathrm{ft} / \mathrm{lbs}^{3}$ to match the data range presented in Section 8.2. All other MDOF vs. SDOF comparisons are tabulated and located in Table

Verification and Expansion of Single-Degree-of-Freedom Transformation Factors for Beams Using a Multi-Degree-of-Freedom Non-Linear Numerical Analysis Method 
28 through Table 34 in the Appendix. In all cases, there is less than 1\% difference between the MDOF and SDOF methods in the elastic range. The displacements vary more in the inelastic response, up to about $35 \%$. 


\subsection{CONCLUSION AND RECOMMENDATIONS}

This project studies the equivalent single-degree-of-freedom (SDOF) factors presented by Biggs in 1964. The study presents the derivation of these factors, a validation of the factors using a multi-degree-of-freedom (MDOF) numerical analysis, the accuracy of the SDOF analysis compared to the MDOF analysis, and suggests factors for other cases to expand on what is known as the "Biggs Factors" table.

\subsection{Verification of Biggs Values}

There are four values from Biggs' tables that the study tried to verify: load factor $\left(\mathrm{K}_{\mathrm{L}}\right)$, mass factor $\left(\mathrm{K}_{\mathrm{M}}\right)$, maximum resistance $\left(\mathrm{R}_{\mathrm{m}}\right)$, and the spring constant $(\mathrm{k})$. Of the four, the spring constant is based on a MDOF static deflection. The load factor, mass factor, and the maximum resistance value are solved for through using the MDOF numerical method and averaged over varying loading magnitude cases.

As seen on Table 8, the stiffness values taken from the MDOF for a 24-element beam model is no more than $0.3 \%$ different from the theoretical values based on the Euler-Bernoulli Beam Theory. The source of this small $0.3 \%$ error comes from the discretization assumption built into the MDOF method, specifically of the elements and the loading, as shown in Table 7 and Figure LL. The deflection values from theory are based on a continuous beam, and while the MDOF attempts to mimic a continuous beam, it is still a discretized beam with material properties only applied to the nodes. By replacing the loading matrix with a consistent loading matrix, or formulating the loads so 
that fixed end moments are applied to the end nodes, deflection values may be made more accurate with larger mesh sizes. ${ }^{3}$

In order to compare the study to the Biggs factors, the $\mathrm{K}_{\mathrm{L}}$ and $\mathrm{K}_{\mathrm{M}}$ factors from the study are rounded to two significant figures; therefore, the factors are rounded to two significant figures for consistency. After rounding, the average $K_{L}$ and $K_{M}$ values from the MDOF numerical analysis are the same as the $\mathrm{K}_{\mathrm{L}}$ and $\mathrm{K}_{\mathrm{M}}$ values from the Biggs tables.

The maximum resistance factors varied more between each case ran. The average resistance factor for the uniform load on a fixed-fixed beam hovered around $12 \mathrm{M}_{\mathrm{p}} / \mathrm{L}$ between the (3) cases (Table 12: W24x131 over $24 \mathrm{ft}$, Table 13: W21x93 over $24 \mathrm{ft}$, Table 14: W24x131 over $30 \mathrm{ft}$ ), ranging between $10.8 \mathrm{M}_{\mathrm{p}} / \mathrm{L}$ and $12.8 \mathrm{M}_{\mathrm{p}} / \mathrm{L}$. With enough cases, a statistical analysis may provide a reasonable average resistance value; however, running excessive cases is beyond the scope of the study. The three different beam cases, changing the length or the size of the beam, are enough to conclude that one case for each boundary condition and loading patter combination is not enough data to validate or produce a resistance factor.

The load factor $\left(\mathrm{K}_{\mathrm{L}}\right)$, mass factor $\left(\mathrm{K}_{\mathrm{M}}\right)$, and the spring constant $(\mathrm{k})$ from this study adequately validates Biggs' factors while the maximum resistance $\left(R_{m}\right)$ factors derived from this study were too inconsistent to come to the same conclusion as the other factors.

\footnotetext{
${ }^{3}$ Personal correspondence between Shalva Marjanishvili, Ph.D., S.E., and Takayuki Yokoyama 10/9/2011

Verification and Expansion of Single-Degree-of-Freedom Transformation Factors for Beams Using a Multi-Degree-of-Freedom Non-Linear Numerical Analysis Method
} 


\subsection{Expanded Biggs Tables}

The expanded Biggs' tables, based on the MDOF numerical analysis, is shown below.

Table 16: SDOF transformation factors for beams with pin-pin boundary conditions

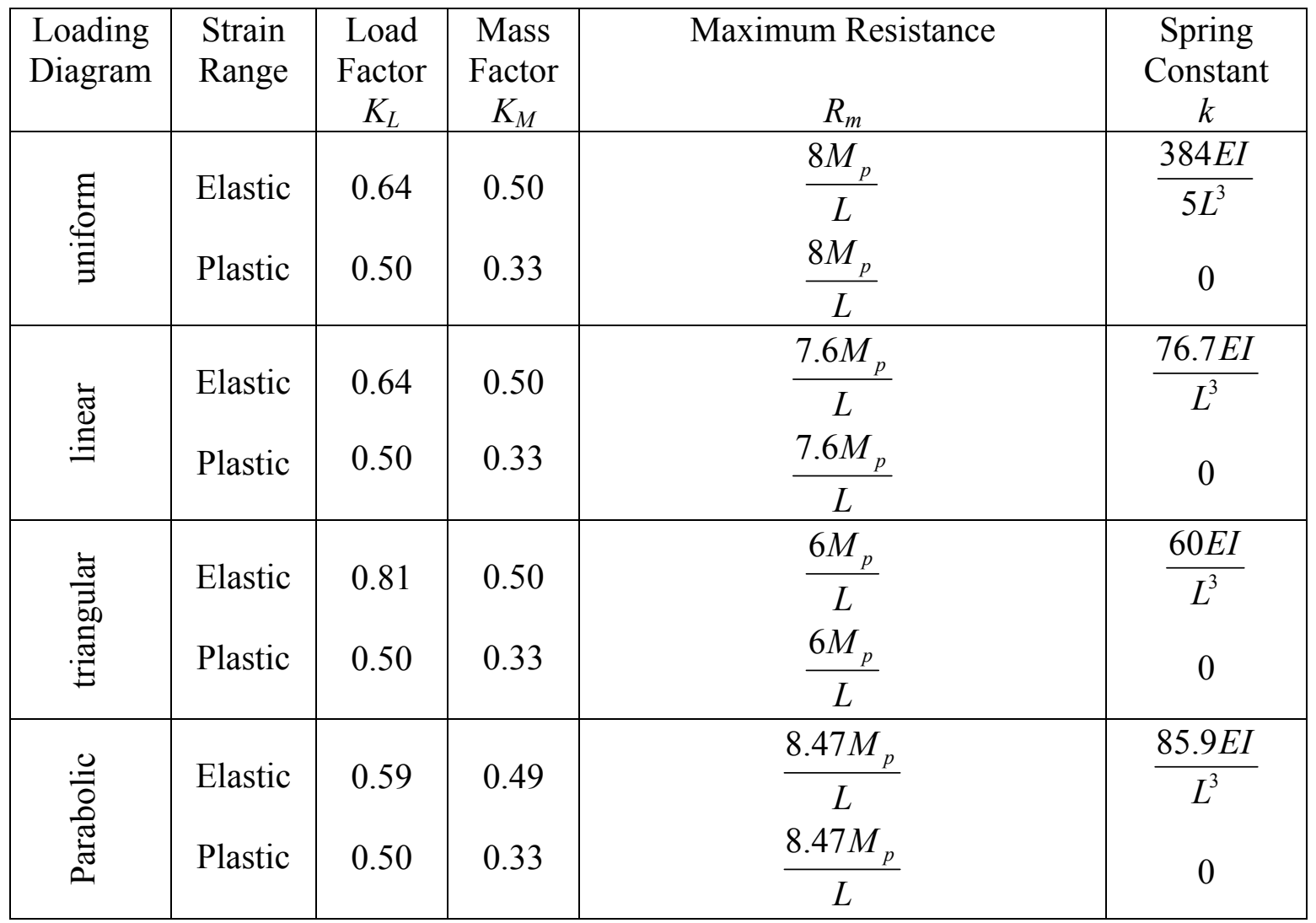

For a graphic of the pin-pin boundary condition, refer to Figure $\mathbf{F}$.

Verification and Expansion of Single-Degree-of-Freedom Transformation Factors for Beams Using a Multi-Degree-of-Freedom Non-Linear Numerical Analysis Method 
Table 17: SDOF transformation factors for beams with fix-fix boundary conditions

\begin{tabular}{|c|c|c|c|c|c|}
\hline $\begin{array}{l}\text { Loading } \\
\text { Diagram }\end{array}$ & $\begin{array}{l}\text { Strain } \\
\text { Range }\end{array}$ & $\begin{array}{c}\text { Load } \\
\text { Factor } \\
K_{L} \\
\end{array}$ & $\begin{array}{c}\text { Mass } \\
\text { Factor } \\
K_{M} \\
\end{array}$ & $\begin{array}{c}\text { Maximum Resistance } \\
R_{m}\end{array}$ & $\begin{array}{c}\text { Spring } \\
\text { Constant } \\
k \\
\end{array}$ \\
\hline$\stackrel{\Xi}{\stackrel{\Xi}{0}}$ & $\begin{array}{c}\text { Elastic } \\
\text { E-P } \\
\text { Plastic }\end{array}$ & $\begin{array}{l}0.52 \\
0.64 \\
0.50\end{array}$ & $\begin{array}{l}0.40 \\
0.50 \\
0.33\end{array}$ & $\begin{array}{c}\frac{12 M_{p}}{L} \\
\frac{8}{L}\left(M_{p s}+M_{p m}\right) \\
\frac{8}{L}\left(M_{p s}+M_{p m}\right)\end{array}$ & $\begin{array}{c}\frac{384 E I}{L^{3}} \\
\frac{384 E I}{5 L^{3}} \\
0\end{array}$ \\
\hline 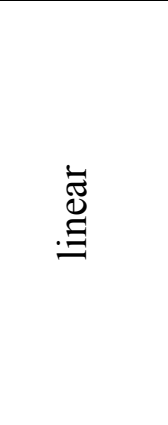 & $\begin{array}{l}\text { Elastic } \\
\text { E-P (1) } \\
\text { E-P (2) } \\
\text { Plastic }\end{array}$ & $\begin{array}{l}0.52 \\
0.65 \\
0.64 \\
0.50\end{array}$ & $\begin{array}{l}0.39 \\
0.44 \\
0.50 \\
0.33\end{array}$ & $\begin{array}{c}\frac{10 M_{p}}{L} \\
\frac{30}{7 L}\left(2 M_{p L}+M_{p R}\right) \\
\frac{5.872}{L}\left(1.327 M_{p M}-M_{p R}+2.329 M_{p L}\right) \\
\frac{5.872}{L}\left(1.327 M_{p M}-M_{p R}+2.329 M_{p L}\right)\end{array}$ & $\begin{array}{c}\frac{383.2 E I}{L^{3}} \\
\frac{164.4 E I}{L^{3}} \\
\frac{76.7 E I}{L^{3}} \\
0\end{array}$ \\
\hline 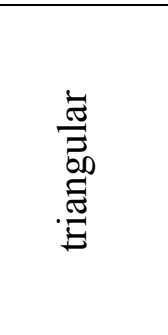 & $\begin{array}{c}\text { Elastic } \\
\text { E-P } \\
\text { Plastic }\end{array}$ & $\begin{array}{l}0.72 \\
0.81 \\
0.50\end{array}$ & $\begin{array}{l}0.40 \\
0.50 \\
0.33\end{array}$ & $\begin{array}{c}\frac{9.7 M_{p}}{L} \\
\frac{6}{L}\left(M_{p s}+M_{p m}\right) \\
\frac{6}{L}\left(M_{p s}+M_{p m}\right)\end{array}$ & $\begin{array}{c}\frac{275.8 E I}{L^{3}} \\
\frac{60 E I}{L^{3}} \\
0\end{array}$ \\
\hline 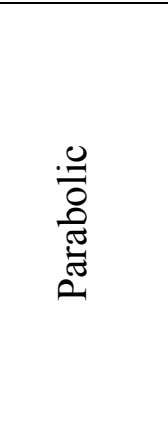 & $\begin{array}{l}\text { Elastic } \\
\text { E-P (1) } \\
\text { E-P (2) } \\
\text { Plastic }\end{array}$ & $\begin{array}{l}0.45 \\
0.61 \\
0.59 \\
0.50\end{array}$ & $\begin{array}{l}0.39 \\
0.43 \\
0.49 \\
0.33\end{array}$ & $\begin{array}{c}\frac{12 M_{p}}{L} \\
\frac{10}{L}\left(M_{p L}+M_{p R}\right) \\
\frac{3.132}{L}\left(2.7 M_{p M}+5.4 M_{p R}+M_{p L}\right) \\
\frac{3.132}{L}\left(2.7 M_{p M}+5.4 M_{p R}+M_{p L}\right)\end{array}$ & $\begin{array}{c}\frac{447.2 E I}{L^{3}} \\
\frac{172.6 E I}{L^{3}} \\
\frac{85.9 E I}{L^{3}} \\
0\end{array}$ \\
\hline
\end{tabular}

For a graphic of the fix-fix boundary condition, refer to Figure G. 


\subsection{Validity of Expanded Factors}

Based on the MDOF analysis and the existing transformation factors table, the transformations factors $\mathrm{K}_{\mathrm{L}}$ and $\mathrm{K}_{\mathrm{M}}$ can be assumed accurate for practical use. This conclusion is based off the data on Section 8.3. The average $K_{L}$ and $K_{M}$ factors match the Biggs' table values to two significant digits in the elastic response cases. While the $\mathrm{K}_{\mathrm{L}}$ and $K_{M}$ values are confirmed based on the parallel test cases of the MDOF and SDOF methods, the transformation factors can only be assumed accurate for dynamic loads that result in the beam reacting elastically. The maximum deflection values diverge when the system behaves inelastically. This divergence is mild when the beam has an elasto-plastic response range, and large when the loading is too large and too fast for the beam to respond in the assumed quasi-static behavior. While the hinge property assumptions are consistent between the two analysis methods, the differences in deflection data, and the inelastic response comparison done in Figure $\mathbf{Z}$ in Section 7.4, suggest that the assumed simplified inelastic beam configuration for the SDOF is erroneous when the loading is too large and too fast.

The inelastic configuration is based on the elastic configuration of a beam with altered boundary conditions. Subsequently, the factors used are also based on the assumed elastic deflection of an altered beam configuration. As seen in Figure MM, the scaled inelastic deflected shape does not match the theoretical elastic deflected shape of the post-yield beam configuration. This difference in deflected shape causes the factors to vary post-yield; consequently, when the Biggs' assumptions are used in the SDOF method, the deflections also vary from the MDOF method when the beam behaves 
inelastically. This approach for deriving post-yield assumed deflected shape and factors is acceptable for the elasto-plastic range, with minimal error.

While further study with significant data will help in establishing better stiffness transitions, this study shows that the MDOF approach produces the same factors as the static deflection assumptions found in (Biggs 1964) for the elastic and elasto-plastic responses. This study has also shown that compared to a MDOF analysis, the SDOF analysis is, as advertised, only a simplified method good enough to produce rough response information.

\subsection{Opportunities for Further Study}

The scope of the study was to verify Biggs' transformation factors by creating and using a MDOF numerical analysis program, and to expand upon the table using the same program. The study was unable to derive a consistent resistance value, which should be the first focus when expanding on this study.

Another focus for further study should be on the post-yield behavior of the components. The goal is to find assumptions that lead to SDOF analysis data to match the MDOF analysis data.

Once the above issues can be improved upon, further study can focus on adding variables to the MDOF system. Variables to consider include boundary fixity, effect of axial loads, and material properties. 


\subsection{REFERENCES}

(AISC 2005a) American Institute of Steel Construction. Seismic provisions for structural steel buildings. ANSI/AISC 341-05. Chicago: American Institute of Steel Construction, 2005.

(AISC 2005b) American Institute of Steel Construction. Specification for structural steel buildings. ANSI/AISC 360-05. Chicago: American Institute of Steel Construction, 2005.

(ASCE 1985) American Society of Civil Engineers. Design of Structures to Resist Nuclear Weapons Effects. New York: American Society of Civil Engineers, 1985.

(ASCE 1997) American Society of Civil Engineers. Design of Blast Resistant Buildings in Petrochemical Facilities. New York: American Society of Civil Engineers, 1997.

(Baker et al. 1983) Baker, W.E., P.A. Cox, P.S. Westine, J.J. Kulesz and R.A. Strehlow. Explosion Hazards and Evaluation. Amsterdam, Netherlands: Elsevier Scientific Publishing Company, 1983.

(Biggs 1964) Biggs, John. Introduction to Structural Dynamics. New York: McGraw Hill Book Company, 1964.

(Chopra 2007) Chopra, Anil K. Dynamics of Structures: Theory and Applications to Earthquake Engineering Third Edition. Upper Saddle River, New Jersey: Pearson Prentice Hall, 2007.

(Clough and Penzien 1975) Clough, R.W., and J. Penzien. Dynamics of Structures. New York: McGraw-Hill, 1975 ( $2^{\text {nd }}$ edition 1993).

(Conrath et al. 1999) Conrath, Edward J., Ted Krauthammer, Kirk A. Marchand and Paul F. Mlakar. Structural Design for Physical Security: State of the Practice. Reston, Virginia: American Society of Civil Engineers, 1999.

(Etter, Kuncicky, and Moore 2005) Etter, Delores M., David C. Kuncicky and Holly Moore. Introduction to MATLAB 7.Upper Saddle River, NJ: The Prentice Hall Engineering Source, 2005.

(FEMA 426 2003) Federal Emergency Management Agency. Reference Manual to Mitigate Potential Terrorist Attacks Against Buildings. Washington, D.C.: Federal Emergency Management Agency, 2003.

Verification and Expansion of Single-Degree-of-Freedom Transformation Factors for Beams Using a Multi-Degree-of-Freedom Non-Linear Numerical Analysis Method 
(FEMA 427 2003) Federal Emergency Management Agency. Primer for Design of Commercial Buildings to Mitigate Terrorist Attacks. Washington, D.C.: Federal Emergency Management Agency, 2003.

(GSA 2005) United States General Services Administration, Office of the Chief Architect. Facilities Standards for the Public Buildings Service. Washington, D.C.: United States General Services Administration, 2005.

(Krauthammer 1998) Krauthammer, Theodor. "Blast mitigation technologies: developments and numerical considerations for behavior assessment and design." Structures Under Shock and Impact V. (1998) 3-12.

(Lawver et al. 2003) Lawver, Darell, Raymond Daddazio, David Vaughan, Michael Stanley and Howard Levine. "Response of AISC Steel Column Sections to Blast Loading." The 2003 ASME Pressure Vessels and Piping Conference: Problems Involving Thermal-Hydraulics, Liquid Sloshing, and Extreme Loads on Structures: Proceedings of the Conference. 20-24 July 2003, Cleveland, Ohio. New York: American Society of Mechanical Engineers, 2003.

(Marchand and Alfawakhiri 2005) Marchand, Kirk A. and Farid Alfawakhiri. Facts for Steel Buildings: Blast and Progressive Collapse. USA: American Institute of Steel Construction, Inc., 2005.

(Mays and Smith 1995) Mays, G.C. and P.D. Smith. Blast Effects on Buildings: Design of buildings to optimize resistance to blast loading. London: Thomas Telford Publications, 1995.

(Nebuda and Oswald 2005) Nebuda, Dale, and Charles J. Oswald. SBEDS (Single degree of freedom Blast Effects Design Spreadsheets. U.S. Army Corps of Engineers Protective Design Center, 2005.

(Nonaka 2000) Nonaka, T. "Shear failure of a steel member due to a blast." International Journal of Impact Engineering. 24 (2000) 231-238.

(Sennett 1994) Sennett, Robert E. Matrix Analysis of Structures. Long Grove, Illinois: Waveland Press, Inc. 1994.

(Smith and Hetherington 1994) Smith, P.D. and J. G. Hetherington. Blast and Ballistic Loading of Structures. Oxford, United Kingdom: Butterworth-Heinemann Ltd., 1994.

Verification and Expansion of Single-Degree-of-Freedom Transformation Factors for Beams Using a Multi-Degree-of-Freedom Non-Linear Numerical Analysis Method 
(U.S. Army Corps of Engineers 2008) U.S. Army Corps of Engineers. U.S. Army Corps of Engineers Protective Design Center Technical Report: Methodology Manual for the Single-Degree-of-Freedom Blast Effects Design Spreadsheets. Omaha: U.S. Army Corps of Engineers Protective Design Center, 2008.

(U.S. Department of the Army 1990) U.S. Department of the Army. Structures to Resist the Effects of Accidental Explosions, Army TM 5-1300, Navy NAVFAC P-397, $A F R$ 88-2.Washington, DC: Departments of the Army, Navy and Air Force, 1990.

(Weaver and Johnston 1987) Weaver Jr., William, and Paul R. Johnston. Structural Dynamics by Finite Element. Englewood Cliffs, New Jersey: Prentice-Hall, Inc., 1987. 


\subsection{APPENDIX}

\subsection{Example Derivation of Equivalent SDOF Factors (Biggs’ Method)}

As introduced in Section 2, the Biggs' factors can be derived using the general deflection equation. The following is an example for a uniform load over a fix fixed beam.

Stiffness of the beam is defined as

$$
k=\frac{P}{\delta_{\max }}
$$

Substitute in $P=w l$ and $\delta_{\max }=\frac{w l^{4}}{384 E I}$ for $k$.

$$
k=\frac{384 E I}{l^{3}}
$$

A shape function is needed to derive the mass and stiffness factors. This shape function is based on the deflection equation for a uniform loading on a fix-fixed beam:

$$
\delta(x)=\frac{w x}{24 E I}\left(l^{3}-2 l x^{2}+x^{3}\right)
$$

The shape function is the deflection equation divided by the max deflection

$$
\begin{aligned}
& \phi(x)=\frac{\frac{w x}{24 E I}\left(l^{3}-2 l x^{2}+x^{3}\right)}{\frac{w l^{4}}{384 E I}} \\
& \phi(x)=\frac{16 x}{l^{4}}\left(l^{3}-2 l x^{2}+x^{3}\right)
\end{aligned}
$$

Plug the shape function into the $K_{M}$ Eq. 5 and the $K_{L}$ Eq. 9

Verification and Expansion of Single-Degree-of-Freedom Transformation Factors for Beams Using a Multi-Degree-of-Freedom Non-Linear Numerical Analysis Method 


$$
\begin{gathered}
K_{M}=\frac{\int^{L} m \phi^{2}(x) d x}{m L}=0.410 \\
K_{L}=\frac{\int^{L} p \phi(x) d x}{p L}=0.530
\end{gathered}
$$

For the resistance function, the maximum bending value, $\mathrm{M}_{\mathrm{P}}$, is used.

$$
M_{P}(0, L)=\frac{w l^{2}}{12}
$$

Solve for the load that causes $M_{P}$

$$
w l=R_{m}=\frac{12 M_{P}}{l}
$$

\begin{tabular}{|c|c|c|c|c|c|}
\hline $\begin{array}{l}\text { Loading } \\
\text { Diagram }\end{array}$ & $\begin{array}{l}\text { Strain } \\
\text { Range }\end{array}$ & $\begin{array}{c}\text { Load } \\
\text { Factor } \\
K_{L}\end{array}$ & $\begin{array}{c}\text { Mass } \\
\text { Factor } \\
K_{M}\end{array}$ & $\begin{array}{c}\text { Maximum Resistance } \\
R_{m}\end{array}$ & $\begin{array}{c}\text { Spring } \\
\text { Constant } \\
k\end{array}$ \\
\hline 志 & $\begin{array}{c}\text { Elastic } \\
\text { E-P } \\
\text { Plastic }\end{array}$ & 0.530 & 0.410 & $\frac{12 M_{p}}{L}$ & $\frac{384 E I}{L^{3}}$ \\
\hline
\end{tabular}

With the values calculated above, the elastic factors and values can be filled in on the Biggs Factors Table.

Table 18: Equivalent SDOF factors example

\subsection{SDOF Average Acceleration Matlab program}

The study uses the algorithm below for the analysis of a SDOF system. This algorithm has passed the verification process outlined in Section 7; however, there may 
still be errors contained in the program. It is the responsibility of the user to verify the algorithm.

Table 19: Matlab algorithm for nonlinear numerical analysis of a SDOF system

\begin{tabular}{|c|c|c|}
\hline File & Matlab Algorithm & Commentary \\
\hline & 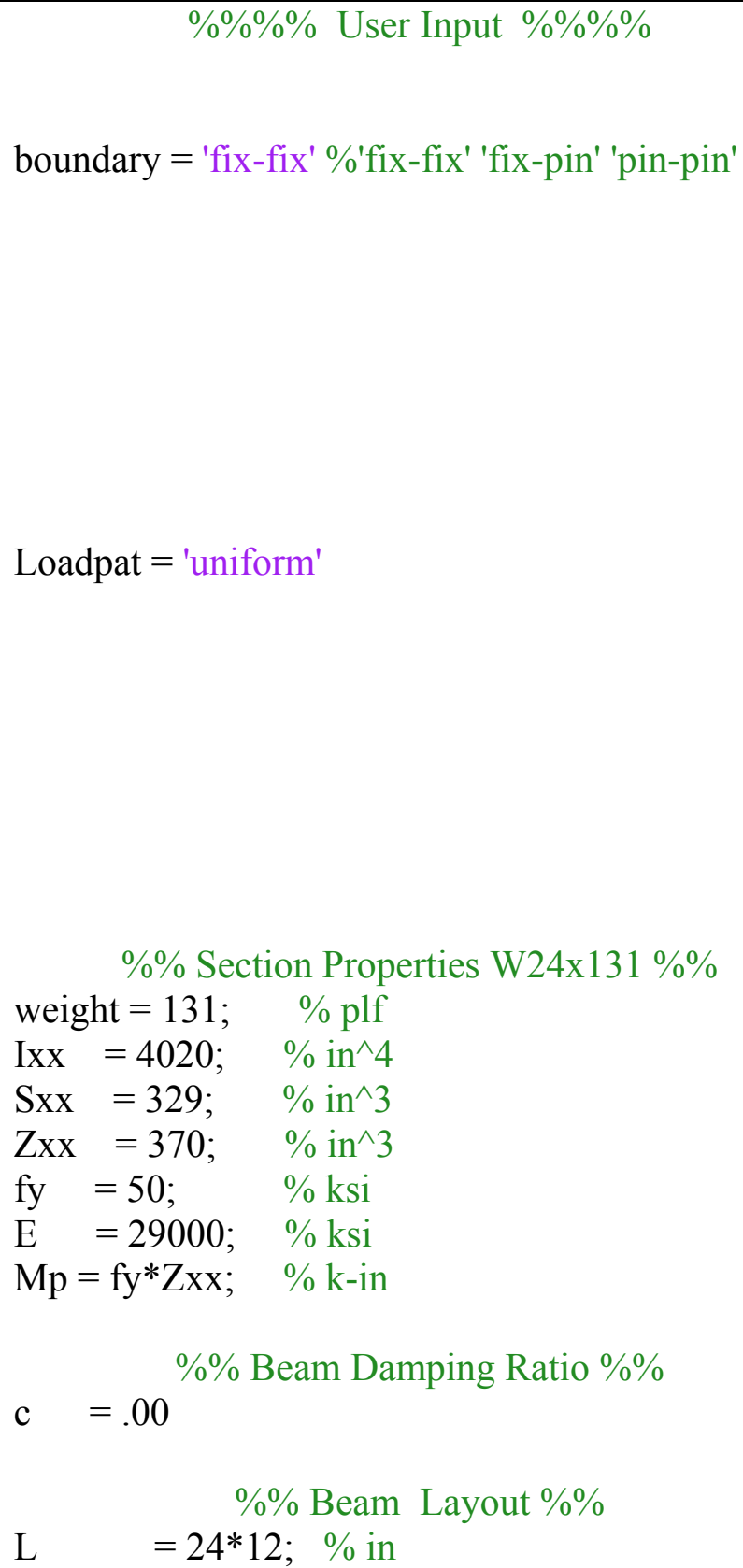 & $\begin{array}{l}\text { "\%" are used as comment } \\
\text { lines. } \\
\text { Select boundary } \\
\text { conditions: } \\
\text { 'fix-fix' for both ends } \\
\text { fixed } \\
\text { 'fix-pin' for (1) fixed end } \\
\text { and (1) pinned end } \\
\text { 'pin-pin' for both ends } \\
\text { pinned } \\
\text { Loading type: } \\
\text { - uniform = 'uniform', } \\
\text { - point load = 'pointld', } \\
\text { - linear starting at } 0(1 \mathrm{eft}) \\
\text { and Pr(right) = 'linearR', } \\
\text { - triangular with peak in } \\
\text { middle = 'triangl' } \\
\text { - parabolic with } 0(\text { left) } \\
\text { and Pr(right) = 'parabol' } \\
\text { Assumes the beam is a } \\
\text { W24x131 and lists the } \\
\text { section properties as well } \\
\text { as the material properties. }\end{array}$ \\
\hline
\end{tabular}

Verification and Expansion of Single-Degree-of-Freedom Transformation Factors for Beams Using a Multi-Degree-of-Freedom Non-Linear Numerical Analysis Method 


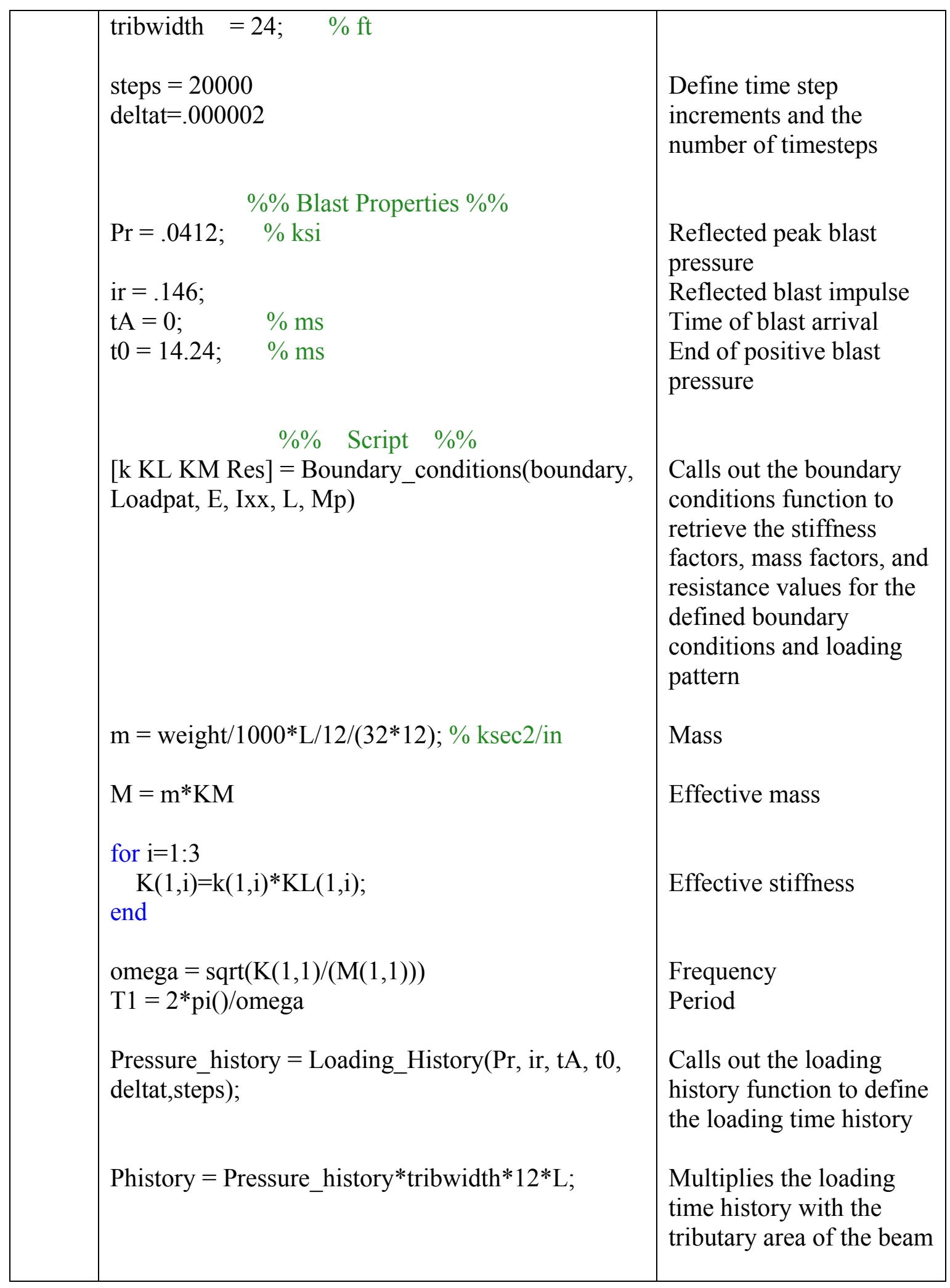

Verification and Expansion of Single-Degree-of-Freedom Transformation Factors for Beams Using a Multi-Degree-of-Freedom Non-Linear Numerical Analysis Method 


\begin{tabular}{|c|c|c|}
\hline & $\begin{array}{l}\mathrm{u} \text { R] }= \\
\text { Newmark_Average(k,K,KL,Res,Phistory,c,M,delta } \\
\text { t,steps); }\end{array}$ & $\begin{array}{l}\text { Calls out the Newmark } \\
\text { Average function that } \\
\text { runs the SDOF system } \\
\text { through Newmark's } \\
\text { Average Acceleration } \\
\text { numerical analysis } \\
\text { method }\end{array}$ \\
\hline 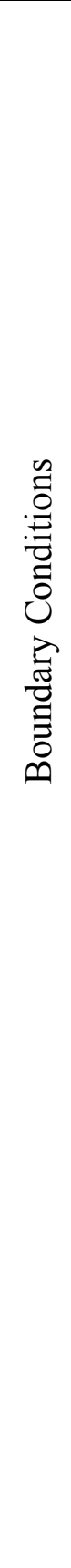 & 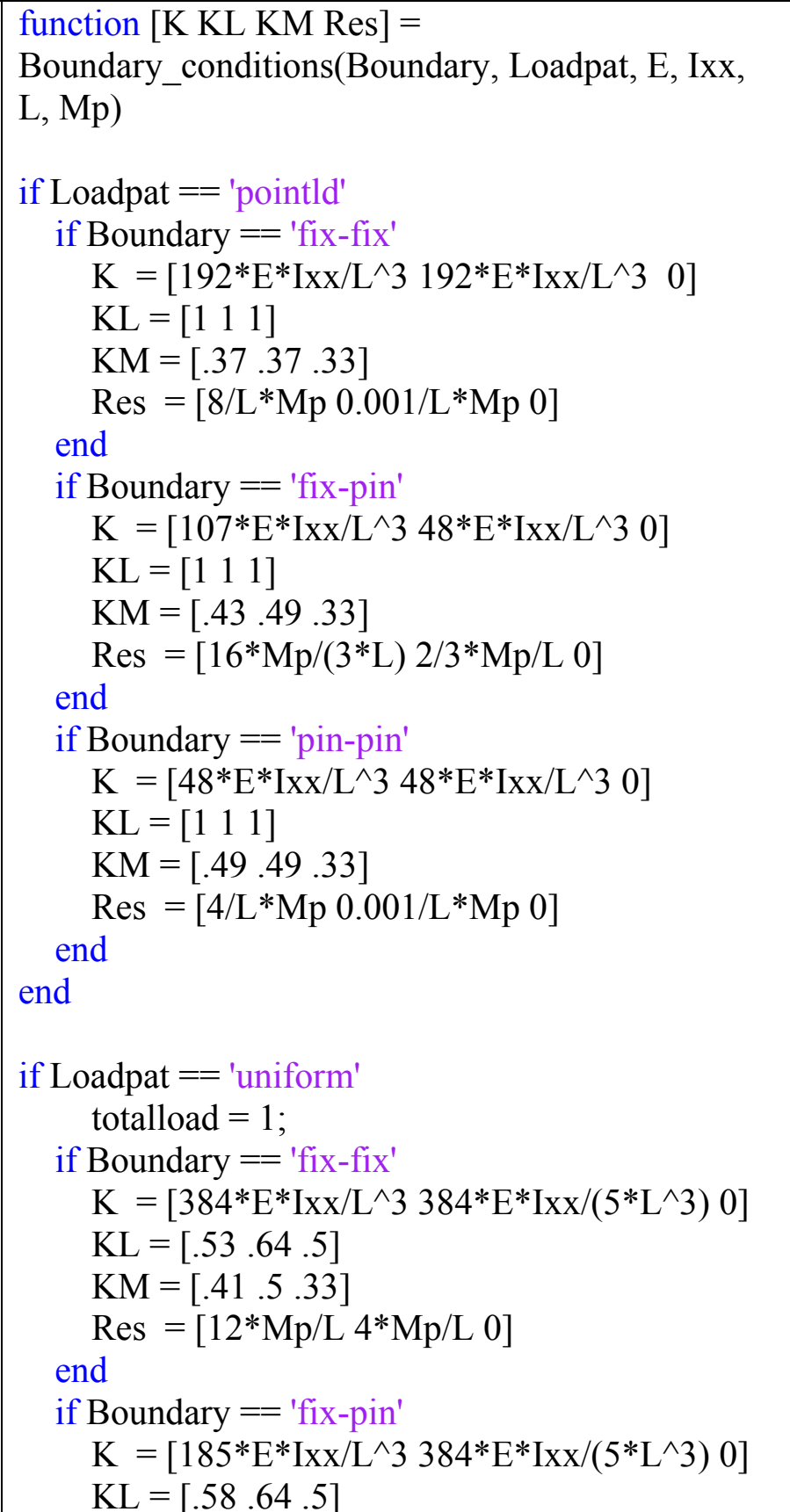 & $\begin{array}{l}\text { Assigns the stiffness, } \\
\text { stiffness factors, mass } \\
\text { factors and resistance } \\
\text { values based on the } \\
\text { boundary conditions and } \\
\text { loading pattern }\end{array}$ \\
\hline
\end{tabular}

Verification and Expansion of Single-Degree-of-Freedom Transformation Factors for Beams Using a Multi-Degree-of-Freedom Non-Linear Numerical Analysis Method 


\begin{tabular}{|c|}
\hline 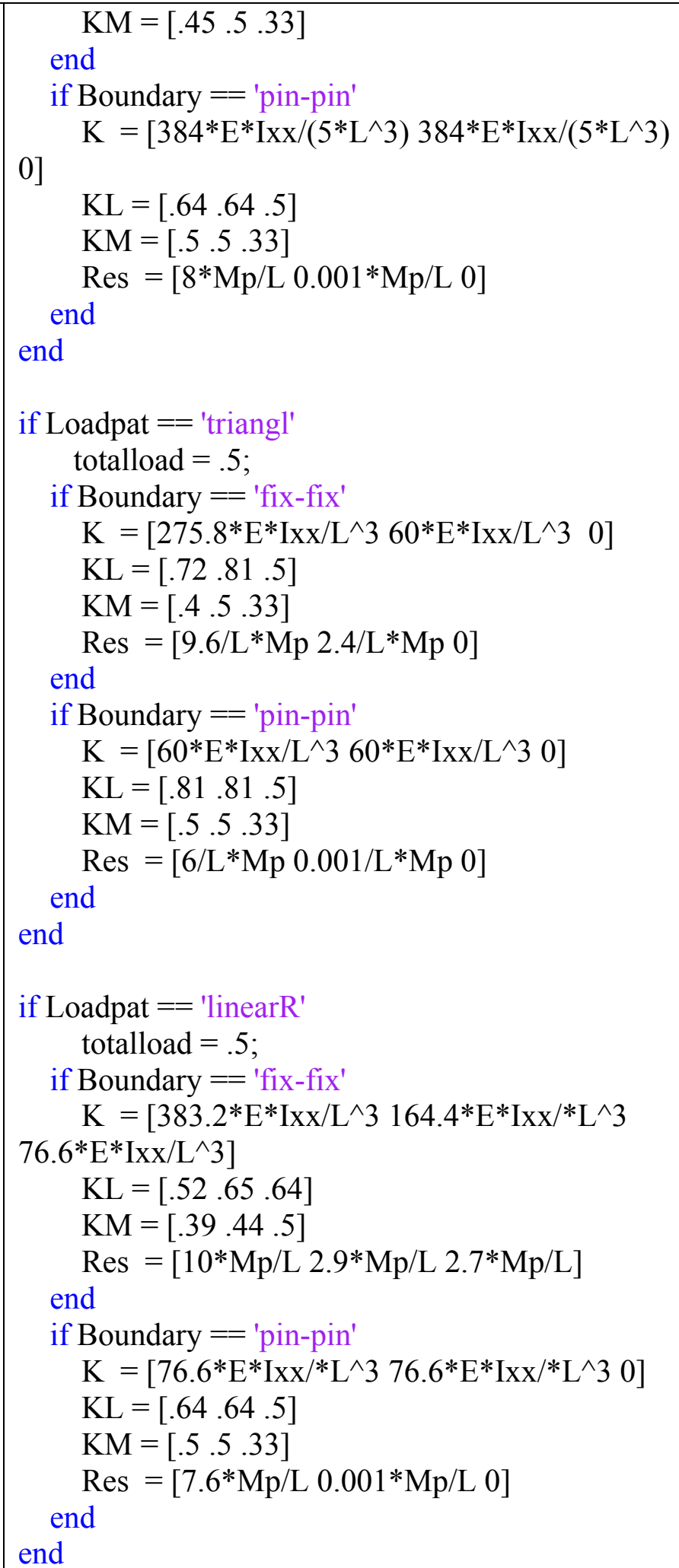 \\
\hline
\end{tabular}

Verification and Expansion of Single-Degree-of-Freedom Transformation Factors for Beams Using a Multi-Degree-of-Freedom Non-Linear Numerical Analysis Method 


\begin{tabular}{|c|c|c|}
\hline & $\begin{array}{l}\text { if Loadpat }==\text { 'parabol' } \\
\text { totalload }=1 / 3 \text {; } \\
\text { if Boundary }==\text { 'fix-fix' } \\
\mathrm{K}=\left[447.2^{*} \mathrm{E}^{*} \mathrm{Ixx} / \mathrm{L}^{\wedge} 3172.6^{*} \mathrm{E}^{*} \mathrm{Ixx} / \mathrm{L}^{\wedge} 3\right. \\
\left.85.9^{*} \mathrm{E}^{*} \mathrm{Ixx} / \mathrm{L}^{\wedge} 3\right] \\
\mathrm{KL}=[.45 .61 .59] \\
\mathrm{KM}=[.39 .43 .49] \\
\mathrm{Res}=\left[12^{*} \mathrm{Mp} / \mathrm{L} 8^{*} \mathrm{Mp} / \mathrm{L} 10.5^{*} \mathrm{Mp} / \mathrm{L}\right] \\
\text { end } \\
\text { if Boundary }==\text { 'pin-pin' } \\
\mathrm{K}=\left[85.9 * \mathrm{E}^{*} \mathrm{Ixx} / \mathrm{L}^{\wedge} 385.9 * \mathrm{E}^{*} \mathrm{Ixx} / \mathrm{L}^{\wedge} 30\right] \\
\mathrm{KL}=[.59 .59 .5] \\
\mathrm{KM}=[.49 .49 .33] \\
\mathrm{Res}=\left[8.47^{*} \mathrm{Mp} / \mathrm{L} 0.001 * \mathrm{Mp} / \mathrm{L} 0\right] \\
\text { end } \\
\text { end }\end{array}$ & \\
\hline $\begin{array}{l}\stackrel{\lambda}{0} \\
0 \\
.00 \\
0 \\
0 \\
0 \\
0 \\
0 \\
0 \\
0 \\
0\end{array}$ & 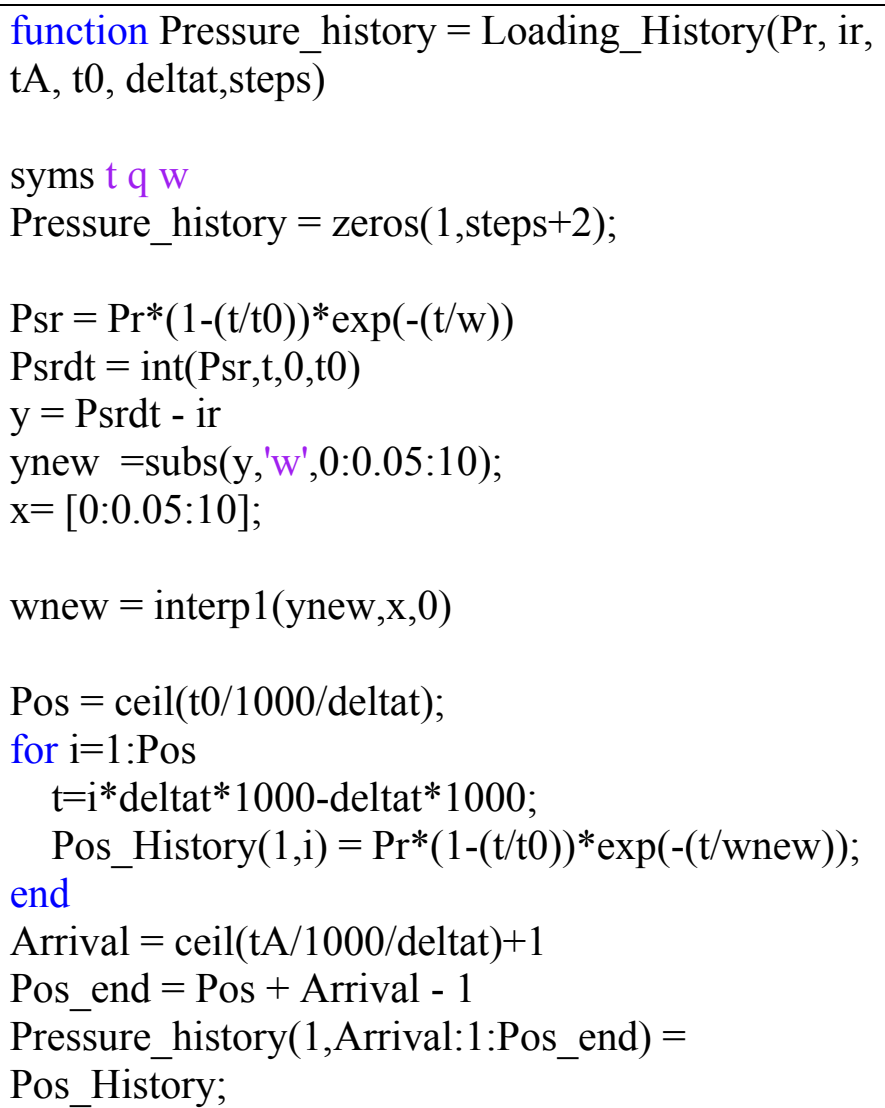 & $\begin{array}{l}\text { Creates the pressure time } \\
\text { history as outlined in } \\
\text { Section } 6.3\end{array}$ \\
\hline & function $[\mathrm{u} \mathrm{R}]=$ & Runs the numerical \\
\hline
\end{tabular}

Verification and Expansion of Single-Degree-of-Freedom Transformation Factors for Beams Using a Multi-Degree-of-Freedom Non-Linear Numerical Analysis Method 


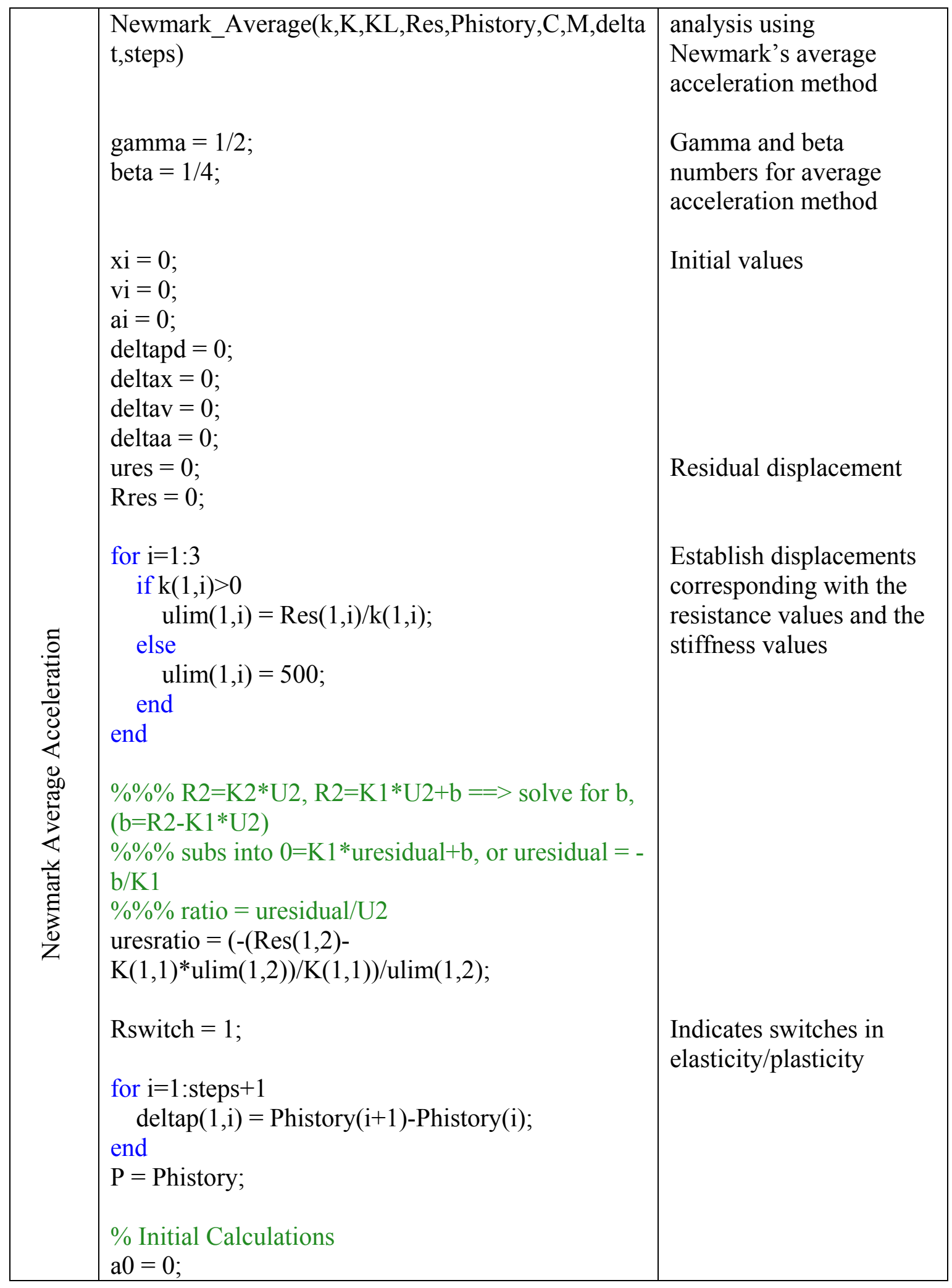

Verification and Expansion of Single-Degree-of-Freedom Transformation Factors for Beams Using a Multi-Degree-of-Freedom Non-Linear Numerical Analysis Method 


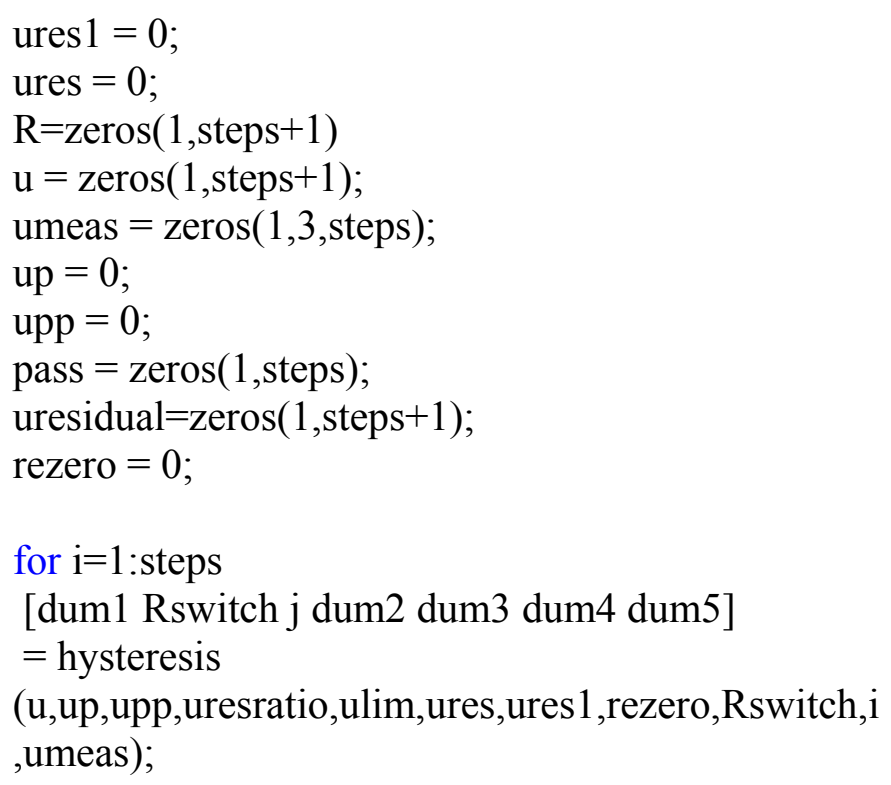

Verification and Expansion of Single-Degree-of-Freedom Transformation Factors for Beams Using a Multi-Degree-of-Freedom Non-Linear Numerical Analysis Method
Start of time-steps Calls out the hysteresis function to calculate the state of plasticity of the system

2.2

2.3

2.4 calculate incremental effective load

2.5 calculate $\Delta \mathrm{x}$

2.6 calculate $\Delta \mathrm{v}$

2.7 new $x$ 


\begin{tabular}{|c|c|c|}
\hline & $\begin{array}{l}\text { end } \\
\text { vi = vi }+ \text { deltav; } \\
\text { ai }=\left(P(i+1) * K L(1, j)-C^{*} v i-R(i+1)\right) / M(1, j) \\
\text { uresidual(i) = ures; } \\
\text { end }\end{array}$ & $\begin{array}{l}2.7 \text { new } \mathrm{v} \\
2.8 \text { new a }\end{array}$ \\
\hline 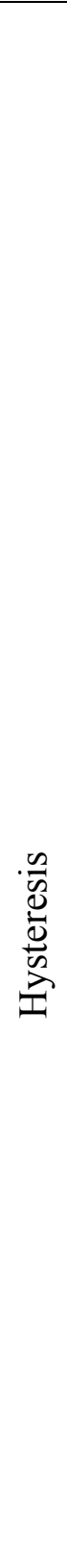 & 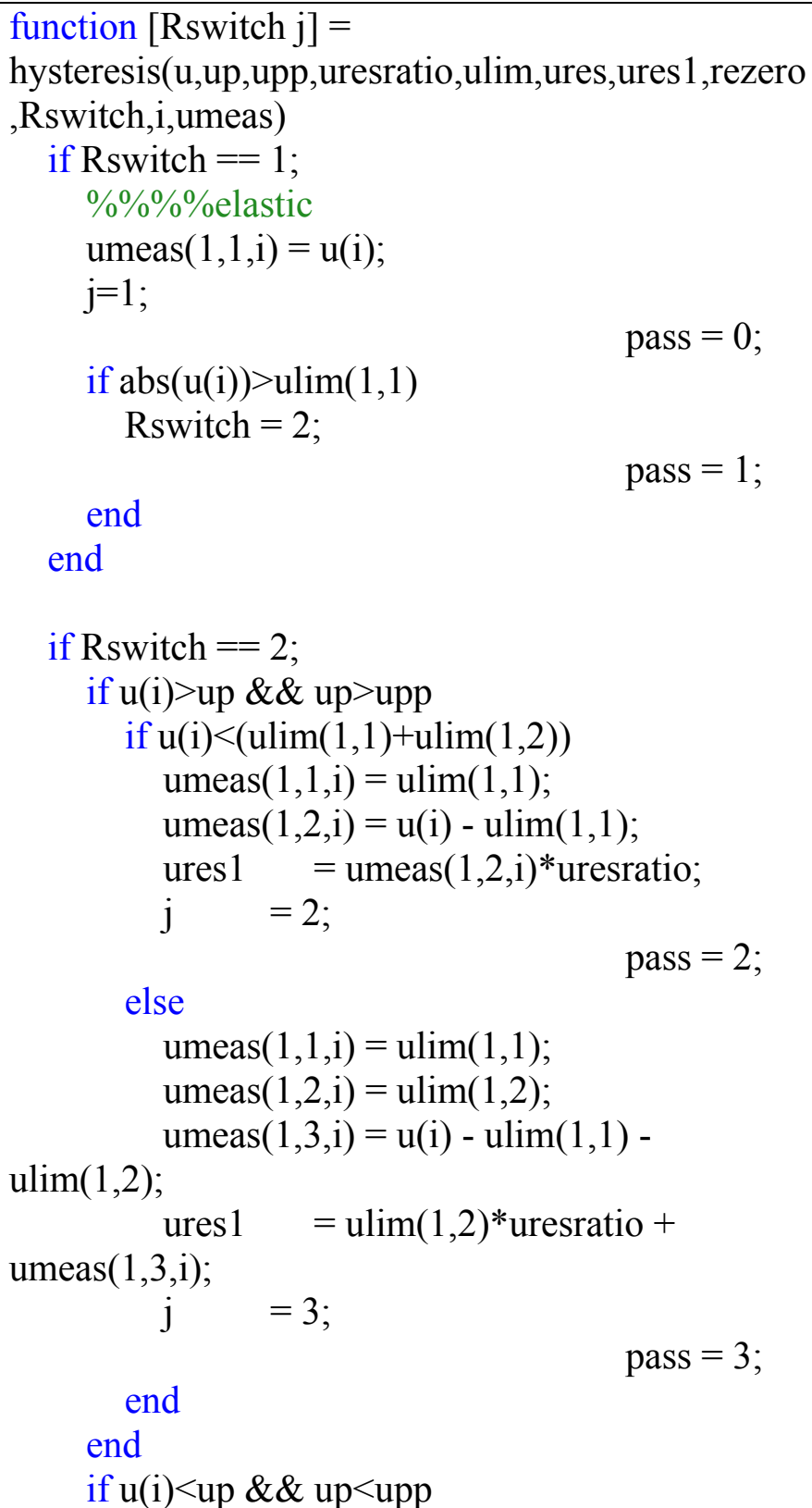 & $\begin{array}{l}\text { This function dictates } \\
\text { what stage of the } \\
\text { hysteresis loop the } \\
\text { system is in. } \\
\text { Rswitch }=1 \text { : elastic } \\
\text { Rswitch }=2 \text { : yield } \\
\text { Rswitch }=3 \text { : direction } \\
\text { change } \\
\mathrm{j}=1 \text { : elastic } \\
\mathrm{j}=2 \text { : elasto-plastic } \\
\mathrm{j}=3 \text { : plastic }\end{array}$ \\
\hline
\end{tabular}

Verification and Expansion of Single-Degree-of-Freedom Transformation Factors for Beams Using a Multi-Degree-of-Freedom Non-Linear Numerical Analysis Method 


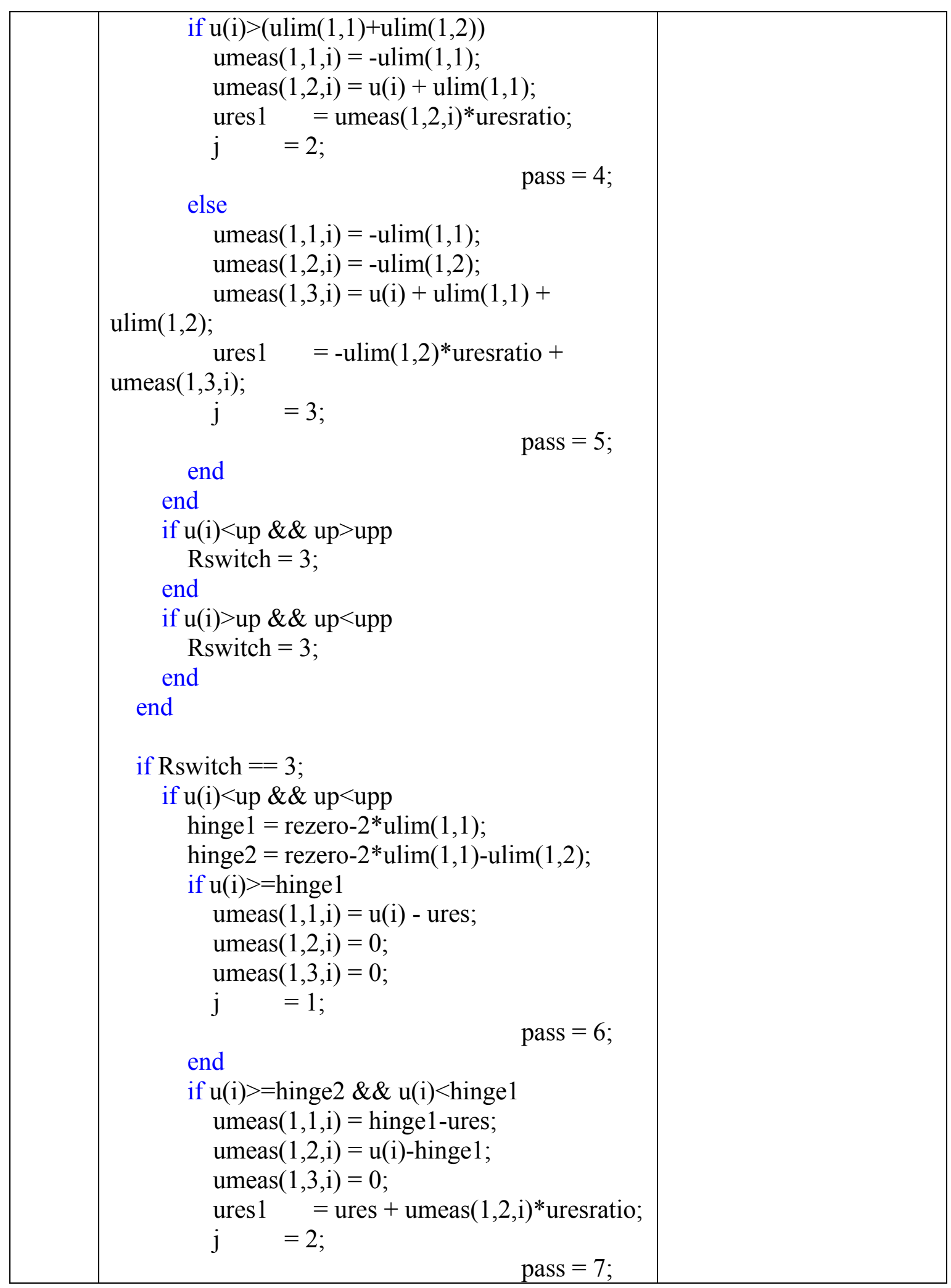

Verification and Expansion of Single-Degree-of-Freedom Transformation Factors for Beams Using a Multi-Degree-of-Freedom Non-Linear Numerical Analysis Method 


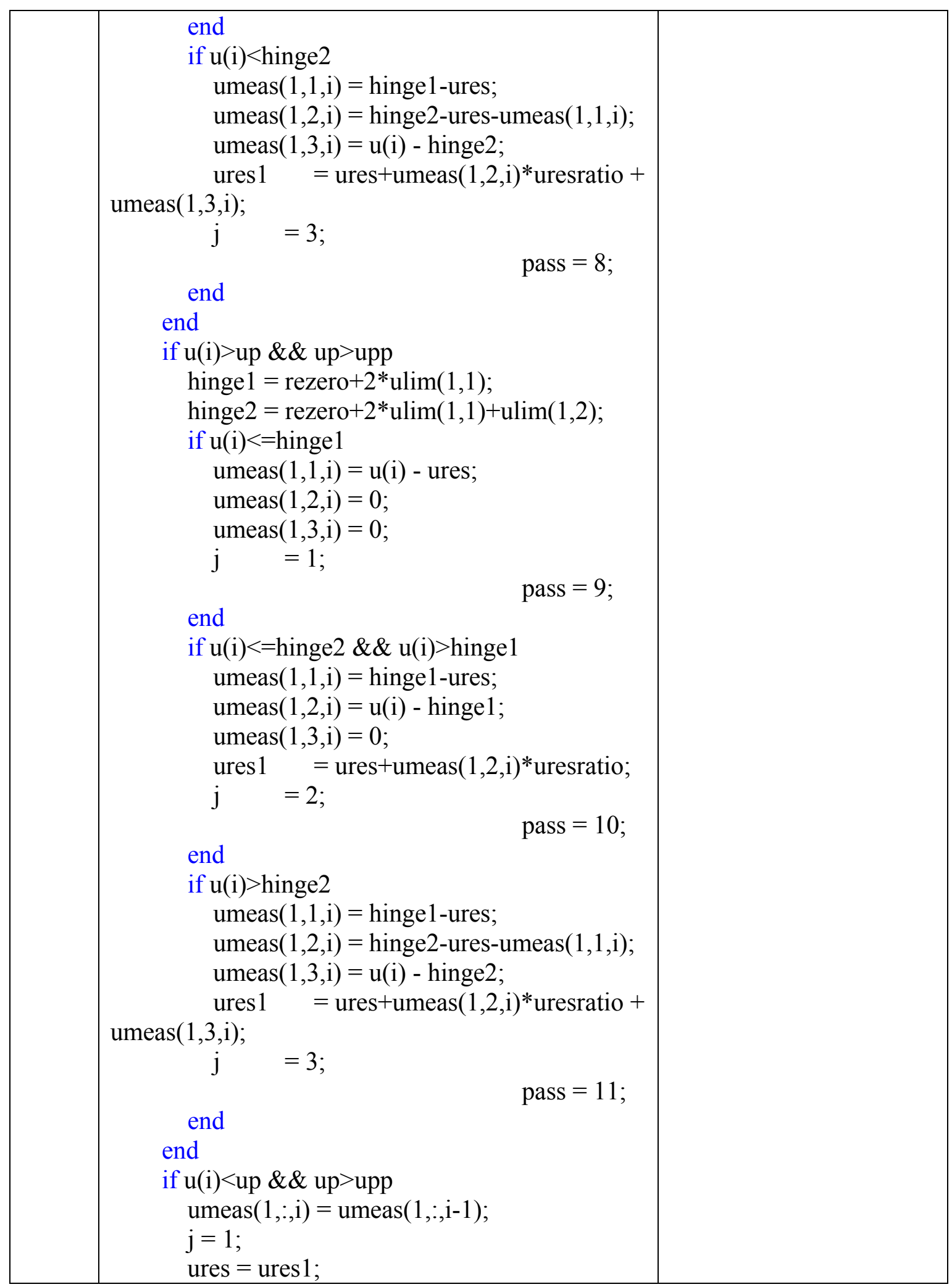

Verification and Expansion of Single-Degree-of-Freedom Transformation Factors for Beams Using a Multi-Degree-of-Freedom Non-Linear Numerical Analysis Method 


\begin{tabular}{|l|l|l|}
\hline rezero $=$ up; & pass $=12 ;$ \\
end & \\
if $\mathrm{u}(\mathrm{i})>$ up \& \& up<upp & \\
umeas $(1,:, \mathrm{i})=\operatorname{umeas}(1,:, \mathrm{i}-1) ;$ & \\
$\mathrm{j}=1 ;$ & \\
ures = ures1; & \\
rezero = up; & pass $=13 ;$ \\
end & \\
end & \\
\hline
\end{tabular}

\subsection{MDOF Average Acceleration Matlab program}

The study uses the algorithm below for the analysis of a SDOF system. This algorithm has passed the verification process outlined in Section 7; however, there may still be errors contained in the program. It is the responsibility of the user to verify the algorithm.

Table 20: Matlab algorithm for nonlinear numerical analysis of a MDOF system

\begin{tabular}{|c|c|c|}
\hline File & Matlab Algorithm & Commentary \\
\hline 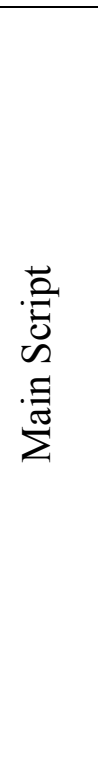 & 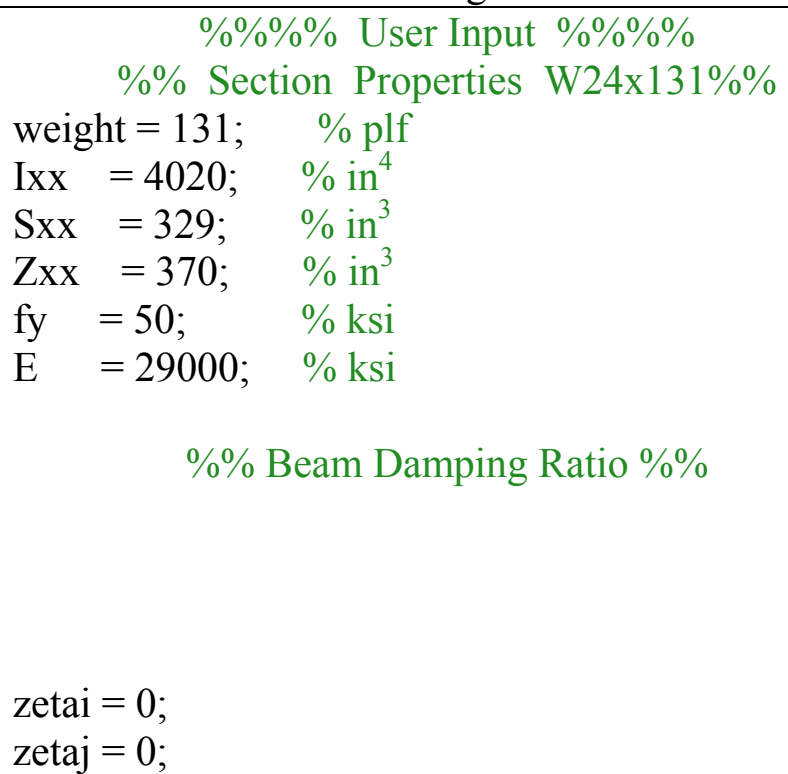 & $\begin{array}{l}\text { Damping is not used for } \\
\text { analysis in this study, but } \\
\text { the program is capable of } \\
\text { Rayleigh Damping } \\
1^{\text {st }} \text { mode damping } \\
2^{\text {nd }} \text { mode damping }\end{array}$ \\
\hline
\end{tabular}

Verification and Expansion of Single-Degree-of-Freedom Transformation Factors for Beams Using a Multi-Degree-of-Freedom Non-Linear Numerical Analysis Method 


\begin{tabular}{|c|c|}
\hline 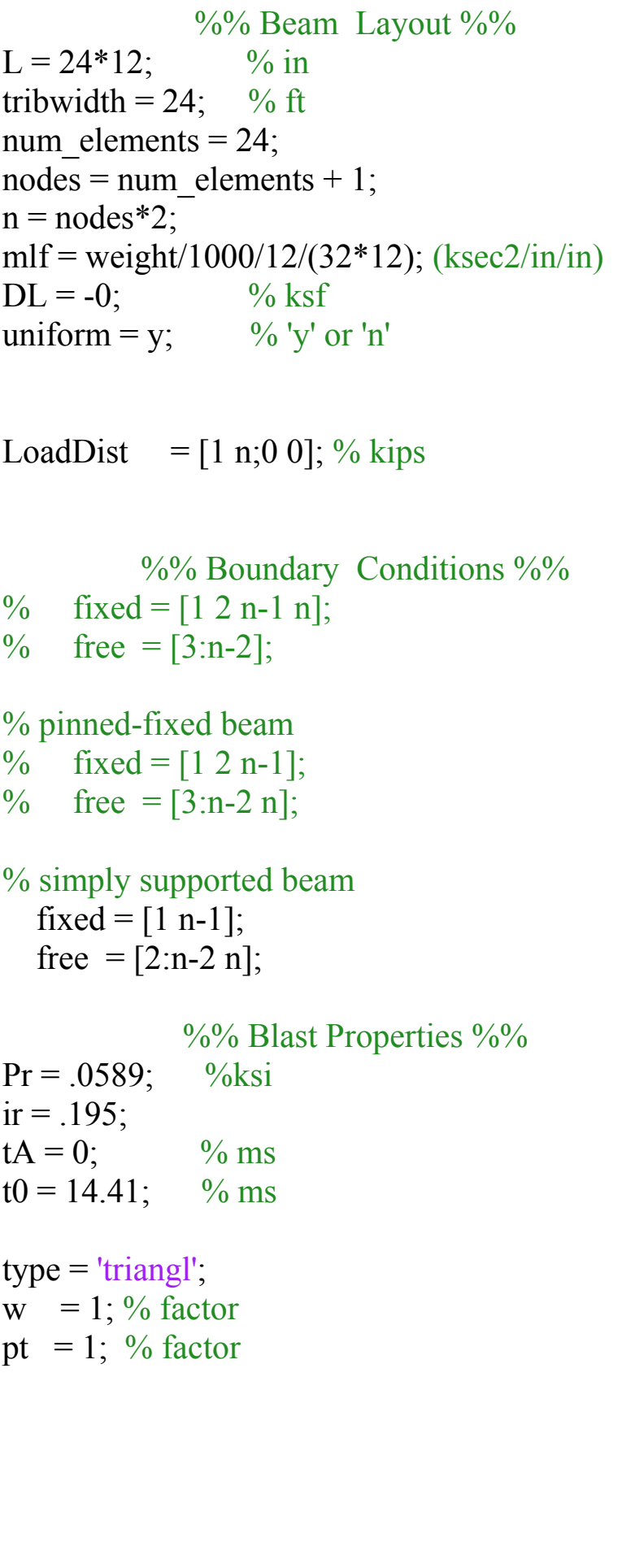 & $\begin{array}{l}\text { Beam geometry } \\
\text { Length of beam } \\
\text { Tributary width } \\
\text { Number of finite } \\
\text { elements } \\
\text { Mass per lineal foot } \\
\text { Dead load } \\
\text { Dead load distribution - } \\
\text { 'y'= uniform load, ' } n \text { ' }= \\
\text { point loads } \\
\text { Point load location and } \\
\text { load } \\
\text { Boundary conditions } \\
\text { Comment out the } \\
\text { conditions not in use } \\
1 \text { and ( } 2 n-1) \text { are vertical } \\
\text { translation at the ends } \\
2 \text { and ( } 2 n) \text { are rotation at } \\
\text { the ends }\end{array}$ \\
\hline & \\
\hline
\end{tabular}

Verification and Expansion of Single-Degree-of-Freedom Transformation Factors for Beams Using a Multi-Degree-of-Freedom Non-Linear Numerical Analysis Method 


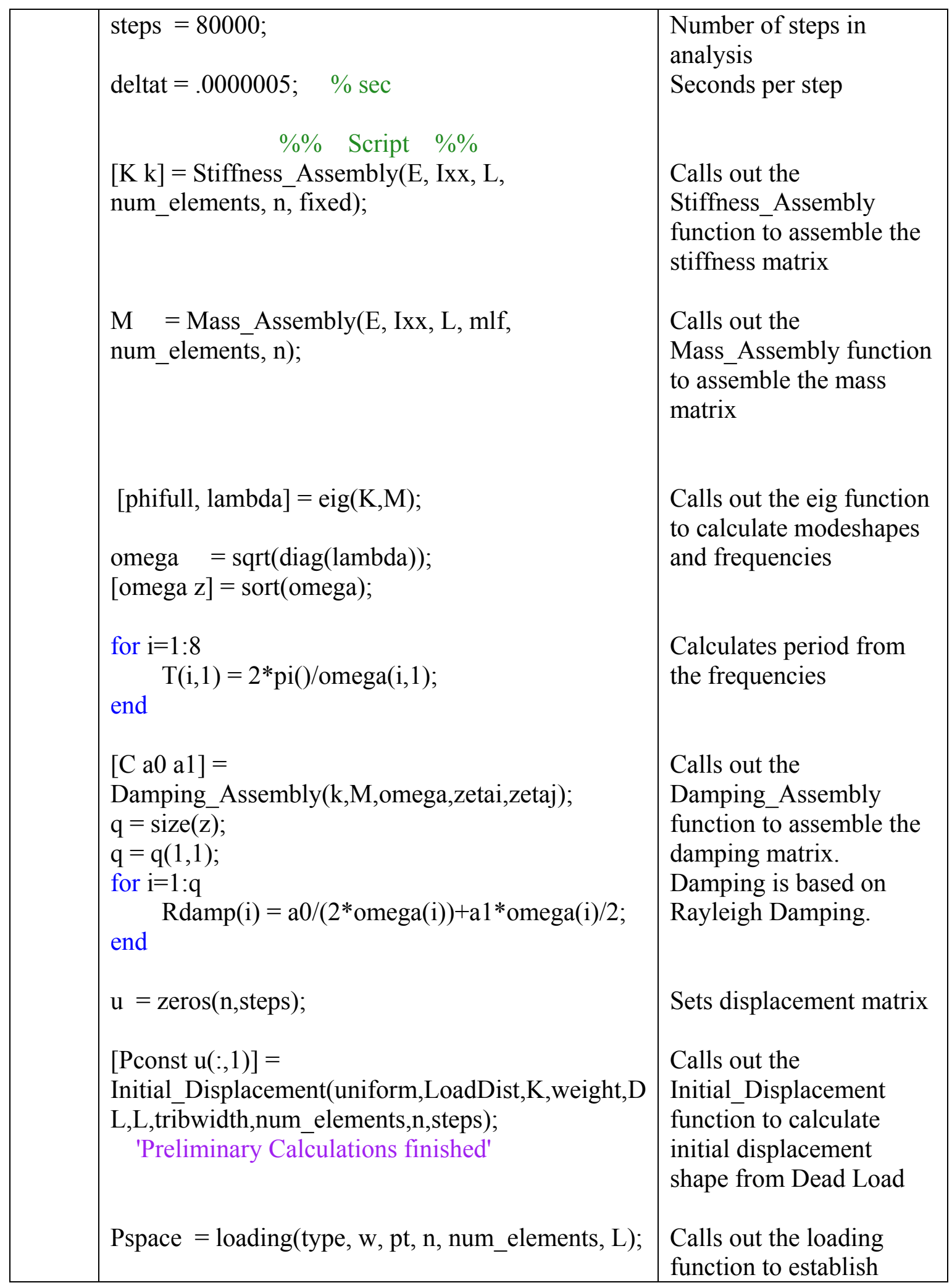

Verification and Expansion of Single-Degree-of-Freedom Transformation Factors for Beams Using a Multi-Degree-of-Freedom Non-Linear Numerical Analysis Method 


\begin{tabular}{|c|c|c|}
\hline & $\begin{array}{l}\text { Phistory = Pressure_history*tribwidth* } 12 * 12 ; \\
\text { P = Pspace * Phistory; } \\
\text { 'Loading finished' } \\
\text { Kfree = K(free,free); } \\
\text { Mfree = M(free,free); } \\
\text { Cfree = C(free,free); } \\
\text { Pspacefree = Pspace(free,1); } \\
\text { [u Ma Keff count] }= \\
\text { NewmarkMDOF(n,Kfree,Phistory,Pspacefree,Pcon } \\
\text { st,Cfree,Mfree,deltat,steps,E,Ixx,Sxx,Zxx,fy,L,num } \\
\text { elements,fixed,free,u); }\end{array}$ & $\begin{array}{l}\text { loading distribution along } \\
\text { the length of the beam } \\
\text { Calls out the } \\
\text { Loading_History } \\
\text { function to calculate the } \\
\text { pressuretime history } \\
\text { Adjusts loading per } \\
\text { tributary width } \\
\text { Builds a full loading } \\
\text { matrix over space and } \\
\text { time }\end{array}$ \\
\hline 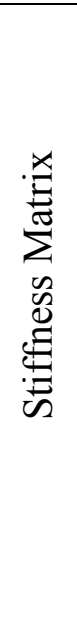 & $\begin{array}{l}\text { function }[\mathrm{K} \mathrm{k}]=\text { Stiffness_Assembly(E, Ixx, L, } \\
\text { num_elements, n, fixed) } \\
\mathrm{K}=\text { zeros(n,n); } \\
\text { l= L/num_elements; } \\
\text { for } \mathrm{i}=1 \text { :num_elements } \\
\quad \mathrm{j}=\mathrm{i}^{*} 2-1\end{array}$ & $\begin{array}{l}\text { Loop structure to insert } \\
\text { the stiffness matrix of } \\
\text { each segment into the } \\
\text { global matrix. } \\
\text { Stiffness matrix of a } \\
\text { single segment }\end{array}$ \\
\hline
\end{tabular}

Verification and Expansion of Single-Degree-of-Freedom Transformation Factors for Beams Using a Multi-Degree-of-Freedom Non-Linear Numerical Analysis Method 


\begin{tabular}{|c|c|c|}
\hline & 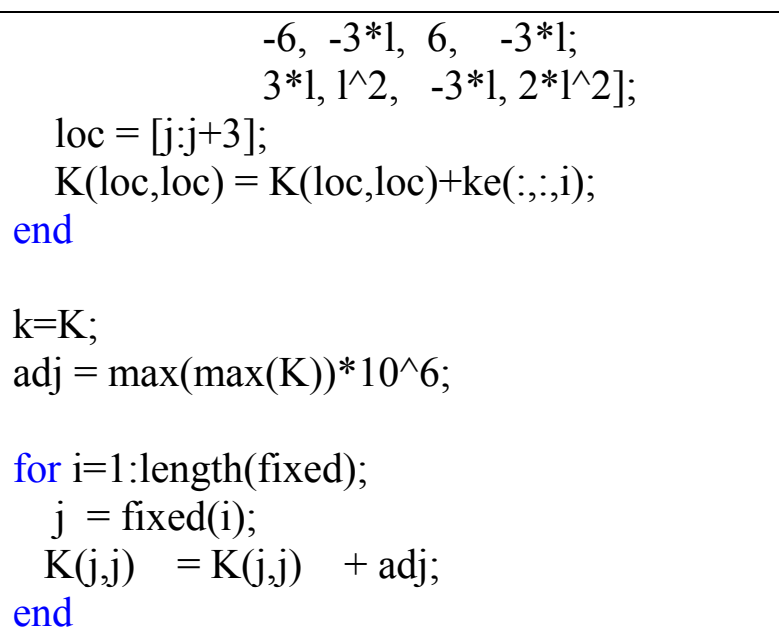 & $\begin{array}{l}\text { Adjust the stiffness of the } \\
\text { boundary condition to be } \\
\text { larger by } 10^{\wedge} 6\end{array}$ \\
\hline 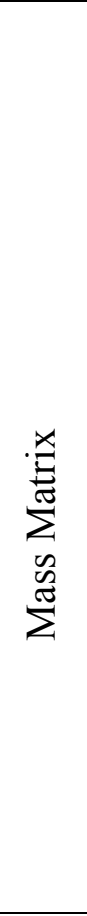 & 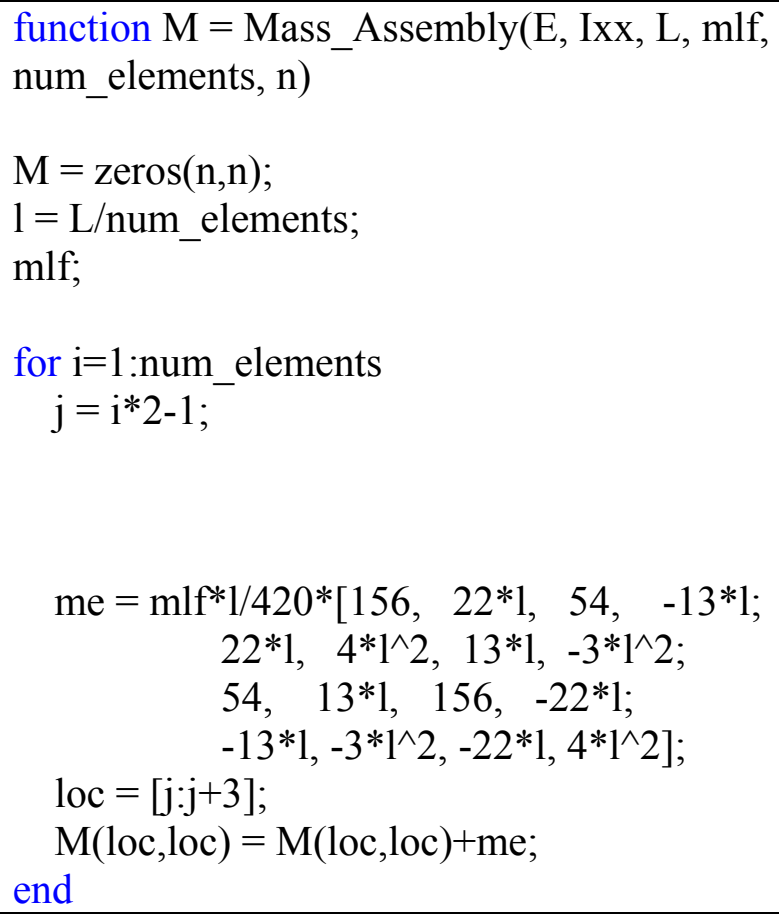 & $\begin{array}{l}\text { Loop structure to insert } \\
\text { the mass matrix of each } \\
\text { segment into the global } \\
\text { matrix. } \\
\text { Mass matrix of a single } \\
\text { segment }\end{array}$ \\
\hline 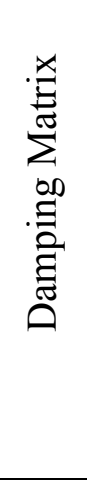 & $\begin{array}{l}\text { function }[\mathrm{C} \text { a } 0 \mathrm{a} 1]= \\
\text { Damping_Assembly }(\mathrm{K}, \mathrm{M}, \text { omega,zetai,zetaj }) \\
\text { omegai = omega }(1,1) ; \\
\text { omegaj = omega }(2,1) ; \\
\text { a = }(1 / 2 *[1 / \text { omegai, omegai; } 1 / \text { omegaj, } \\
\text { omegaj] }] \backslash \text { [zetai;zetaj]; } \\
\text { a0 = a }(1,1)\end{array}$ & $\begin{array}{l}\text { Damping matrix } \\
\text { assembly function, based } \\
\text { on Rayleigh Damping } \\
1^{\text {st }} \text { mode frequency } \\
2^{\text {nd }} \text { mode frequency } \\
\text { Solve for the damping } \\
\text { ratios }\end{array}$ \\
\hline
\end{tabular}

Verification and Expansion of Single-Degree-of-Freedom Transformation Factors for Beams Using a Multi-Degree-of-Freedom Non-Linear Numerical Analysis Method 


\begin{tabular}{|c|c|c|}
\hline & $\begin{array}{l}\mathrm{a} 1=\mathrm{a}(2,1) \\
\mathrm{C}=\mathrm{a} 0 * \mathrm{M}+\mathrm{a} 1 * \mathrm{~K}\end{array}$ & $\begin{array}{l}\text { Use the damping ratios to } \\
\text { create the Rayleigh } \\
\text { damping factor }\end{array}$ \\
\hline \multirow[t]{2}{*}{ 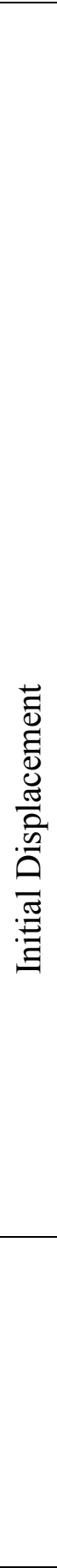 } & 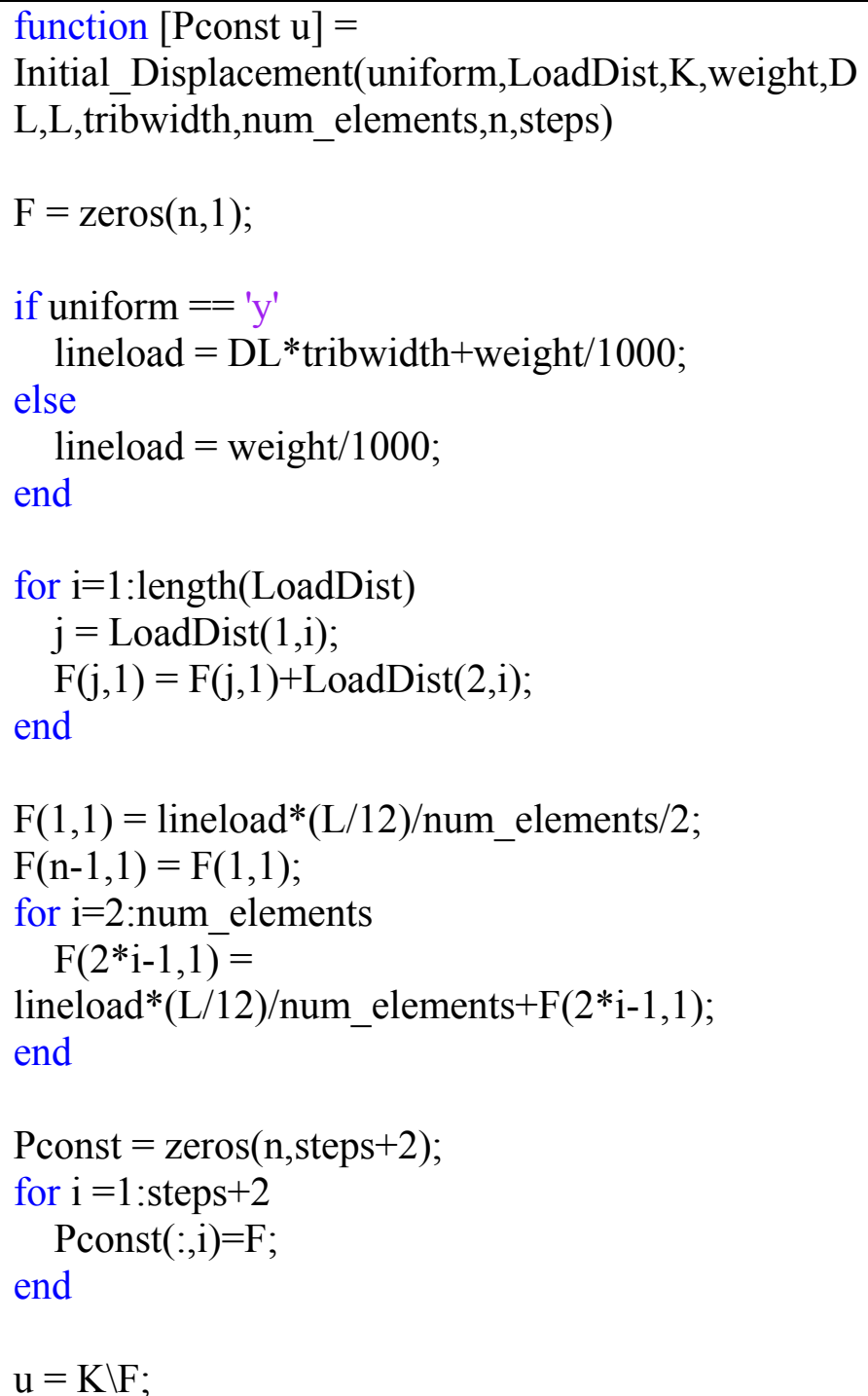 & $\begin{array}{l}\text { Calculate the initial } \\
\text { displacement of the beam } \\
\text { with a uniform } \\
\text { distribution of load } \\
\text { Locate the point loads } \\
\text { along the length of the } \\
\text { beam } \\
\text { Calculate the } \\
\text { displacement of the beam } \\
\text { based on the point loads }\end{array}$ \\
\hline & $\begin{array}{l}\text { function Pspace }=\text { loading(type, w, pt, } \mathrm{n} \text {, } \\
\text { num_elements, L) } \\
\text { Pspace = zeros }(\mathrm{n}, 1) \text {; } \\
\text { if type }==\text { 'uniform' } \\
\quad \text { total_load }=\mathrm{w}^{*} \mathrm{~L} / 12 ; \%(\mathrm{p})\end{array}$ & $\begin{array}{l}\text { Assembles the loading } \\
\text { distribution over the } \\
\text { beam length }\end{array}$ \\
\hline
\end{tabular}

Verification and Expansion of Single-Degree-of-Freedom Transformation Factors for Beams Using a Multi-Degree-of-Freedom Non-Linear Numerical Analysis Method 


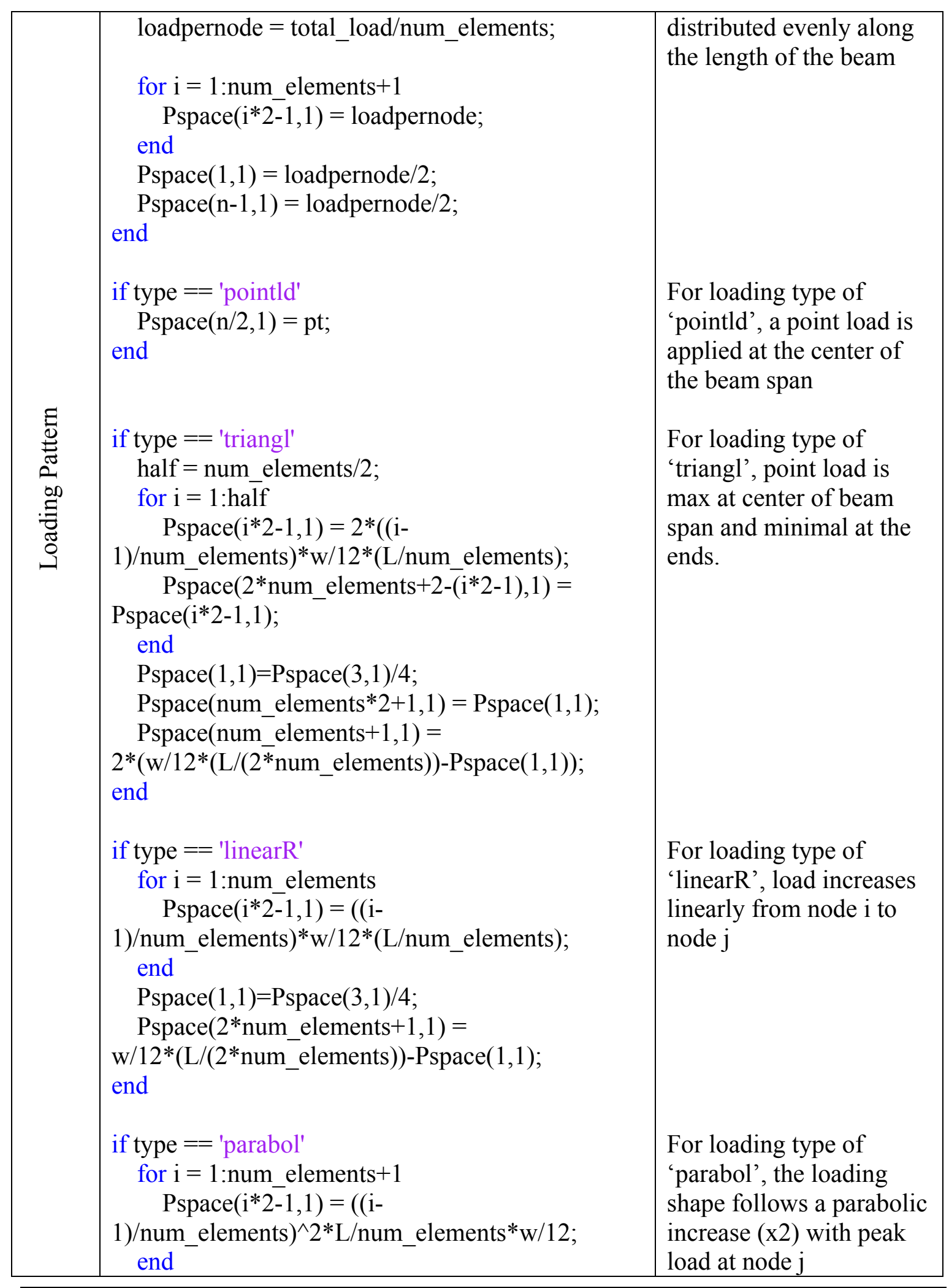

Verification and Expansion of Single-Degree-of-Freedom Transformation Factors for Beams Using a Multi-Degree-of-Freedom Non-Linear Numerical Analysis Method 


\begin{tabular}{|c|c|c|}
\hline & $\begin{array}{l}\text { Pspace }(1,1)=\operatorname{Pspace}(1,1) / 2 ; \\
\text { Pspace }(2 * \text { num_elements }+1,1)=\text { Pspace }(2 * \text { num_ele } \\
\text { ments }+1,1) / 2 \text {; } \\
\text { end }\end{array}$ & \\
\hline 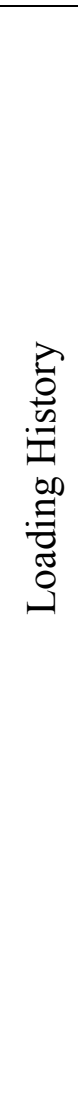 & 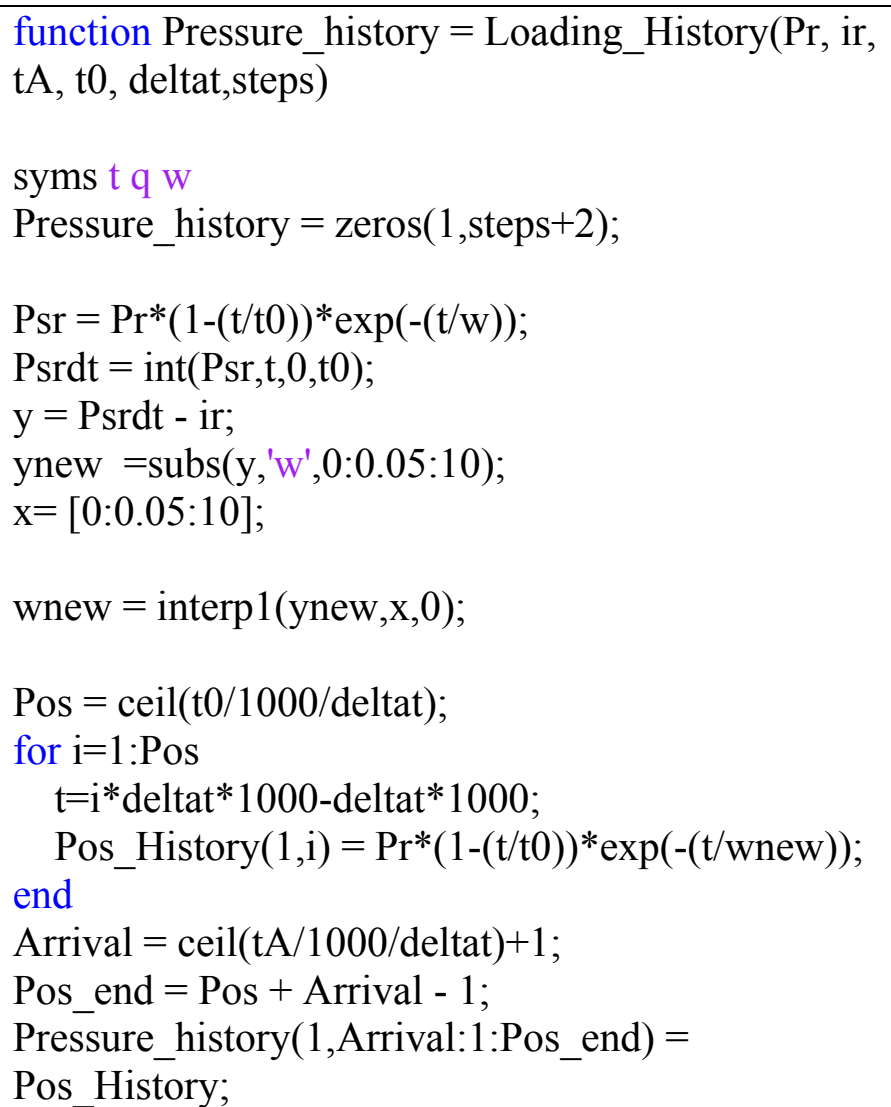 & $\begin{array}{l}\text { Develops the pressure } \\
\text { history of the blast wave } \\
\text { based on the loading } \\
\text { equations in the SBEDS } \\
\text { manual }\end{array}$ \\
\hline & $\begin{array}{l}\text { function [u Ma Keff count] = } \\
\text { NewmarkMDOF(n,K,Phistory,Pspace,Pconst,C,M, } \\
\text { deltat,steps,E,Ixx,Sxx,Zxx,fy,L,num_elements,fixe } \\
\text { d,free,u) } \\
\text { gamma = 1/2; } \\
\text { beta = 1/4; } \\
\text { l=L/num_elements; } \\
\text { flagcount = 0; } \\
\text { f=0; } \\
\text { maxed }(1)=\text { num_elements }+2 \\
\text { Mp = fy*Zxx; }\end{array}$ & $\begin{array}{l}\text { Runs the numerical } \\
\text { analysis using } \\
\text { Newmark's average } \\
\text { acceleration method } \\
\text { Gamma and beta } \\
\text { numbers for average } \\
\text { acceleration method }\end{array}$ \\
\hline
\end{tabular}

Verification and Expansion of Single-Degree-of-Freedom Transformation Factors for Beams Using a Multi-Degree-of-Freedom Non-Linear Numerical Analysis Method 


\begin{tabular}{|c|c|c|}
\hline 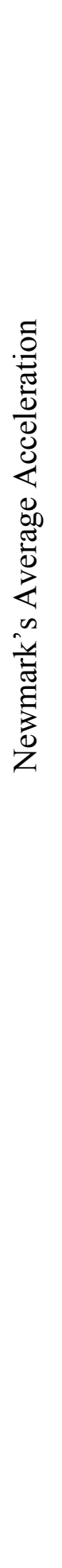 & 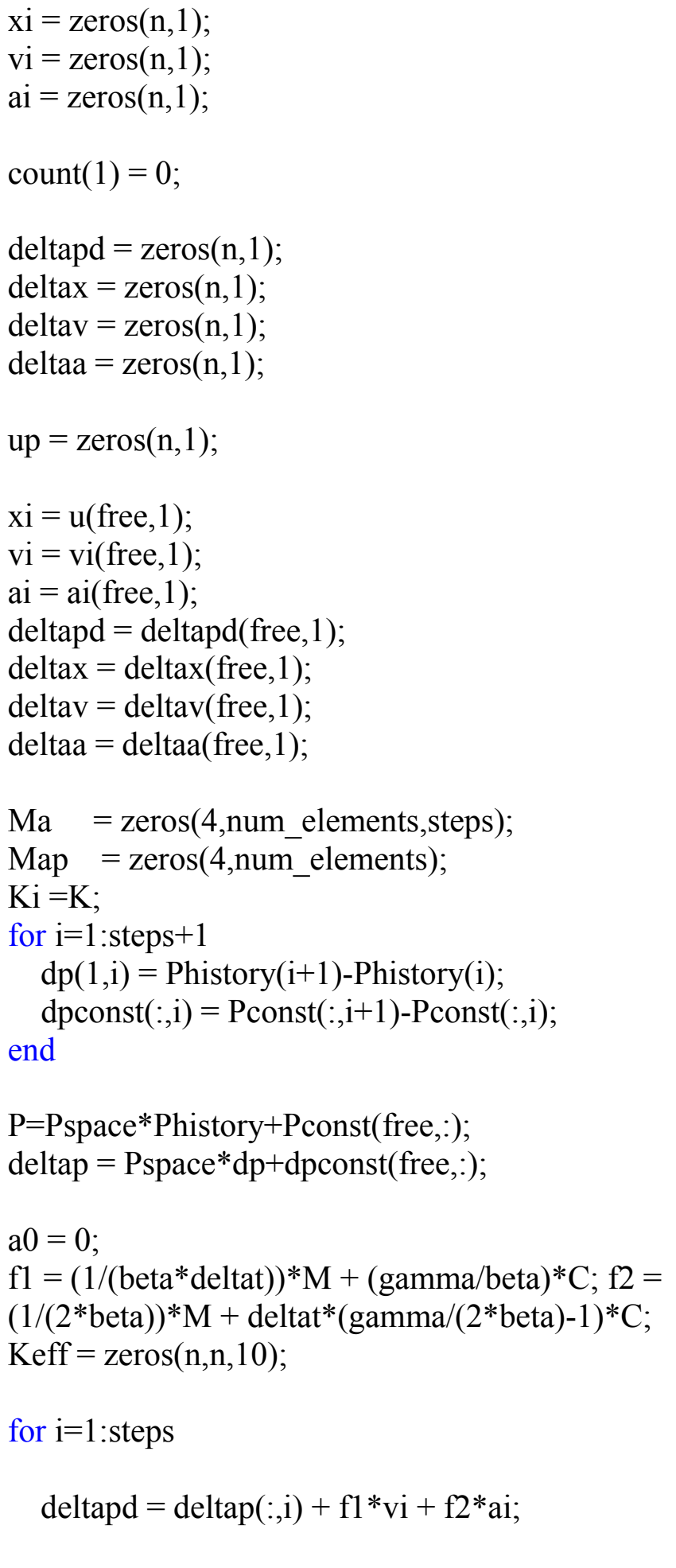 & $\begin{array}{l}\text { Add the static load to the } \\
\text { loading time history } \\
\text { Initial calculations before } \\
\text { the step by step } \\
\text { calculations }\end{array}$ \\
\hline
\end{tabular}

Verification and Expansion of Single-Degree-of-Freedom Transformation Factors for Beams Using a Multi-Degree-of-Freedom Non-Linear Numerical Analysis Method 


\begin{tabular}{|c|c|}
\hline 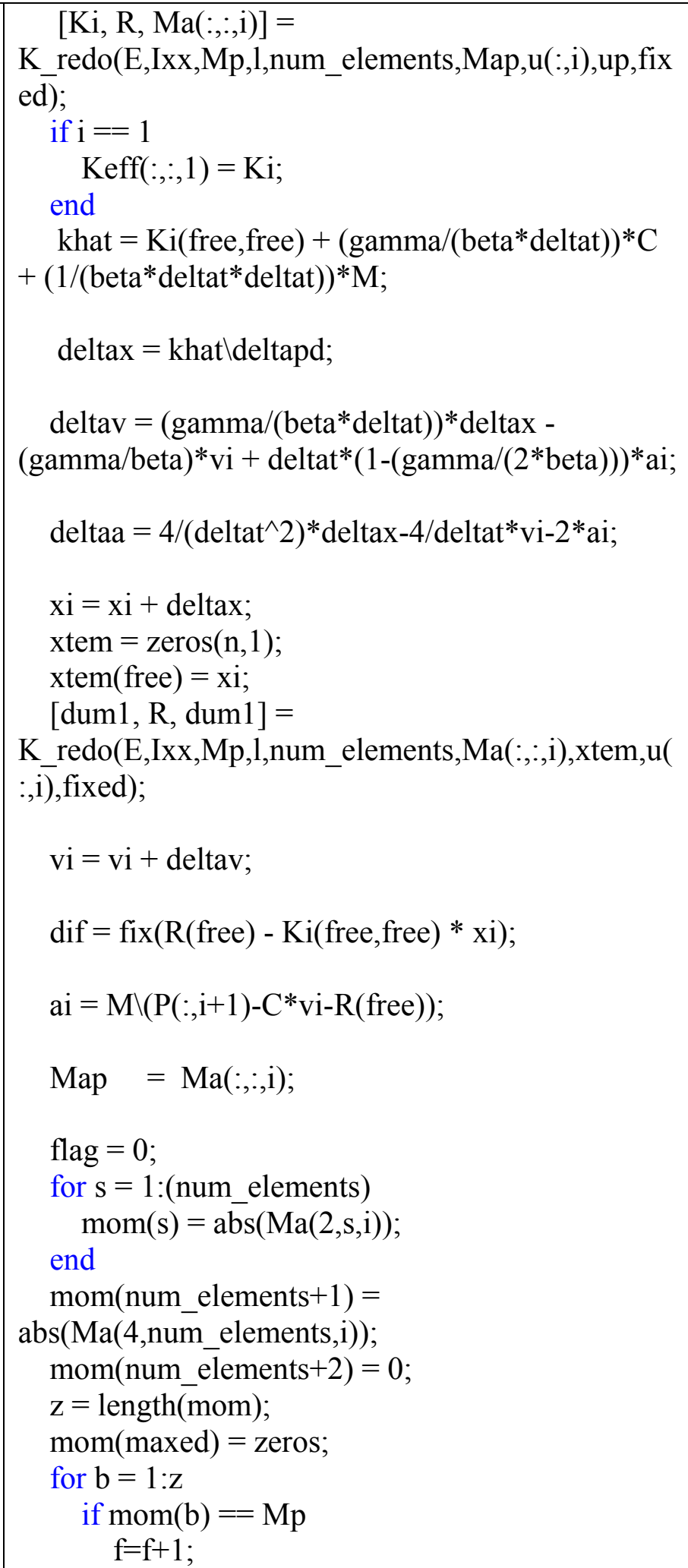 & $\begin{array}{l}\text { 3) tangent stiffness } \\
\text { 4) calculate delta } x \\
\text { 5) calculate delta } v \\
\text { 6) calculate delta a } \\
\text { 7) new } x, v \text {, and a }\end{array}$ \\
\hline
\end{tabular}

Verification and Expansion of Single-Degree-of-Freedom Transformation Factors for Beams Using a Multi-Degree-of-Freedom Non-Linear Numerical Analysis Method 


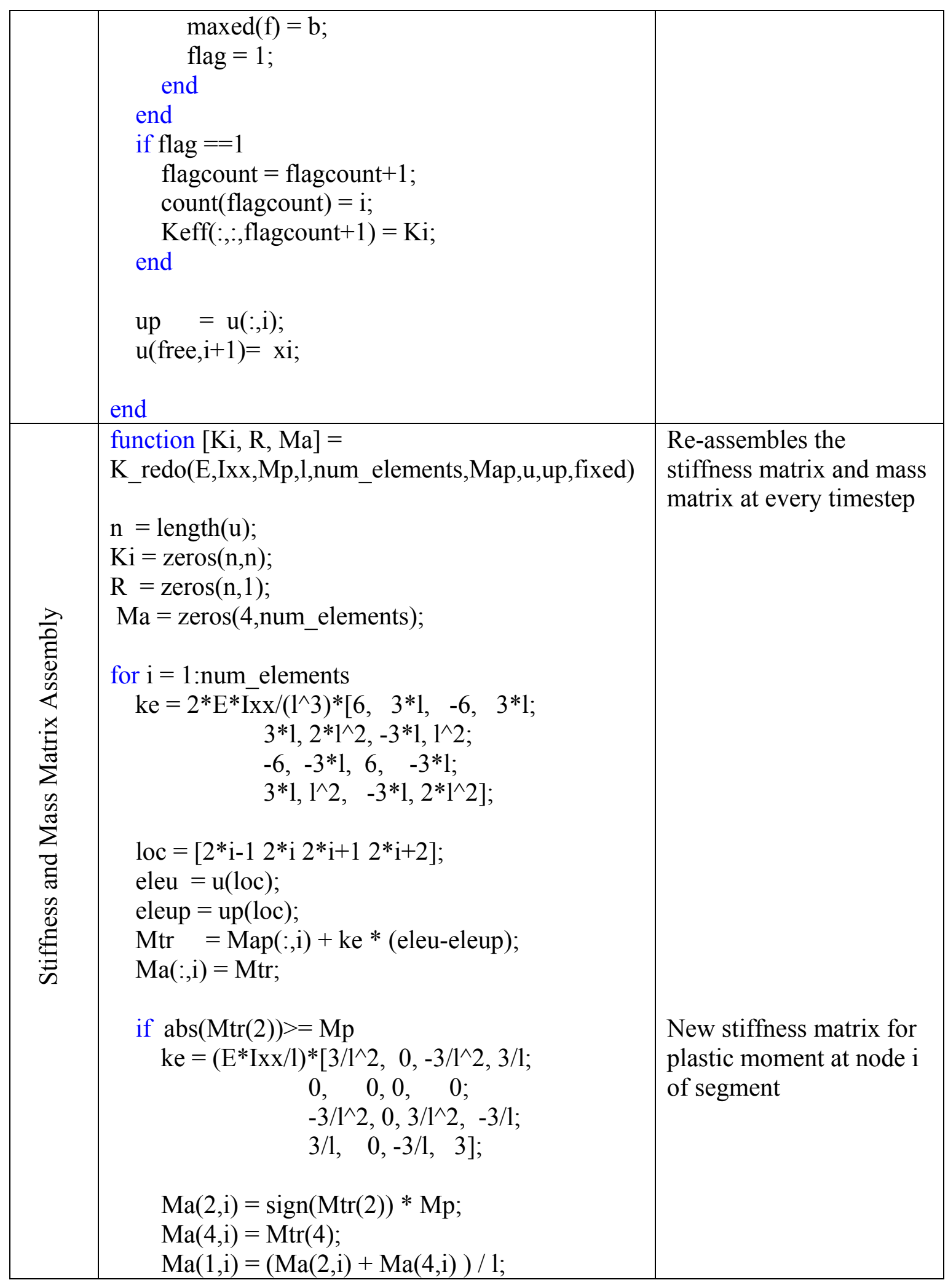

Verification and Expansion of Single-Degree-of-Freedom Transformation Factors for Beams Using a Multi-Degree-of-Freedom Non-Linear Numerical Analysis Method 


\begin{tabular}{|c|c|}
\hline 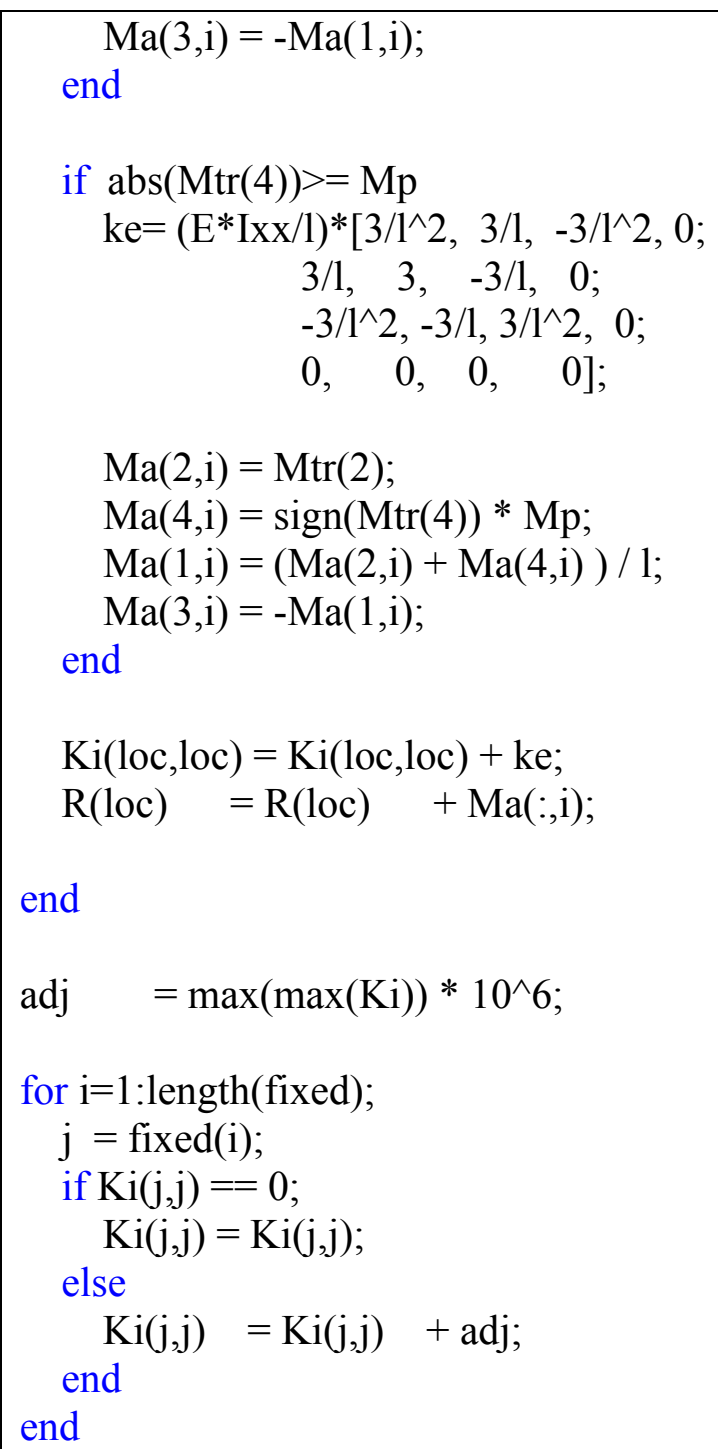 & $\begin{array}{l}\text { New stiffness matrix for } \\
\text { plastic moment at node } j \\
\text { of segment }\end{array}$ \\
\hline
\end{tabular}




\subsection{MDOF Response Data}

The following are tabulated response data as discussed in Section 8.3.

Table 21: Data for pin-pin, uniform load

\begin{tabular}{|c|c|c|c|c|}
\hline Z & $\mathrm{K}_{\mathrm{L}}$ & $\mathrm{K}_{\mathrm{M}}$ & $\begin{array}{c}\mathrm{R}_{\mathrm{m}} \\
\left(\mathrm{M}_{\mathrm{p}} / \mathrm{L}\right)\end{array}$ & $\begin{array}{l}\delta_{\max } \\
\text { (in) }\end{array}$ \\
\hline 30 & - & - & - & 0.456 \\
\hline 25 & 0.6282 & 0.4936 & - & 0.648 \\
\hline 20 & 0.6284 & 0.4942 & - & 1.018 \\
\hline 15 & 0.6280 & 0.4937 & 7.2 & 1.953 \\
\hline 14 & 0.6320 & 0.4960 & 7.5 & 2.386 \\
\hline 13 & 0.6403 & 0.5041 & 7.9 & 3.112 \\
\hline 12 & 0.6560 & 0.5113 & 8.2 & 4.065 \\
\hline 11 & 0.6683 & 0.5167 & 8.6 & 5.673 \\
\hline 10.5 & 0.6623 & 0.5141 & 8.5 & 6.795 \\
\hline 10 & 0.6353 & 0.5006 & 7.6 & 8.349 \\
\hline 9.5 & 0.6285 & 0.4927 & 7.3 & 10.375 \\
\hline 9 & 0.6261 & 0.4873 & 6.5 & 13.185 \\
\hline 8.5 & 0.6292 & 0.4922 & 6.6 & 17.161 \\
\hline 8 & 0.6346 & 0.4987 & 7.0 & 22.737 \\
\hline Average & 0.64 & 0.50 & 7.5 & _ \\
\hline
\end{tabular}

Note: W24x131 beam, $\mathrm{L}=24 \mathrm{ft}$, Tributary width $=24 \mathrm{ft}, \mathrm{f}_{\mathrm{y}}=50 \mathrm{ksi}$, angle of incidence $=0$.

Verification and Expansion of Single-Degree-of-Freedom Transformation Factors for Beams Using a Multi-Degree-of-Freedom Non-Linear Numerical Analysis Method 
Table 22: Data for pin-pin, linear load

\begin{tabular}{|c|c|c|c|c|}
\hline $\mathrm{Z}$ & $\mathrm{K}_{\mathrm{L}}$ & $\mathrm{K}_{\mathrm{M}}$ & $\begin{array}{c}\mathrm{R}_{\mathrm{m}} \\
\left(\mathrm{M}_{\mathrm{p}} / \mathrm{L}\right)\end{array}$ & $\begin{array}{c}\delta_{\max } \\
(\mathrm{in})\end{array}$ \\
\hline 30 & & & & 0.228 \\
\hline 25 & 0.6379 & 0.4939 & & 0.324 \\
\hline 20 & 0.6411 & 0.4948 & & 0.509 \\
\hline 15 & 0.6464 & 0.4972 & & 0.884 \\
\hline 14 & 0.6473 & 0.4977 & & 1.013 \\
\hline 13 & 0.6482 & 0.4982 & & 1.183 \\
\hline 12 & 0.6354 & 0.4992 & 7.6 & 1.401 \\
\hline 11 & 0.6497 & 0.4986 & 7.5 & 1.762 \\
\hline 10.5 & 0.6400 & 0.4950 & 7.2 & 2.018 \\
\hline 10 & 0.6375 & 0.4975 & 7.5 & 2.355 \\
\hline 9.5 & 0.6388 & 0.5016 & 7.9 & 2.804 \\
\hline 9 & 0.6540 & 0.5084 & 7.9 & 3.384 \\
\hline 8.5 & 0.9467 & 0.4482 & 5.0 & 4.258 \\
\hline 8 & 1.0592 & 0.4377 & 5.1 & 5.606 \\
\hline Average & 0.64 & 0.50 & 7.6 & \\
\hline $\mathrm{W}$ & & & & \\
\hline
\end{tabular}

Note: $\mathrm{W} 24 \times 131$ beam, $\mathrm{L}=24 \mathrm{ft}$, Tributary width $=24 \mathrm{ft}, \mathrm{f}_{\mathrm{y}}=50 \mathrm{ksi}$, angle of incidence $=0$. 
Table 23: Data for fix-fix, linear load

\begin{tabular}{|c|c|c|c|c|}
\hline $\mathrm{Z}$ & $\mathrm{K}_{\mathrm{L}}$ & $\mathrm{K}_{\mathrm{M}}$ & $\begin{array}{c}\mathrm{R}_{\mathrm{m}} \\
\left(\mathrm{M}_{\mathrm{p}} / \mathrm{L}\right)\end{array}$ & $\begin{array}{c}\delta_{\max } \\
\text { (in) }\end{array}$ \\
\hline 30 & 0.5181 & 0.3913 & & 0.084 \\
\hline 25 & 0.5171 & 0.3925 & & 0.114 \\
\hline 20 & 0.5174 & 0.3941 & & 0.170 \\
\hline 15 & 0.5180 & 0.3953 & 8.3 & 0.284 \\
\hline 14 & 0.5182 & 0.3955 & 9.4 & 0.323 \\
\hline 13 & 0.5184 & 0.3958 & 10.9 & 0.375 \\
\hline 12 & 0.5335 & 0.4061 & 12.5 & 0.436 \\
\hline 11 & 0.5542 & 0.4097 & 9.9 & 0.522 \\
\hline 10.5 & 0.5497 & 0.3990 & 10.2 & 0.586 \\
\hline 10 & 0.5549 & 0.3863 & 10.2 & 0.671 \\
\hline 9.5 & 0.6415 & 0.3713 & 8.2 & 0.792 \\
\hline 9 & 0.7441 & 0.3646 & 6.5 & 0.953 \\
\hline 8.5 & 0.9369 & 0.3598 & 5.4 & 1.231 \\
\hline 8 & 1.1918 & 0.3506 & 4.5 & 1.665 \\
\hline Average & 0.52 & 0.40 & 10.7 & \\
\hline
\end{tabular}

Note: $\mathrm{W} 24 \mathrm{x} 131$ beam, $\mathrm{L}=24 \mathrm{ft}$, Tributary width $=24 \mathrm{ft}, \mathrm{f}_{\mathrm{y}}=50 \mathrm{ksi}$, angle of incidence $=0$. 
Table 24: Data for pin-pin, triangular load

\begin{tabular}{|c|c|c|c|c|}
\hline $\mathrm{Z}$ & $\mathrm{K}_{\mathrm{L}}$ & $\mathrm{K}_{\mathrm{M}}$ & $\begin{array}{c}\mathrm{R}_{\mathrm{m}} \\
\left(\mathrm{M}_{\mathrm{p}} / \mathrm{L}\right)\end{array}$ & $\begin{array}{c}\delta_{\max } \\
(\mathrm{in})\end{array}$ \\
\hline 30 & 0.815 & 0.5019 & & 0.287 \\
\hline 25 & - & - & & 0.408 \\
\hline 20 & 0.8143 & 0.5015 & & 0.643 \\
\hline 15 & 0.8123 & 0.5003 & & 1.119 \\
\hline 14 & 0.8119 & 0.5001 & 5.8 & 1.284 \\
\hline 13 & 0.8085 & 0.4978 & 6.0 & 1.560 \\
\hline 12 & 0.8130 & 0.5008 & 6.1 & 1.933 \\
\hline 11 & 0.8137 & 0.5012 & 6.1 & 2.589 \\
\hline 10.5 & 0.8087 & 0.4979 & 5.9 & 3.078 \\
\hline 10 & 0.8056 & 0.4954 & 5.8 & 3.697 \\
\hline 9.5 & 0.8053 & 0.4950 & 5.8 & 4.466 \\
\hline 9 & 0.8060 & 0.4958 & 5.9 & 5.569 \\
\hline 8.5 & 0.8085 & 0.4979 & 5.9 & 7.138 \\
\hline 8 & 0.812 & 0.5007 & 6.1 & 9.322 \\
\hline Average & 0.81 & 0.50 & 6.0 & \\
\hline $\mathrm{W}$ & & & & \\
\hline
\end{tabular}

Note: W24x131 beam, $\mathrm{L}=24 \mathrm{ft}$, Tributary width $=24 \mathrm{ft}, \mathrm{f}_{\mathrm{y}}=50 \mathrm{ksi}$, angle of incidence $=0$. 
Table 25: Data for fix-fix, triangular load

\begin{tabular}{|c|c|c|c|c|}
\hline $\mathrm{Z}$ & $\mathrm{K}_{\mathrm{L}}$ & $\mathrm{K}_{\mathrm{M}}$ & $\begin{array}{c}\mathrm{R}_{\mathrm{m}} \\
\left(\mathrm{M}_{\mathrm{p}} / \mathrm{L}\right)\end{array}$ & $\begin{array}{c}\delta_{\max } \\
(\mathrm{in})\end{array}$ \\
\hline 30 & 0.7188 & 0.3960 & & 0.115 \\
\hline 25 & 0.7189 & 0.3961 & & 0.156 \\
\hline 20 & 0.7191 & 0.3962 & & 0.234 \\
\hline 15 & 0.7193 & 0.3963 & & 0.392 \\
\hline 14 & 0.7194 & 0.3963 & & 0.446 \\
\hline 13 & 0.7193 & 0.3963 & 9.7 & 0.515 \\
\hline 12 & 0.7218 & 0.3977 & 9.6 & 0.598 \\
\hline 11 & 0.7212 & 0.3974 & 9.6 & 0.767 \\
\hline 10.5 & 0.7211 & 0.3973 & 9.7 & 0.893 \\
\hline 10 & 0.7194 & 0.3964 & 9.7 & 1.069 \\
\hline 9.5 & 0.7174 & 0.3952 & 9.7 & 1.319 \\
\hline 9 & 0.7170 & 0.3949 & 9.6 & 1.666 \\
\hline 8.5 & 0.7182 & 0.3957 & 9.7 & 2.165 \\
\hline 8 & 0.7206 & 0.3970 & 9.8 & 3.043 \\
\hline Average & 0.72 & 0.40 & 9.7 & \\
\hline
\end{tabular}

Note: $\mathrm{W} 24 \mathrm{x} 131$ beam, $\mathrm{L}=24 \mathrm{ft}$, Tributary width $=24 \mathrm{ft}, \mathrm{f}_{\mathrm{y}}=50 \mathrm{ksi}$, angle of incidence $=0$. 
Table 26: Data for pin-pin, parabolic load

\begin{tabular}{|c|c|c|c|c|}
\hline$Z$ & $\mathrm{~K}_{\mathrm{L}}$ & $\mathrm{K}_{\mathrm{M}}$ & $\begin{array}{c}\mathrm{R}_{\mathrm{m}} \\
\left(\mathrm{M}_{\mathrm{p}} / \mathrm{L}\right)\end{array}$ & $\begin{array}{c}\delta_{\max } \\
(\mathrm{in})\end{array}$ \\
\hline 30 & 0.5837 & 0.486 & & 0.137 \\
\hline 25 & 0.5836 & 0.4875 & & 0.194 \\
\hline 20 & - & - & & 0.305 \\
\hline 15 & 0.5908 & 0.4902 & & 0.529 \\
\hline 14 & 0.5919 & 0.4907 & & 0.606 \\
\hline 13 & 0.5935 & 0.4915 & & 0.708 \\
\hline 12 & 0.5945 & 0.4913 & & 0.825 \\
\hline 11 & 0.5954 & 0.4915 & & 0.991 \\
\hline 10.5 & 0.5958 & 0.4915 & & 1.094 \\
\hline 10 & 0.5981 & 0.4921 & 7.9 & 1.211 \\
\hline 9.5 & 0.5687 & 0.4982 & 8.3 & 1.364 \\
\hline 9 & 0.6024 & 0.5045 & 8.3 & 1.576 \\
\hline 8.5 & 0.5807 & 0.4873 & 7.5 & 1.835 \\
\hline 8 & 0.5767 & 0.4949 & 8.2 & 2.221 \\
\hline Average & 0.59 & 0.49 & 8.0 & \\
\hline
\end{tabular}

Note: $\mathrm{W} 24 \mathrm{x} 131$ beam, $\mathrm{L}=24 \mathrm{ft}$, Tributary width $=24 \mathrm{ft}, \mathrm{f}_{\mathrm{y}}=50 \mathrm{ksi}$, angle of incidence $=0$. 
Table 27: Data for fix-fix, parabolic load

\begin{tabular}{|c|c|c|c|c|}
\hline $\mathrm{Z}$ & $\mathrm{K}_{\mathrm{L}}$ & $\mathrm{K}_{\mathrm{M}}$ & $\begin{array}{c}\mathrm{R}_{\mathrm{m}} \\
\left(\mathrm{M}_{\mathrm{p}} / \mathrm{L}\right)\end{array}$ & $\begin{array}{c}\delta_{\max } \\
\text { (in) }\end{array}$ \\
\hline 30 & 0.4476 & 0.3829 & & 0.048 \\
\hline 25 & 0.4460 & 0.3866 & & 0.065 \\
\hline 20 & 0.4461 & 0.3904 & & 0.097 \\
\hline 15 & 0.4462 & 0.3942 & & 0.162 \\
\hline 14 & 0.4462 & 0.3944 & & 0.184 \\
\hline 13 & 0.4461 & 0.3947 & & 0.214 \\
\hline 12 & 0.4461 & 0.3945 & & 0.249 \\
\hline 11 & 0.4461 & 0.3945 & & 0.298 \\
\hline 10.5 & 0.4461 & 0.3944 & 11.2 & 0.329 \\
\hline 10 & 0.4777 & 0.4060 & 11.5 & 0.365 \\
\hline 9.5 & 0.4741 & 0.4143 & 13.3 & 0.407 \\
\hline 9 & 0.4983 & 0.4062 & 10.3 & 0.459 \\
\hline 8.5 & 0.7205 & 0.3472 & 7.8 & 0.533 \\
\hline 8 & 0.9178 & 0.3184 & 6.3 & 0.653 \\
\hline Average & 0.46 & 0.39 & 11.6 & \\
\hline $\mathrm{W}$ & $0.5 \times 13169 a \mathrm{~L}$ & & & \\
\hline
\end{tabular}

Note: W24x131 beam, $\mathrm{L}=24 \mathrm{ft}$, Tributary width $=24 \mathrm{ft}, \mathrm{f}_{\mathrm{y}}=50 \mathrm{ksi}$, angle of incidence $=0$. 


\subsection{MDOF vs. SDOF Response Comparison Data}

The following are tabulated MDOF vs. SDOF response data as discussed in

\section{Section 8.4.}

Table 28: MDOF vs. SDOF for pin-pin, uniform load

\begin{tabular}{|c|c|c|c|}
\hline $\mathrm{Z}$ & $\begin{array}{l}\text { MDOF } \\
\text { (in) }\end{array}$ & $\begin{array}{l}\text { SDOF } \\
\text { (in) }\end{array}$ & $\%$ Difference \\
\hline 30 & 0.456 & 0.454 & $0.31 \%$ \\
\hline 25 & 0.648 & 0.645 & $0.37 \%$ \\
\hline 20 & 1.018 & 1.015 & $0.29 \%$ \\
\hline 15 & 1.953 & 1.665 & $14.71 \%$ \\
\hline 14 & 2.386 & 1.907 & $20.15 \%$ \\
\hline 13 & 3.112 & 2.295 & $26.25 \%$ \\
\hline 12 & 4.065 & 2.841 & $30.11 \%$ \\
\hline 11 & 5.673 & 3.839 & $32.32 \%$ \\
\hline 10.5 & 6.795 & 4.591 & $32.43 \%$ \\
\hline 10 & 8.349 & 5.567 & $33.32 \%$ \\
\hline 9.5 & 10.375 & 6.821 & $34.26 \%$ \\
\hline 9 & 13.184 & 8.561 & $35.07 \%$ \\
\hline 8.5 & 17.161 & 11.078 & $35.44 \%$ \\
\hline 8 & 22.737 & 14.637 & $35.62 \%$ \\
\hline
\end{tabular}

Note: W24x131 beam, $\mathrm{L}=24 \mathrm{ft}$, Tributary width $=24 \mathrm{ft}, \mathrm{f}_{\mathrm{y}}=50 \mathrm{ksi}$, angle of incidence $=0$. 
Table 29: MDOF vs. SDOF for pin-pin, linear load

\begin{tabular}{|c|c|c|c|}
\hline$Z$ & $\begin{array}{c}\text { MDOF } \\
\text { (in) }\end{array}$ & $\begin{array}{c}\text { SDOF } \\
\text { (in) }\end{array}$ & \% Difference \\
\hline 30 & 0.228 & 0.228 & 0.18 \\
\hline 25 & 0.324 & 0.323 & 0.22 \\
\hline 20 & 0.509 & 0.509 & 0.14 \\
\hline 15 & 0.884 & 1.884 & 0.05 \\
\hline 14 & 1.013 & 1.013 & 0.01 \\
\hline 13 & 1.183 & 1.183 & 0.04 \\
\hline 12 & 1.401 & 1.412 & 3.38 \\
\hline 11 & 1.762 & 1.564 & 11.25 \\
\hline 10.5 & 2.018 & 1.719 & 14.83 \\
\hline 10 & 2.355 & 1.919 & 18.51 \\
\hline 9.5 & 2.804 & 2.178 & 22.32 \\
\hline 9 & 3.384 & 2.545 & 24.79 \\
\hline 8.5 & 4.258 & 3.088 & 27.47 \\
\hline 8 & 5.606 & 3.869 & 30.99 \\
\hline
\end{tabular}

Note: W24x131 beam, $\mathrm{L}=24 \mathrm{ft}$, Tributary width $=24 \mathrm{ft}, \mathrm{f}_{\mathrm{y}}=50 \mathrm{ksi}$, angle of incidence $=0$. 
Table 30: MDOF vs. SDOF for fix-fix, linear load

\begin{tabular}{|c|c|c|c|}
\hline$Z$ & $\begin{array}{c}\text { MDOF } \\
\text { (in) }\end{array}$ & $\begin{array}{c}\text { SDOF } \\
\text { (in) }\end{array}$ & \% Difference \\
\hline 30 & 0.084 & 0.083 & 3.05 \\
\hline 25 & 0.114 & 0.113 & 2.34 \\
\hline 20 & 0.170 & 0.169 & 1.69 \\
\hline 15 & 0.284 & 0.282 & 1.12 \\
\hline 14 & 0.323 & 0.322 & 1.02 \\
\hline 13 & 0.375 & 0.381 & 1.36 \\
\hline 12 & 0.436 & 0.467 & 6.69 \\
\hline 11 & 0.522 & 0.602 & 14.94 \\
\hline 10.5 & 0.586 & 0.705 & 19.88 \\
\hline 10 & 0.671 & 0.834 & 23.72 \\
\hline 9.5 & 0.792 & 0.993 & 24.82 \\
\hline 9 & 0.953 & 1.202 & 25.64 \\
\hline 8.5 & 1.231 & 1.476 & 19.31 \\
\hline 8 & 1.665 & 1.831 & 9.46 \\
\hline
\end{tabular}

Note: W24x131 beam, $\mathrm{L}=24 \mathrm{ft}$, Tributary width $=24 \mathrm{ft}, \mathrm{f}_{\mathrm{y}}=50 \mathrm{ksi}$, angle of incidence $=0$. 
Table 31: MDOF vs. SDOF for pin-pin, triangular load

\begin{tabular}{|c|c|c|c|}
\hline $\mathrm{Z}$ & $\begin{array}{c}\text { MDOF } \\
\text { (in) }\end{array}$ & $\begin{array}{l}\text { SDOF } \\
\text { (in) }\end{array}$ & $\%$ Difference \\
\hline 30 & 0.287 & 0.289 & 0.66 \\
\hline 25 & 0.408 & 0.411 & 0.69 \\
\hline 20 & 0.643 & 0.647 & 0.64 \\
\hline 15 & 1.119 & 1.125 & 0.49 \\
\hline 14 & 1.284 & 1.289 & 0.41 \\
\hline 13 & 1.560 & 1.444 & 7.47 \\
\hline 12 & 1.933 & 1.632 & 15.55 \\
\hline 11 & 2.589 & 1.952 & 24.60 \\
\hline 10.5 & 3.078 & 2.186 & 29.00 \\
\hline 10 & 3.697 & 2.484 & 32.81 \\
\hline 9.5 & 4.466 & 2.865 & 35.85 \\
\hline 9 & 5.569 & 3.395 & 39.04 \\
\hline 8.5 & 7.138 & 4.157 & 41.76 \\
\hline 8 & 9.322 & 5.241 & 43.78 \\
\hline
\end{tabular}

Note: W24x131 beam, $\mathrm{L}=24 \mathrm{ft}$, Tributary width $=24 \mathrm{ft}, \mathrm{f}_{\mathrm{y}}=50 \mathrm{ksi}$, angle of incidence $=0$. 
Table 32: MDOF vs. SDOF for fix-fix, triangular load

\begin{tabular}{|c|c|c|c|}
\hline $\mathrm{Z}$ & $\begin{array}{c}\text { MDOF } \\
\text { (in) }\end{array}$ & $\begin{array}{l}\text { SDOF } \\
\text { (in) }\end{array}$ & $\%$ Difference \\
\hline 30 & 0.115 & 0.114 & 0.52 \\
\hline 25 & 0.156 & 0.155 & 0.51 \\
\hline 20 & 0.234 & 0.233 & 0.47 \\
\hline 15 & 0.392 & 0.390 & 0.43 \\
\hline 14 & 0.446 & 0.444 & 0.43 \\
\hline 13 & 0.515 & 0.537 & 4.23 \\
\hline 12 & 0.598 & 0.672 & 12.30 \\
\hline 11 & 0.767 & 0.891 & 16.18 \\
\hline 10.5 & 0.893 & 1.020 & 14.20 \\
\hline 10 & 1.069 & 1.131 & 5.76 \\
\hline 9.5 & 1.319 & 1.275 & 3.37 \\
\hline 9 & 1.666 & 1.480 & 11.14 \\
\hline 8.5 & 2.165 & 1.782 & 17.67 \\
\hline 8 & 3.043 & 2.234 & 26.59 \\
\hline
\end{tabular}

Note: W24x131 beam, $\mathrm{L}=24 \mathrm{ft}$, Tributary width $=24 \mathrm{ft}, \mathrm{f}_{\mathrm{y}}=50 \mathrm{ksi}$, angle of incidence $=0$. 
Table 33: MDOF vs. SDOF for pin-pin, parabolic load

\begin{tabular}{|c|c|c|c|}
\hline$Z$ & $\begin{array}{c}\text { MDOF } \\
\text { (in) }\end{array}$ & $\begin{array}{c}\text { SDOF } \\
\text { (in) }\end{array}$ & \% Difference \\
\hline 30 & 0.137 & 0.139 & 1.47 \\
\hline 25 & 0.194 & 0.197 & 1.39 \\
\hline 20 & 0.305 & 0.309 & 1.25 \\
\hline 15 & 0.529 & 0.536 & 1.21 \\
\hline 14 & 0.606 & 0.614 & 1.17 \\
\hline 13 & 0.708 & 0.717 & 1.21 \\
\hline 12 & 0.825 & 0.834 & 1.18 \\
\hline 11 & 0.991 & 1.002 & 1.18 \\
\hline 10.5 & 1.094 & 1.107 & 1.18 \\
\hline 10 & 1.211 & 1.225 & 1.15 \\
\hline 9.5 & 1.364 & 1.340 & 1.78 \\
\hline 9 & 1.576 & 1.461 & 7.31 \\
\hline 8.5 & 1.835 & 1.637 & 10.78 \\
\hline 8 & 2.221 & 1.893 & 14.75 \\
\hline
\end{tabular}

Note: W24x131 beam, $\mathrm{L}=24 \mathrm{ft}$, Tributary width $=24 \mathrm{ft}, \mathrm{f}_{\mathrm{y}}=50 \mathrm{ksi}$, angle of incidence $=0$. 
Table 34: MDOF vs. SDOF for fix-fix, parabolic load

\begin{tabular}{|c|c|c|c|}
\hline $\mathrm{Z}$ & $\begin{array}{c}\text { MDOF } \\
\text { (in) }\end{array}$ & $\begin{array}{l}\text { SDOF } \\
\text { (in) }\end{array}$ & $\%$ Difference \\
\hline 30 & 0.048 & 0.047 & 1.66 \\
\hline 25 & 0.065 & 0.065 & 1.07 \\
\hline 20 & 0.097 & 0.097 & 0.41 \\
\hline 15 & 0.162 & 0.162 & 0.19 \\
\hline 14 & 0.184 & 0.184 & 0.11 \\
\hline 13 & 0.214 & 0.213 & 0.05 \\
\hline 12 & 0.249 & 0.249 & 0.12 \\
\hline 11 & 0.298 & 0.298 & 0.10 \\
\hline 10.5 & 0.329 & 0.329 & 0.09 \\
\hline 10 & 0.365 & 0.368 & 0.82 \\
\hline 9.5 & 0.407 & 0.426 & 4.62 \\
\hline 9 & 0.459 & 0.503 & 9.55 \\
\hline 8.5 & 0.533 & 0.681 & 27.79 \\
\hline 8 & 0.653 & 0.738 & 13.09 \\
\hline
\end{tabular}

Note: W24x131 beam, $\mathrm{L}=24 \mathrm{ft}$, Tributary width $=24 \mathrm{ft}, \mathrm{f}_{\mathrm{y}}=50 \mathrm{ksi}$, angle of incidence $=0$. 